André Santos Dória

\title{
ANÁLISE DA ESTABILIDADE DE PÓRTICOS PLANOS DE AÇO COM BASE NO CONCEITO DE FORÇAS HORIZONTAIS FICTÍCIAS
}

\author{
Dissertação apresentada à Escola de \\ Engenharia de São Carlos da Universidade \\ de São Paulo, como parte dos requisitos \\ para obtenção do Título de Mestre em \\ Engenharia de Estruturas.
}

Orientador: Maximiliano Malite 


\section{FOLHA DE JULGAMENTO}

Candidato: Engenheiro ANDRÉ SANTOS DÓRIA

Dissertação defendida e julgada em 13/02/2007 perante a Comissão Julgadora:

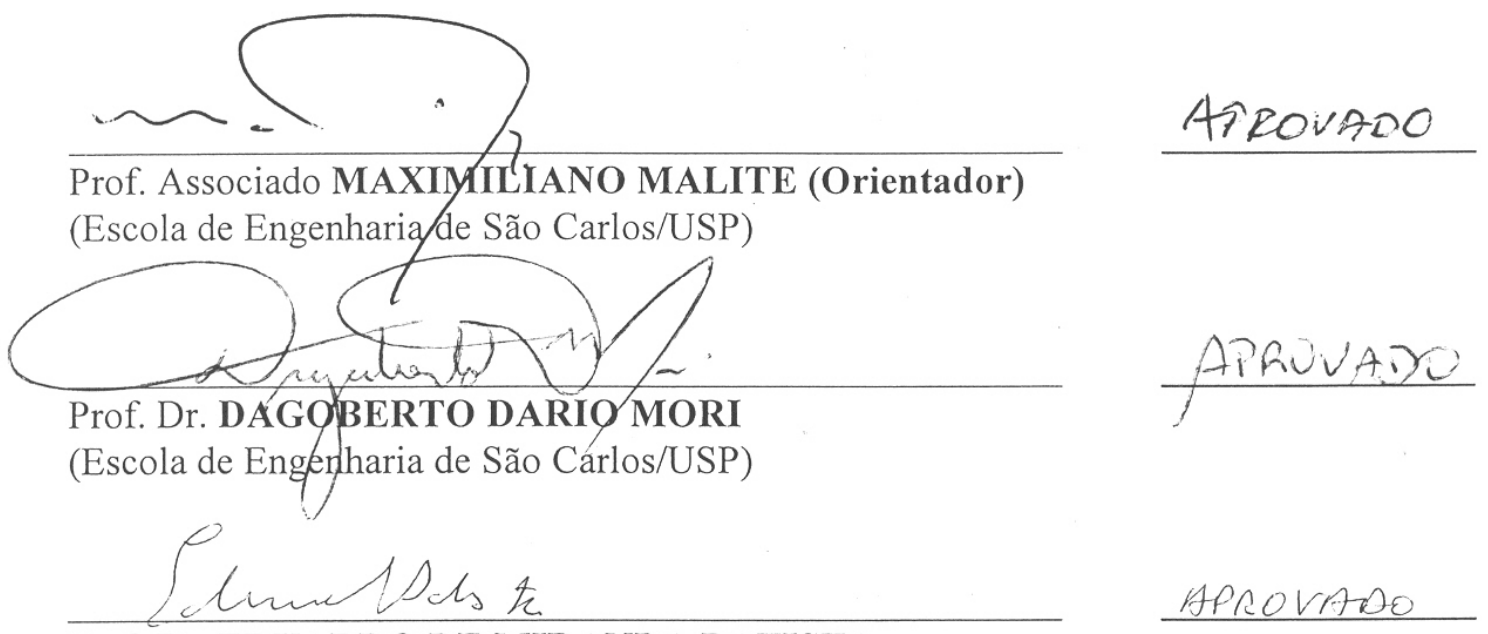

Prof. Dr. EDUARDO DE MIRANDA BATISTA

(Universidade Federal do Rio de Janeiro/UFRJ)

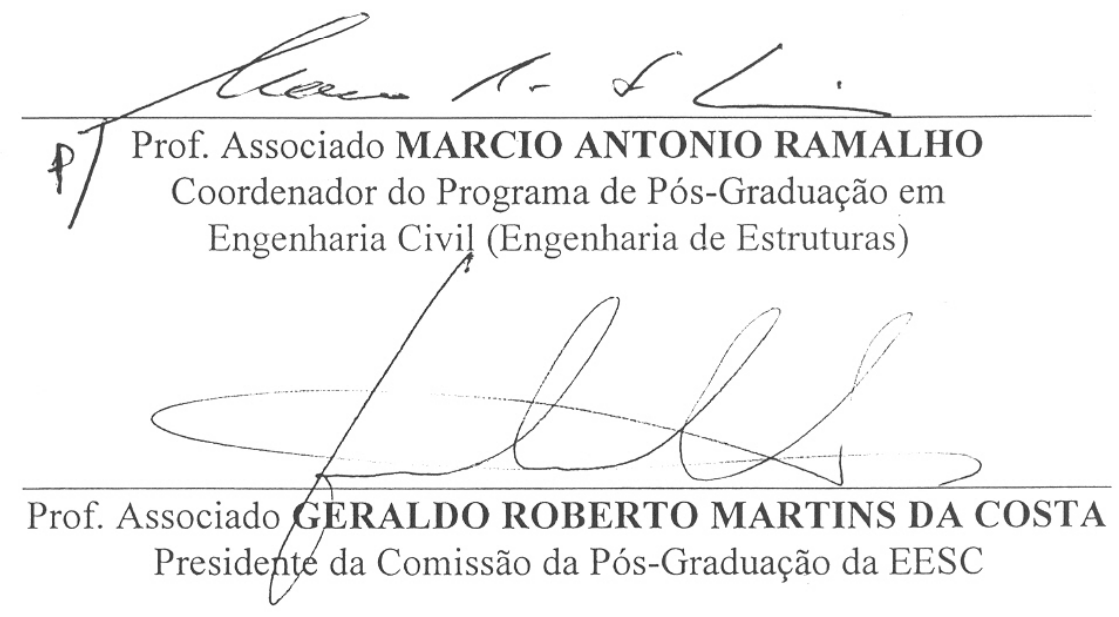


À minha mãe, ao meu irmão e ao meu pai, com amor e gratidão. 


\section{Agradecimentos}

A Deus, pela tranqüilidade e serenidade.

Aos meus pais e ao meu irmão, pelo amor, compreensão e apoio.

À Michele, pelo carinho, paciência e compreensão.

Ao Prof. Maximiliano Malite, pelo aprendizado e atenção.

Aos Professores Dagoberto Dario Mori e Eduardo de Miranda Batista, pelo empenho e contribuições na avaliação do trabalho.

Ao Saulo José, o Joseph, pela paciência e apoio nos momentos mais complicados. Muito obrigado e sucesso na sua vida.

Aos verdadeiros amigos, pelas palavras de incentivo, conselhos e apoio irrestrito.

Aos amigos de Maceió e do departamento, pelos incontáveis momentos de alegria e descontração. Aliás, um agradecimento especial aos desbravadores da turma do funil, pelas viagens e eventos sociais promovidos durante essa temporada.

Aos professores do Curso de Engenharia Civil da UFAL, pelo incentivo antes e durante o Mestrado.

Ao Sr. Wilson, guardião do Res. Ubatuba, pela prontidão e destreza inquestionáveis, garantindo a segurança durante as madrugadas. Na sua prosa coloquial e sábia havia sempre palavras de incentivo. 
“...não vem pra fazer barulho

vem só dizer... e com satisfação

queiram ou não queiram os juízes

o nosso bloco é de fato campeão...."

(Capiba, 1963) 


\section{Resumo}

DÓRIA, A.S. (2007). Análise da Estabilidade de Pórticos Planos de Aço com Base no Conceito de Forças Horizontais Fictícias. Dissertação (Mestrado) - Escola de Engenharia de São Carlos, Universidade de São Paulo, São Carlos, 2007.

Esse trabalho apresenta um estudo comparativo entre métodos simplificados para avaliação da estabilidade de pórticos planos de aço. Aspectos relacionados à classificação das estruturas de aço quanto à deslocabilidade e sistema de contraventamento são apresentados e discutidos. $\mathrm{O}$ tradicional procedimento do comprimento efetivo de flambagem, ainda presente em algumas normas, é confrontado com métodos que empregam forças horizontais fíctícias para contabilizar os efeitos desestabilizantes, tais como imperfeições geométricas iniciais e tensões residuais. Uma análise numérica avançada via MEF que permite a modelagem explícita dos efeitos que contribuem para a instabilidade de pórticos é empregada como referência na comparação dos resultados. É avaliada a resposta de pilares isolados, edifícios industriais e de múltiplos andares. Os métodos que empregam forças horizontais fictícias foram considerados adequados, pois além de eliminar o cálculo do comprimento efetivo de flambagem, apresentaram resultados mais consistentes em relação à análise avançada.

Palavras-chave: estabilidade estrutural, edifícios de aço, comprimento efetivo de flambagem, forças horizontais fictícias, análise estrutural avançada. 


\begin{abstract}
DÓRIA, A.S. (2007). Notional Load Approach for Steel Frame Stability Analisys. Dissertação (Mestrado) - Escola de Engenharia de São Carlos, Universidade de São Paulo, São Carlos, 2007.

Two strategies for assessing steel frame stability and beam-column design are studied and compared. Some aspects related to bracing system and sway or non-sway classification are also discussed. The traditional procedure based on effective lengths are compared with some approaches based on notional loads, which propose a set of notional horizontal loads for account stability effects such as initial geometric imperfections and residual stresses. The results are compared with an advanced analysis using FEM, which consists in an explicit modeling of stability effects. Some industrial and multistory frames are studied and the results show that the notional load based procedures are accurate. These procedures are also practical because the need for effective length factors is eliminated.
\end{abstract}

Keywords: structural stability, steel frames, effective length, notional load, advanced structural analysis. 


\section{Lista de Símbolos}

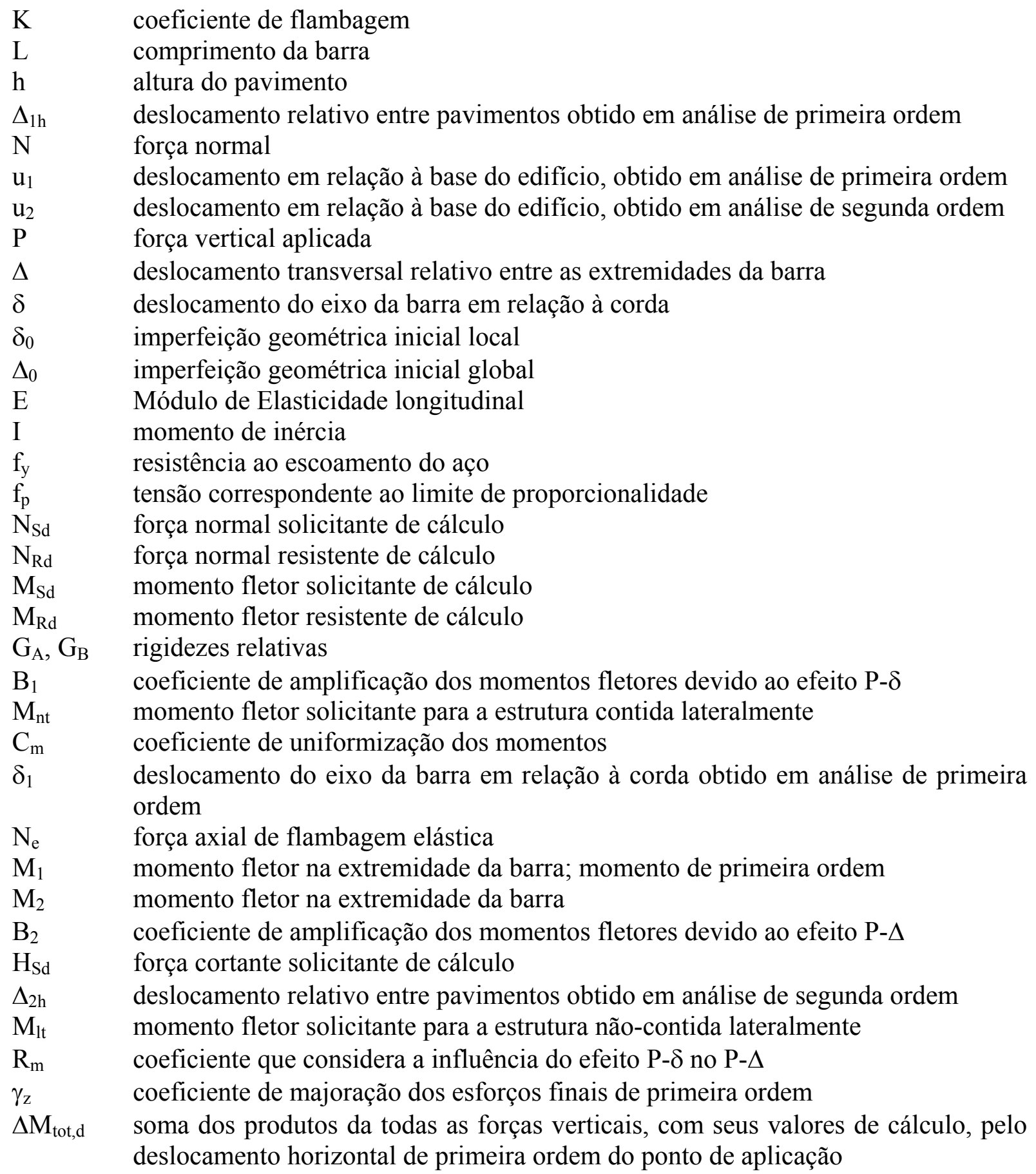




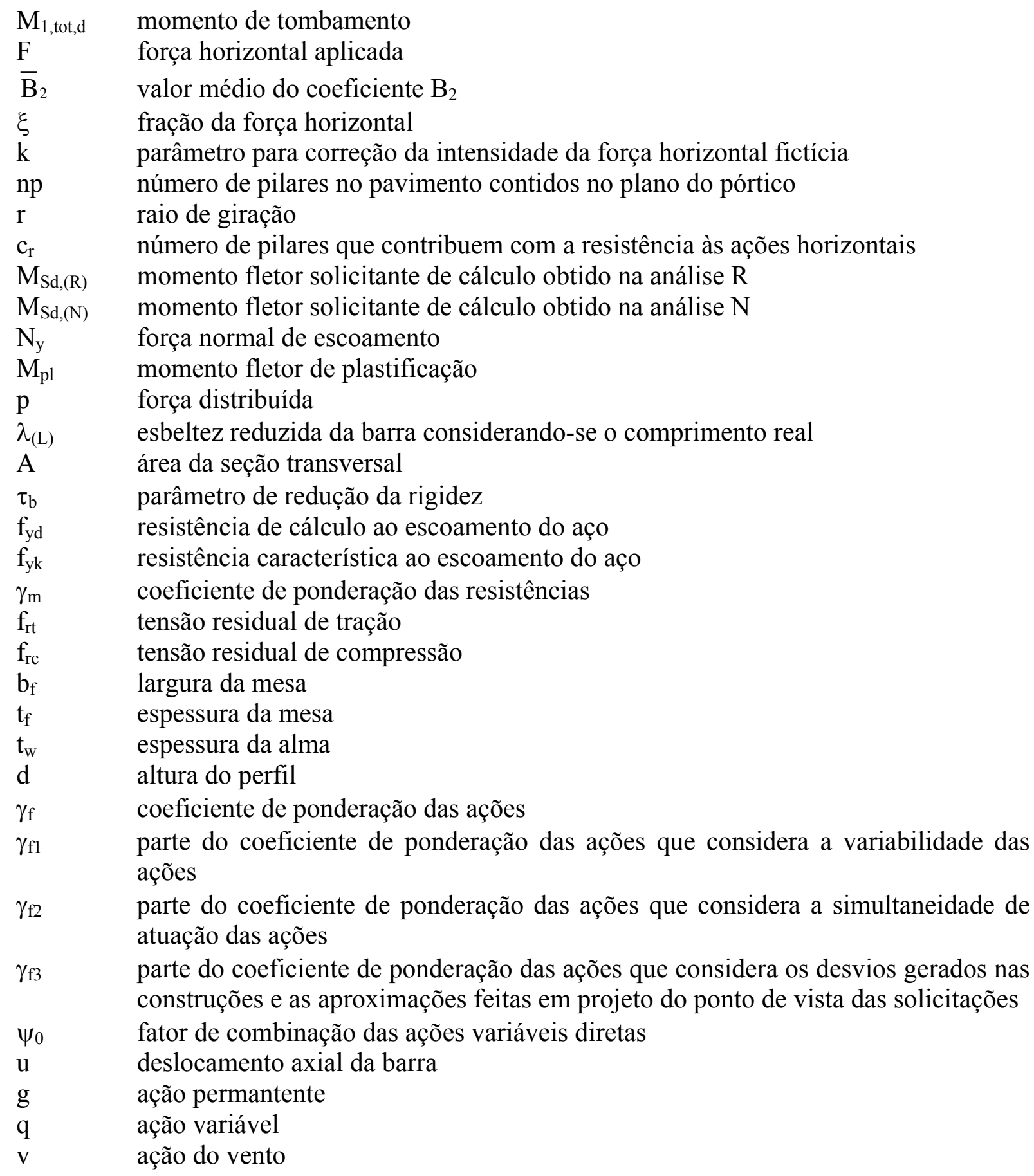




\section{Sumário}

Capítulo 1: INTRODUÇÃO ........................................................................................ 1

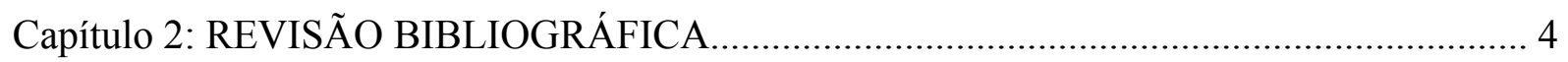

2.1 TIPOS DE ANÁLISE DE ESTABILIDADE ............................................................

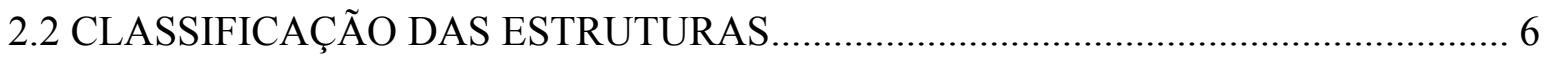

2.2.1 QUANTO AO SISTEMA DE CONTRAVENTAMENTO .................................... 6

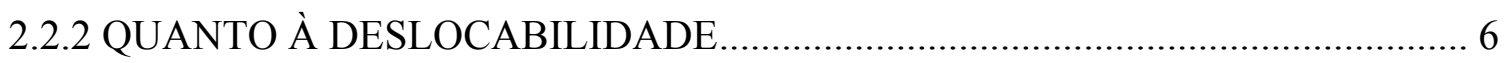

2.2.3 PROCEDIMENTO DA NORMA BRITÂNICA BS 5950-1:2000_........................... 7

2.2.4 PROCEDIMENTO DA NORMA BRASILEIRA NBR 8800:1986 …………….... 8

2.2.5 PROJETO DE REVISÃO DA NBR 8800 (SET. 2006) ………………………...... 8

2.3 EFEITOS QUE CONTRIBUEM PARA A INSTABILIDADE DE PÓRTICOS ......... 10

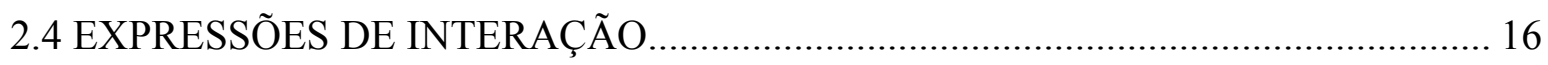

2.5 MODELOS PARA AVALIAÇÃO DE PÓRTICOS …………………………….......... 18

2.5.1 COMPRIMENTO EFETIVO DE FLAMBAGEM................................................ 18

2.5.2 EFEITOS DE SEGUNDA ORDEM................................................................ 22

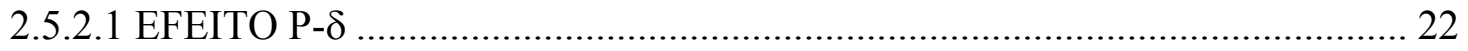

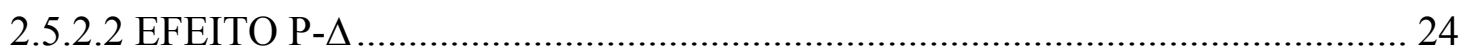

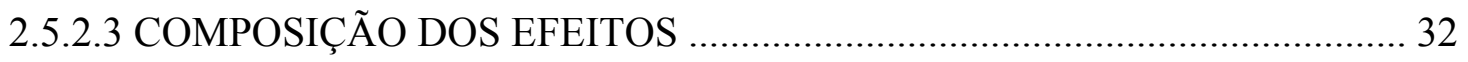

2.5.3 MÉTODOS DAS FORÇAS HORIZONTAIS FICTÍCIAS ……………………….... 34

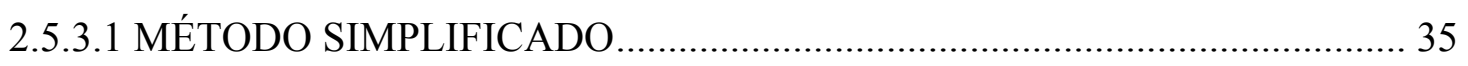

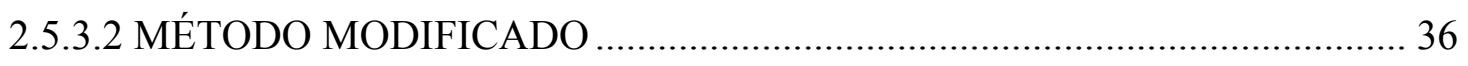

2.5.3.3 MÉTODO REFINADO (ASCE, 1997) …………………………………...... 37

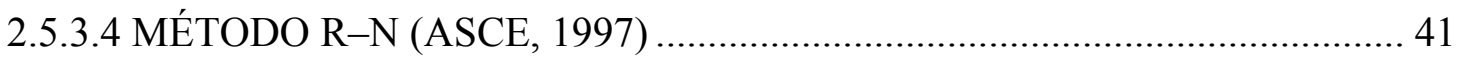

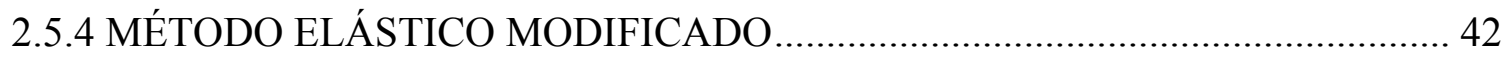

2.5.5 EFEITOS DE PLASTIFICAÇÃO DA SEÇÃO TRANSVERSAL........................... 44 
2.6 CALIBRAÇÃO DOS MÉTODOS SIMPLIFICADOS .............................................4

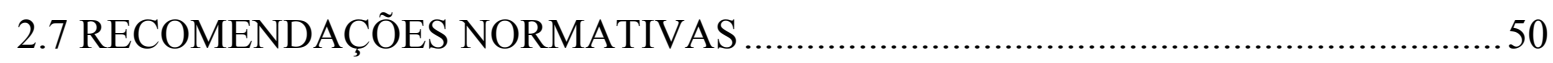

2.7.1 PROCEDIMENTO DA NORMA CANADENSE CSA S16.1-94 ..........................50

2.7.2 PROCEDIMENTO DA NORMA AUTRALIANA AS 4100/1990........................51

2.7.3 PROCEDIMENTO DO EUROCÓDIGO prEN 1993:3/2003 ................................52

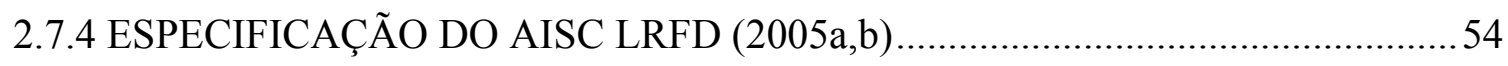

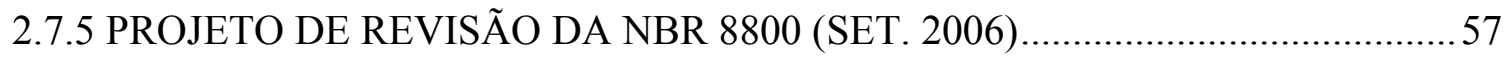

2.7.5.1 ESTRUTURAS DE PEQUENA DESLOCABILIDADE ...............................57

2.7.5.2 ESTRUTURAS DE MÉDIA E GRANDE DESLOCABILIDADE.................57

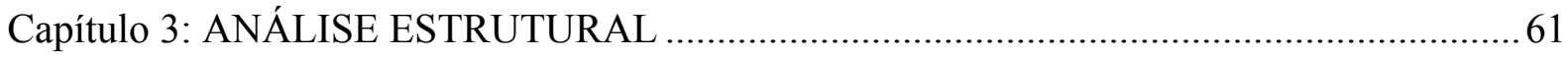

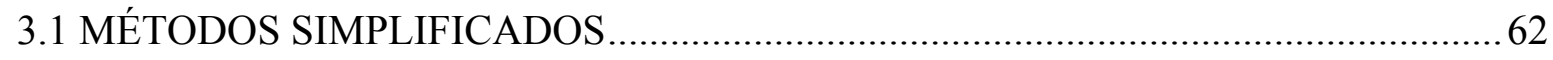

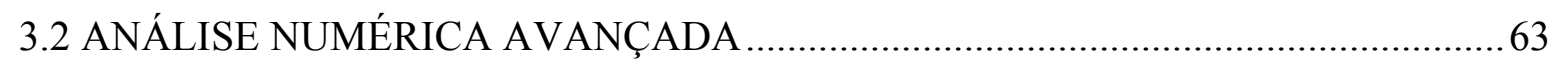

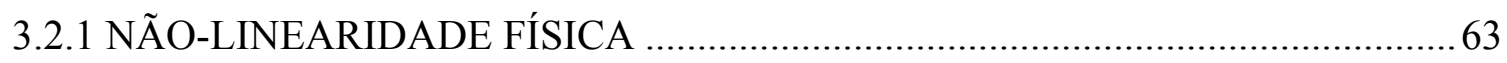

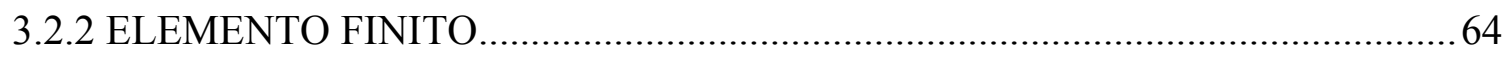

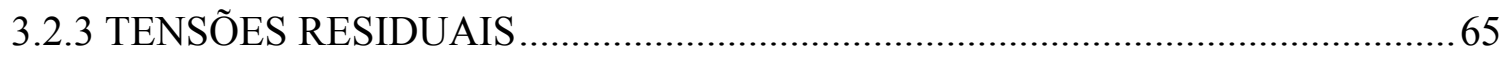

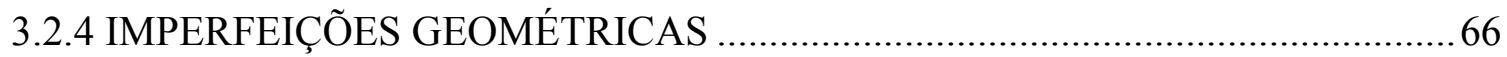

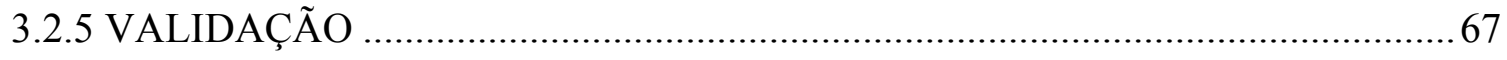

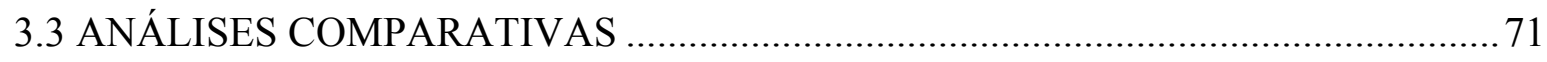

Capítulo 4: ANÁLISE COMPARATIVA - EXEMPLOS .................................................... 73

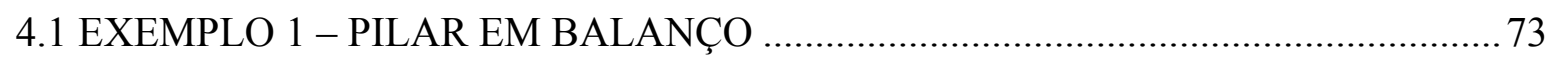

4.2 EXEMPLO 2 - PÓRTICO REGULAR COM UM PAVIMENTO ...............................76

4.3 EXEMPLO 3 - EDIFÍCIO INDUSTRIAL SEM PONTE ROLANTE .........................78

4.4 EXEMPLO 4 - EDIFÍCIO INDUSTRIAL COM PONTE ROLANTE..........................80

4.5 EXEMPLO 5 - PÓRTICO ASSIMÉTRICO COM DOIS PAVIMENTOS ...................82

4.6 EXEMPLO 6 - PÓRTICO IRREGULAR E ASSIMÉTRICO .................................... 88

4.7 EXEMPLO 7 - EDIFÍCIO COM 15 PAVIMENTOS .............................................93

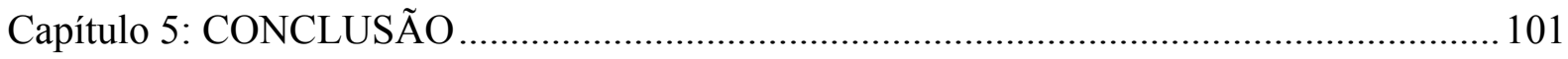

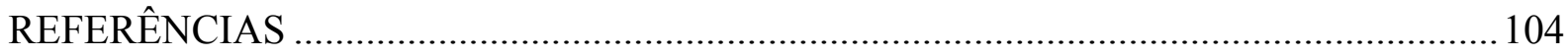





\section{Capítulo 1: INTRODUÇÃO}

Os projetos de estruturas em geral são tradicionalmente desenvolvidos considerandose a estrutura perfeita, sem imperfeições iniciais e utilizando uma análise elástica linear. Essa é uma situação confortável para o projetista, pela facilidade de modelagem e avaliação estrutural que, no entanto, não reflete a condição real.

Devido à simplicidade dos modelos estruturais, alguns métodos aproximados foram desenvolvidos para contabilizar os efeitos não contemplados na análise estrutural. Deste modo, permite-se que a avaliação estrutural seja elástica linear, com a estrutura perfeita e sem contabilizar os efeitos de segunda ordem. O dimensionamento dos elementos é que traz as expressões aproximadas para considerar a não-linearidade física, as tensões residuais, as imperfeições geométricas e os efeitos de segunda ordem.

Vários pacotes comerciais de análise estrutural já permitem, por exemplo, calcular os efeitos de segunda ordem diretamente. Conforme será apresentado, uma tendência semelhante se verifica para avaliação aproximada das imperfeições geométricas e a não-linearidade física, uma vez que os métodos propostos estão saindo do contexto do dimensionamento do elemento para a análise estrutural.

Seguindo esse raciocínio, estão incluídos os métodos das forças horizontais fictícias e o método da análise direta, os quais serão investigados no presente trabalho.

O conceito de comprimento efetivo de flambagem foi introduzido no AISC em 1963 (ASCE, 1997). Para verificação da estabilidade de uma barra com restrições elásticas à 
rotação nas extremidades, efetua-se uma correção no comprimento real (L) por um coeficiente de flambagem K, obtendo-se uma barra bi-rotulada com comprimento efetivo de flambagem (KL), mantendo-se a força crítica de flambagem. Para cada barra da estrutura, calcula-se o coeficiente $\mathrm{K}$, que considera a contribuição de rigidez à flexão dos elementos conectados às extremidades.

O conceito de comprimento efetivo é admitido até hoje e novas técnicas de cálculo do coeficiente de flambagem $\mathrm{K}$ foram sendo desenvolvidas para capturar efeitos como a semirigidez das ligações entre vigas e pilares (ANTUNES, 2001) e o regime inelástico. A evolução dessas técnicas aprimorou o método, mas penalizou a praticidade e se mostrou pouco interessante para implementação computacional (HAJJAR; WHITE, 2000).

Uma alternativa ao modelo de comprimento efetivo foi apresentada pelas normas australiana (AS4100, 1990) e canadense (CSA-S16.1, 1994), além do regulamento europeu (prEN 1993-3, 2003). O modelo consiste em utilizar forças horizontais fictícias ${ }^{1}$ aplicadas aos pavimentos da estrutura, as quais representam efeitos que influenciam na estabilidade do pórtico, tais como imperfeições geométricas da estrutura e do pilar, não-linearidade física e tensões residuais.

A utilização desse método resgatou a praticidade do cálculo estrutural, mantendo os conceitos associados à estabilidade. Em 1997, foi publicado um estudo detalhado sobre estabilidade de pórticos de aço (ASCE, 1997), o qual comparou o método do comprimento efetivo de flambagem com o das forças horizontais fictícias. O estudo confirmou resultados existentes (LIEW; WHITE; CHEN, 1994) que apontavam o método das forças horizontais fictícias como ferramenta mais interessante para aplicação cotidiana, fazendo algumas ressalvas.

\footnotetext{
${ }^{1}$ Em inglês, notional loads.
} 
Hajjar e White (2000) constataram algumas deficiências do método, para as quais foram propostas alterações (MALECK; WHITE, 2004a). Essa versão modificada do método das forças horizontais fictícias como instrumento de consideração da instabilidade de pórticos planos foi adotado pelo do Projeto de Revisão da NBR 8800 (set. 2006), pela nova versão da norma americana de perfis pesados (AISC, 2005a) e está em discussão no comitê de revisão da norma americana de perfis formados a frio (AISI, 2006).

A atual norma brasileira de estruturas de aço NBR 8800:1986 não considera explicitamente os efeitos desestabilizantes das imperfeições geométricas globais e insere as imperfeições locais no contexto das curvas de resistência à compressão. O Projeto de Revisão da NBR 8800 (set. 2006) apresenta o método da análise direta como procedimento aproximado para consideração das imperfeições geométricas globais e não-linearidade física, permitindo o dimensionamento com o comprimento real da barra $(\mathrm{K}=1)$.

Nesse contexto, o objetivo desse trabalho é investigar a estabilidade de pórticos planos não-contraventados de aço, com base no Método das Forças Horizontais Fictícias e Método da Análise Direta, comparando os resultados aos obtidos pelo tradicional procedimento do comprimento efetivo de flambagem, no contexto da proposta do Projeto de Revisão da NBR 8800 (set. 2006). 


\section{Capítulo 2: REVISÃO BIBLIOGRÁFICA}

A avaliação de uma estrutura deve levar em consideração a resistência e estabilidade dos elementos estruturais e da estrutura como um todo. De acordo com o Structural Stability Research Council - SSRC (1976), Kanchanalai e Le-Wu (1979) os estudos mostram de forma conclusiva que pórticos susceptíveis a deslocamentos horizontais são mais propensos à falha por instabilidade do que por formação de mecanismo plástico, e qualquer análise racional deve levar em consideração esse efeito.

O dimensionamento de estruturas de aço pode ser dividido, segundo os procedimentos normativos, em duas etapas: análise estrutural e dimensionamento dos elementos. Conforme a recomendação do SSRC, os critérios suficientes para garantir a estabilidade global da estrutura devem estar contidos em uma das duas etapas.

\subsection{TIPOS DE ANÁLISE DE ESTABILIDADE}

A estabilidade de pórticos pode ser avaliada à luz da teoria da estabilidade elástica ou empregando-se uma análise estrutural de segunda ordem que considere os efeitos desestabilizantes.

$\mathrm{Na}$ análise de estabilidade conhecida como "flambagem clássica" considera-se a estrutura sem imperfeições iniciais e com as forças centradas nos pilares. As forças distribuídas nas vigas são substituídas por forças nodais equivalentes. Nesse caso, a estrutura 
apresenta apenas deslocamentos axiais até que a configuração de forças seja correspondente à bifurcação do equilíbrio.

Uma das técnicas de avaliação dessa configuração crítica é a análise pelo MEF. As equações de equilíbrio são escritas para a configuração deslocada do elemento dando origem à matriz de rigidez elástica clássica e uma matriz geométrica. A montagem do sistema de equações recai em um problema de autovalor, cuja solução fornece o carregamento de referência correspondente à bifurcação do equilíbrio.

O emprego da flambagem elástica para avaliação da estabilidade de pórticos de aço não é usual em projeto, entretanto é possível definir um modelo simplificado que represente um pilar genérico, contendo outros pilares e vigas conectados aos nós. Para o modelo simplificado, desenvolvem-se expressões que avaliam a estabilidade e estende-se a solução para pórticos maiores. Esse é o conceito envolvido para o cálculo do comprimento efetivo de flambagem utilizando o diagrama de alinhamento, o qual será detalhado mais adiante.

A segunda possibilidade envolve uma análise onde as forças distribuídas são aplicadas diretamente nas vigas, transferindo esforços de flexão aos pilares. Os efeitos de flexão e as imperfeições iniciais geram excentricidades que, associadas às forças de compressão, provocam a amplificação dos momentos fletores e deslocamentos laterais. Nesse caso, a instabilidade é definida quando pequenos incrementos de força produzem grandes incrementos de deslocamentos, ou seja, a rigidez da estrutura torna-se insuficiente para sua sustentação (KANCHANALAI; LE-WU, 1979). Bem entendido, o problema da flambagem clássica é substituído por um problema de flexo-compressão, considerando os efeitos de segunda ordem.

A susceptibilidade da estrutura aos deslocamentos laterais depende fortemente das condições de vínculo e dos elementos que compõem o sistema de contraventamento. A partir dessas características é possível classificar as estruturas quanto à estabilidade. 


\subsection{CLASSIFICAÇÃO DAS ESTRUTURAS}

Existem duas classificações distintas para estruturas de edifícios que algumas vezes são confundidas. As estruturas podem ser classificadas quanto ao sistema de contraventamento e quanto à deslocabilidade.

\subsubsection{QUANTO AO SISTEMA DE CONTRAVENTAMENTO}

São classificadas como contraventadas e não-contraventadas. Sistemas de contraventamento são aqueles que resistem aos efeitos das ações horizontais e das imperfeições geométricas. Quando a resistência às ações horizontais é garantida pela rigidez à flexão de vigas e pilares rigidamente ligados entre si, diz-se que a estrutura é nãocontraventada. Quando existe um sistema de contraventamento constituído por diagonais e/ou paredes de cisalhamento, diz-se que a estrutura é contraventada.

Ainda, para que a estrutura seja considerada contraventada é necessário que o sistema de contraventamento possua elevada rigidez em relação à estrutura. Segundo Ballio e Mazzolani (1983) e Englekirk (1994), os sistemas de contraventamento são suficientes para conter um pórtico quando aumentam em pelo menos cinco vezes a rigidez da estrutura. $\mathrm{Ou}$ seja, os deslocamentos laterais da estrutura contraventada devem ser inferiores a $20 \%$ dos deslocamentos da estrutura sem o sistema de contraventamento.

\subsubsection{QUANTO À DESLOCABILIDADE}

São classificadas como deslocáveis e indeslocáveis. De acordo com Liew e Chen (1999), uma estrutura pode ser considerada indeslocável quando a influência dos efeitos de segunda ordem puder ser desprezada. Essa influência dos efeitos de segunda ordem pode ser 
avaliada, por exemplo, pela razão entre os deslocamentos de segunda e primeira ordem ou pela razão entre os deslocamentos relativos entre pavimentos e a altura do pavimento.

É interessante ressaltar que a classificação quanto ao sistema de contraventamento é baseada na rigidez relativa do sistema de contraventamento e da estrutura. A classificação quanto à deslocabilidade dá uma idéia da rigidez da estrutura às ações horizontais. Portanto, é possível que uma estrutura contenha um sistema de contraventamento suficientemente rígido, em relação à estrutura sem contraventamento, mas que apresente deslocamentos elevados e seja classificada como deslocável.

A norma brasileira de estruturas de concreto NBR 6118:2003 define um critério baseado num coeficiente global $\gamma_{z}$ para avaliar a importância do efeito de segunda ordem global. Portanto, é um parâmetro de classificação da estrutura quanto à deslocabilidade. Esse parâmetro será discutido no item 2.5.2.2.

\subsubsection{PROCEDIMENTO DA NORMA BRITÂNICA BS 5950-1:2000}

A norma britânica de estruturas de aço define estrutura indeslocável como aquela cujos deslocamentos são suficientemente pequenos de modo que os incrementos nos esforços internos devido ao efeito de segunda ordem sejam desprezíveis.

Para edifícios de múltiplos andares, é apresentado o seguinte critério para classificar uma estrutura como indeslocável:

$$
\Delta_{1 h} \leq \frac{h}{2000}
$$

onde $\Delta_{1 \mathrm{~h}}$ é o máximo valor do deslocamento entre pavimentos, obtido em análise de primeira ordem, desprezando-se a contribuição de rigidez dos elementos de fechamento e sob ação de forças horizontais fictícias aplicadas em cada pavimento, com intensidade igual a $0,5 \%$ das 
forças verticais que atuam no respectivo pavimento e h é a altura do pavimento. Quando essa condição não é atendida, a estrutura é classificada como deslocável e os efeitos de segunda ordem devem ser considerados.

\subsubsection{PROCEDIMENTO DA NORMA BRASILEIRA NBR 8800:1986}

A NBR 8800:1986 classifica as estruturas apenas como contraventadas e nãocontraventadas, ou seja, a classificação depende do sistema de contraventamento da estrutura, mas não estabelece um critério para definir a eficiência do sistema de contraventamento.

O problema é que essa classificação é empregada para indicar um procedimento de avaliação da carga crítica de flambagem dos pilares. Esse é um parâmetro que depende da interação entre a estabilidade do pórtico e do pilar e está relacionado com a deslocabilidade da estrutura e não com o sistema de contraventamento.

A terminologia empregada pela NBR 8800:1986 não é interessante, pois, no escopo desta norma, as estruturas contraventadas são confundidas com estruturas indeslocáveis e as estruturas não-contraventadas com estruturas deslocáveis, o que nem sempre é verdadeiro.

Uma classificação que parece ser mais adequada é simplesmente tratar as estruturas como contidas ou não contidas lateralmente, onde a contenção pode ser interpretada como nodal ou relativa, conforme a descrição apresentada pelo Projeto de Revisão da NBR 8800 (set. 2006). Nesse caso, a classificação indica qual sistema estrutural será responsável pela rigidez da estrutura e, portanto, resistirá às ações horizontais.

\subsubsection{PROJETO DE REVISÃO DA NBR 8800 (SET. 2006)}

O Projeto de Revisão da NBR 8800 (set. 2006) define dois tipos de contenção lateral: nodal e relativa. A contenção nodal atua diretamente no ponto contido, sem interação com os 
pontos adjacentes. Um apoio pontual é um exemplo de contenção nodal (Figura 2.1b). Enquanto que a relativa atua entre dois pontos contidos adjacentes, por exemplo, os painéis rígidos e diagonais de contraventamento (Figura 2.1a). Claramente, essa é uma classificação aplicável aos sistemas de contraventamento.

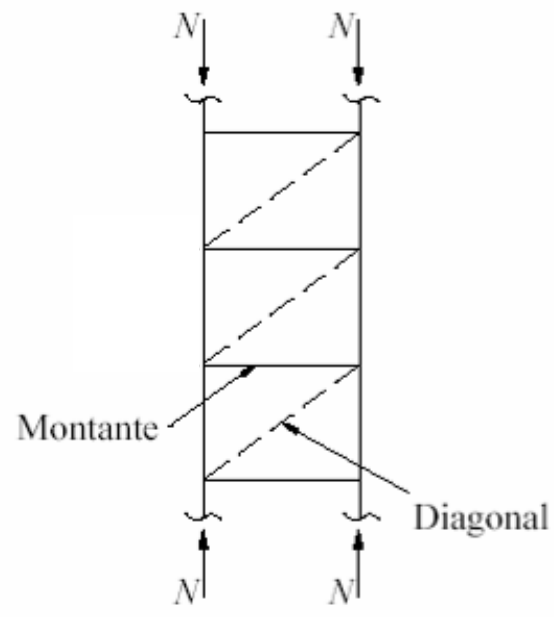

(a) relativa

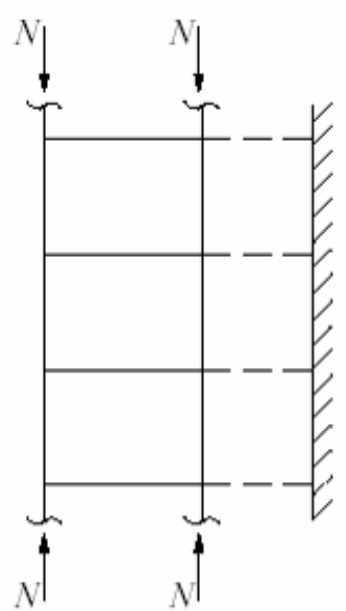

(b) nodal

Figura 2.1 - Contenções laterais (Projeto de Revisão da NBR 8800, set. 2006).

O parâmetro de classificação das estruturas quanto à deslocabilidade é a razão entre o deslocamento horizontal obtido numa análise de segunda ordem e o deslocamento obtido por uma análise de primeira ordem $\left(\mathrm{u}_{2} / \mathrm{u}_{1}\right)$.

Quando essa razão é inferior a 1,10, diz-se que a estrutura é de pequena deslocabilidade. Para valores entre 1,10 e 1,50, classifica-se como média deslocabilidade. Finalmente, para valores acima de 1,50, a estrutura é de grande deslocabilidade. As implicações de cada grupo são discutidas no item 2.7.5.

A classificação quanto à deslocabiliadade é importante, pois permite ao projetista avaliar quais serão relevantes na verificação da estabilidade da estrutura. 


\subsection{EFEITOS QUE CONTRIBUEM PARA A INSTABILIDADE DE PÓRTICOS}

Os efeitos desestabilizantes são provenientes de imperfeições geométricas oriundas dos processos de fabricação, transporte, montagem e da própria constituição do material (aspectos físicos). Uma lista dos fenômenos que contribuem para a perda de estabilidade de um pórtico é fornecida pela ASCE (1997) e Galambos (1998), dentre os quais citam-se:

- Efeito P- $\Delta$ : efeito da força axial associada ao deslocamento transversal relativo entre as extremidades da barra, proveniente da rotação da corda (Figura 2.2);

- Efeito P- $\delta$ : efeito da força axial associada aos deslocamentos do eixo da barra em relação à corda (Figura 2.2);

- Imperfeições iniciais de caráter local (elemento) e global (pórtico) (Figura 2.3);

- Tensões residuais;

- Plastificação ao longo do elemento;

- Condições de vínculo dos elementos; e

- Rigidez das ligações e estruturas de contraventamento.

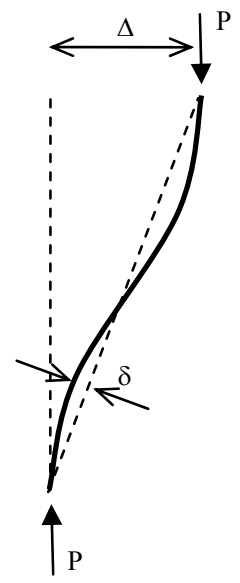

Figura 2.2 - Efeitos P- $\Delta$ e P- $\delta$ (ASCE, 1997). 
Os efeitos P- $\delta$ e P- $\Delta$ podem ser avaliados empregando-se uma análise estrutural de segunda ordem ou por meio de expressões aproximadas de amplificação dos esforços internos. Esses métodos serão detalhados no item 2.5.2.

As imperfeições iniciais caracterizam-se pela falta de alinhamento ao longo do elemento (local) ou da estrutura como um todo (global). A imperfeição local tem como principais causas os processos de fabricação, armazenagem e transporte, enquanto que a imperfeição global decorre principalmente do processo de montagem da estrutura (Figura 2.3).

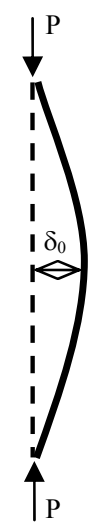

(a) local

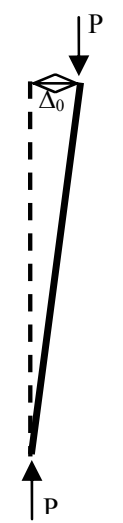

(b) global

Figura 2.3 - Imperfeições geométricas iniciais.

Um problema que ocorre na avaliação das imperfeições iniciais e existe até nas análises mais sofisticadas é a definição da forma, amplitude e sentido, ou seja, da configuração imperfeita da estrutura.

Alvarenga e Silveira (2006) realizaram estudo sobre a influência da configuração geométrica inicial na resposta de pórticos planos. A configuração geométrica inicial inclui imperfeições nas barras (locais) e desaprumos (globais). Foi empregada uma análise numérica avançada considerando a não-linearidade física e geométrica. Os resultados mostraram que quando a força normal nos pilares é baixa, a configuração geométrica inicial pouco interfere nos resultados. Por outro lado, quando a força normal nos pilares é significativa, a 
configuração geométrica inicial mais severa é aquela que mais se aproxima do modo de flambagem inelástica.

A ASCE (1997) fornece uma lista com as tolerâncias admitidas pelas normas e regulamentos estrangeiros para as imperfeições geométricas, as quais são complementadas e apresentadas na Tabela 2.1 .

Tabela 2.1 - Tolerância das imperfeições geométricas.

\begin{tabular}{lcc}
\hline & $\delta_{0} / \mathrm{L}^{(\mathrm{a})}$ & $\Delta_{0} / \mathrm{h}^{(\mathrm{b})}$ \\
\hline AISC (2005) & $1 / 1000$ & $1 / 500$ \\
CSA - S16.1 (1994) & $1 / 1000$ & $1 / 1000$ \\
AS 4100 - 1990 & $1 / 1000$ ou $3 \mathrm{~mm}$ & $1 / 500$ \\
prEN 1993 - 3 (2004) & $1 / 1000$ & $1 / 500$ \\
NBR 8800:1986 & $1 / 1000$ & - \\
Projeto de Revisão da NBR 8800 (set. 2006) & $1 / 1000$ & $1 / 500$ \\
\hline$\delta_{0}$ e $\Delta_{0}$ conforme Figura 2.3. & & \\
(a) L é o comprimento da barra. & & \\
(b) h é a altura do pavimento. & & \\
\hline
\end{tabular}

Chan e Zhou (1995) utilizaram elementos finitos curvos para representar as imperfeições locais das barras. A geometria das barras foi definida por uma função parabólica, cujo valor máximo pode ser ajustado de acordo com a norma vigente. A análise estrutural de duas cúpulas mostrou que as imperfeições iniciais locais são mais significativas em estruturas cuja estabilidade não é muito afetada pelo efeito P- $\Delta$. Entretanto, como esse julgamento não foi considerado trivial, recomendou-se a utilização de elementos curvos em todas as estruturas.

Liew et al. (1995) propuseram a utilização de conjunto de forças concentradas transversais ao eixo da barra para representar a imperfeição local. Esse conjunto de forças transversais é constituído por uma força aplicada no meio do vão com intensidade $\alpha \mathrm{N}_{\mathrm{Sd}}$, além de uma força aplicada em cada extremidade da barra com intensidade $0,5 \alpha \mathrm{N}_{\mathrm{Sd}}$, onde $\alpha$ é uma fração da força normal atuante no pilar. 
É importante ressaltar que as imperfeições geométricas locais já estão inseridas nas curvas de resistência para dimensionamento de barras comprimidas apresentadas pelas normas. Portanto, a introdução dessas imperfeições na análise estrutural deve acompanhar modificações no dimensionamento da barra para que o efeito não seja contabilizado duas vezes. Esse cuidado deve ser estendido para todos os efeitos desestabilizantes.

As imperfeições globais podem ser inseridas ao modelo geométrico da estrutura diretamente, mas esse não é um procedimento prático. Outras formas de inserir imperfeições é aplicar deslocamentos nodais ou utilizar um modo de flambagem da estrutura afetado por um fator de escala para definir a configuração inicial de aplicação dos carregamentos (HIBBITT, KARLSSON AND SORENSON INC., 2005).

Bayo e Loureiro (2001) apresentaram um procedimento que utiliza o primeiro modo de flambagem do pórtico como configuração inicial da estrutura. É empregada uma análise linear com as forças gravitacionais para determinar a energia de deformação dos pilares. Em seguida, uma análise de autovalor determina o primeiro modo de flambagem. $\mathrm{O}$ fator de escala que é aplicado ao modo de flambagem é calculado por uma expressão que envolve a energia de deformação dos pilares. Finalmente, aplica-se uma análise geometricamente nãolinear para a estrutura considerando a configuração inicial imperfeita.

O método das forças horizontais fictícias e o método da análise direta propõem a utilização de forças horizontais aplicadas aos pavimentos da estrutura e à cobertura para representar as imperfeições geométricas globais.

Com o objetivo de avaliar estratégias simplificadas de simulação das imperfeições iniciais globais, Chen e Kim $(1996,1998)$ utilizaram um programa de análise estrutural baseado no MEF que considerava a não-linearidade física e as tensões residuais. As imperfeições globais foram modeladas de três formas: (i) modelagem explícita da estrutura imperfeita, (ii) inclusão de forças horizontais, definidas como fração $(0,2 \%)$ do total de forças 
gravitacionais que atuam no pavimento, e (iii) redução da rigidez à flexão das barras $\left(\mathrm{EI}_{\mathrm{red}}=0,85 \mathrm{EI}\right)$.

As duas estratégias aproximadas (ii e iii) foram capazes de reproduzir o efeito das imperfeições quando comparadas à modelagem explícita. Entretanto, a redução da rigidez à flexão das barras foi considerada mais adequada pela simplicidade do processo e porque, em alguns casos, a aplicação de forças horizontais apresentou resultados diferentes dependendo do lado da estrutura que fosse carregado.

As tensões residuais são ocasionadas principalmente pelo processo de laminação e de fabricação dos perfis (perfis soldados, por exemplo). De acordo com Galambos (1998), no processo de laminação são originadas tensões residuais auto-equilibradas devido ao gradiente térmico da seção transversal do perfil que podem ser da ordem de $30 \%$ da resistência ao escoamento $\left(f_{\mathrm{y}}\right)$ do aço (Figura 2.4).

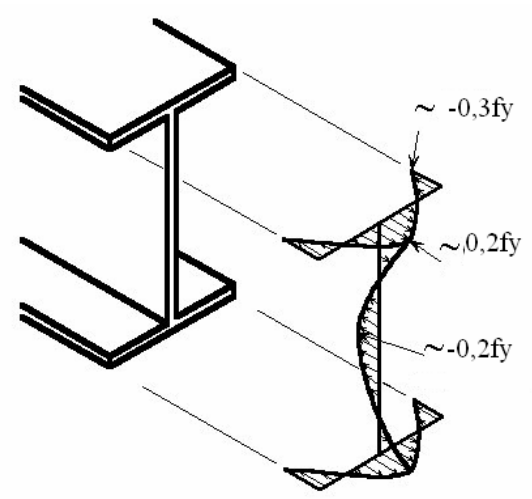

Figura 2.4 - Diagrama de tensões residuais provenientes do processo de laminação (EDESP, 2006).

Segundo Bild e Trahair (1989), a distribuição e a magnitude das tensões residuais do perfil variam bastante de acordo com o processo de fabricação (laminação, soldagem) e com a geometria. Deste modo, é difícil estabelecer uma configuração que represente razoavelmente todos os casos. Para os perfis I, amplamente utilizados em pilares, o parâmetro que mais influencia a resistência é a tensão residual atuante nas extremidades das mesas. Esse parâmetro foi definido como $35 \%$ da resistência ao escoamento do aço. 
O estado de tensões iniciais (residuais) é responsável pelo aparecimento antecipado de deformações plásticas. Evidentemente, esse fenômeno se verifica apenas quando as tensões provenientes do carregamento externo possuem o mesmo sinal da tensão residual no ponto considerado. Em um perfil I laminado submetido à compressão centrada as extremidades das mesas irão desenvolver deformações plásticas para um nível de tensão proveniente do carregamento externo igual a $\mathrm{f}_{\mathrm{p}}=0,7 \mathrm{f}_{\mathrm{y}}$, que é somado à tensão residual no ponto e dá origem a um trecho de comportamento inelástico (Figura 2.5).
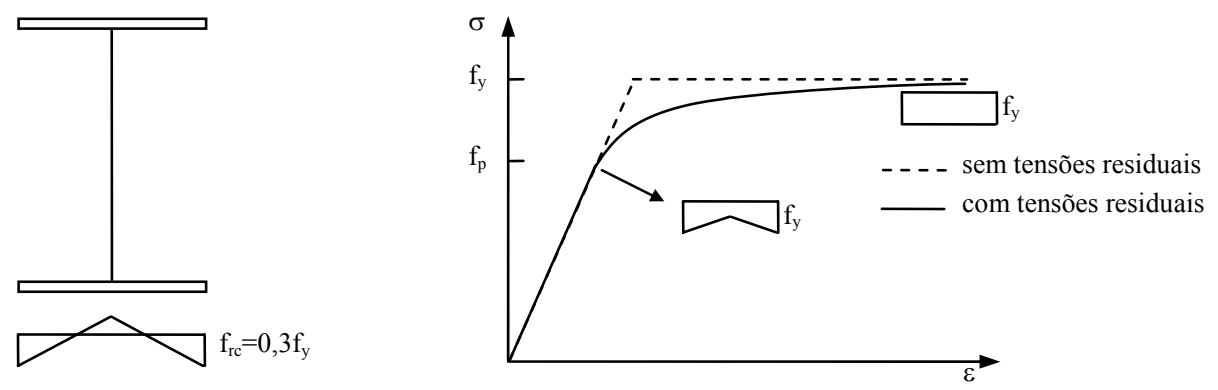

Figura 2.5 - Diagrama tensão-deformação de um perfil I laminado comprimido (REIS e CAMOTIM, 2006).

Os estudos realizados por Galambos e Ketter (1959) mostram que a influência das tensões residuais é mais significativa em barras submetidas a uma força axial de compressão elevada, superior a $60 \%$ da força que provoca o escoamento da seção transversal.

O processo de plastificação da estrutura não é pontual. O início da plastificação se dá numa seção mais solicitada, mas se propaga ao longo da seção e do comprimento do elemento. A representação desse fenômeno numa análise numérica não é trivial, uma vez que são necessárias ferramentas que permitam captar o efeito da plastificação ao longo da seção e do elemento.

As condições de vinculação da estrutura e dos elementos entre si são mais fáceis de serem compreendidas e modeladas. Os programas de análise estrutural utilizados nos escritórios já permitem considerar ligações semi-rígidas entre vigas e pilares e diversos tipos de vinculação de apoio. Ademais, as estruturas de contraventamento compostas por barras e 
painéis também podem ser inseridas facilmente (COMPUTER AND STRUCTURES INC., 2004).

Os efeitos desestabilizantes podem ser modelados explicitamente, utilizando ferramentas numéricas ou por meio de expressões e métodos simplificados apresentados na literatura. Segundo Maleck et al. (2005), embora as ferramentas computacionais avançadas que consideram modelos não-lineares físicos e geométricos, imperfeições geométricas e tensões residuais evoluam rapidamente, ainda não existe um programa comercial disponível com esses recursos para uso em escritórios. A grande contribuição das análises avançadas é aprimorar o entendimento do comportamento estrutural e servir de referência para calibração de ferramentas mais simples.

Existem outras formas de levar em consideração os efeitos da plastificação e das tensões residuais. Os métodos da força horizontal fictícia e o método da análise direta também consideram esses efeitos e são exemplos apresentados por normas estrangeiras (AISC, 2005; prEN 1993-3, 2003).

\subsection{EXPRESSÕES DE INTERAÇÃO}

As normas de estruturas de aço adotam expressões de interação para a verificação de barras submetidas à flexão composta e definem uma superfície de escoamento em função do momento fletor e força normal solicitantes na seção transversal. Esse é o efeito predominante nas barras de pórticos planos admitindo-se contenção lateral apropriada e perfis de seção compacta, isto é, não propensas à instabilidade lateral e instabilidades locais.

As normas de dimensionamento de estruturas de aço apresentam algumas variações nos procedimentos de avaliação da capacidade resistente de elementos submetidos à flexocompressão. A especificação do AISC (2005a) apresenta as seguintes expressões de interação, que também foram incorporadas ao Projeto de Revisão da NBR 8800 (set. 2006). 


$$
\begin{aligned}
& \frac{N_{S d}}{N_{R d}}+\frac{8}{9} \frac{M_{S d}}{M_{R d}} \leq 1 \text { se } \frac{N_{S d}}{N_{R d}} \geq 0,2 \\
& \frac{N_{S d}}{2 N_{R d}}+\frac{M_{S d}}{M_{R d}} \leq 1 \text { se } \frac{N_{S d}}{N_{R d}}<0,2
\end{aligned}
$$

onde $\mathrm{N}$ e $\mathrm{M}$ são os esforços normais e momentos fletores, respectivamente e os índices $\mathrm{Sd}$ e Rd referem-se aos esforços solicitantes e resistentes de cálculo, respectivamente. Os esforços solicitantes devem incluir os efeitos de segunda ordem.

A análise de qualquer uma das expressões anteriores é suficiente para discutir as estratégias de avaliação da estabilidade de pórticos deslocáveis. Nos procedimentos que envolvem o cálculo do comprimento efetivo de flambagem, o comprimento real do elemento é aumentado, portanto a força normal de compressão resistente de cálculo $\left(\mathrm{N}_{\mathrm{Rd}}\right)$ diminui. Deste modo, o resultado final das expressões sofre um aumento.

Os efeitos de segunda ordem têm como uma das conseqüências a amplificação dos momentos solicitantes $\left(\mathrm{M}_{\mathrm{Sd}}\right)$. Portanto, também provocam um aumento no resultado da expressão de interação. De acordo com Liew et al. (1991), a avaliação do momento fletor solicitante por meio de uma análise de segunda ordem ou de procedimentos simplificados já foi considerada como garantia da verificação da estabilidade da estrutura, ou seja, quando os efeitos de segunda ordem eram considerados, permitia-se dimensionar os elementos com seu comprimento real $(\mathrm{K}=1)$.

A explicação mais provável é que o aumento dos momentos solicitantes compensaria o acréscimo do esforço normal resistente. Entretanto, mostrou-se que os resultados obtidos por esse procedimento eram contra a segurança e deixaram evidentes que outros efeitos ainda precisavam ser considerados.

O método das forças horizontais fictícias e o método da análise direta foram propostos para avaliação aproximada dos efeitos desestabilizantes das imperfeições geométricas além da 
análise de segunda ordem. Deste modo, esses métodos buscam representar o comportamento de elementos submetidos à flexo-compressão sem precisar recorrer ao cálculo do comprimento efetivo de flambagem.

\subsection{MODELOS PARA AVALIAÇÃO DE PÓRTICOS}

Os modelos aqui apresentados são propostas de representação aproximada dos efeitos de segunda ordem, das tensões residuais, imperfeições geométricas e não-linearidade física.

\subsubsection{COMPRIMENTO EFETIVO DE FLAMBAGEM}

O comprimento efetivo de flambagem é uma estratégia que modifica o comprimento real da barra para a avaliação da força normal resistente. A análise estrutural é realizada sem alteração da configuração de forças de projeto. $\mathrm{O}$ coeficiente $\mathrm{K}$ associado às curvas de resistência é que irá contabilizar a contribuição de rigidez à flexão que os elementos conectados fornecem às extremidades do pilar em análise. Segundo Liew et al. (1991), o comprimento efetivo tem por objetivo relacionar a susceptibilidade à flambagem do elemento isolado com a da estrutura.

Um dos procedimentos mais difundidos para cálculo do coeficiente de flambagem $\mathrm{K}$ é o diagrama de alinhamento, que será apresentado segundo as recomendações da NBR 8800:1986. Outros métodos para cálculo do comprimento efetivo de flambagem são apresentados por Duan e Chen (1999).

O procedimento da NBR 8800:1986 foi proposto por Julian e Lawrence e apresentado por Kavanagh (1962). Esse procedimento adota uma subestrutura que represente um pilar pertencente a um pórtico plano. Essa subestrutura é capaz de representar a contribuição de 
rigidez dos pilares superior e inferior bem como das vigas conectadas aos nós do pilar considerado (Figura 2.6).

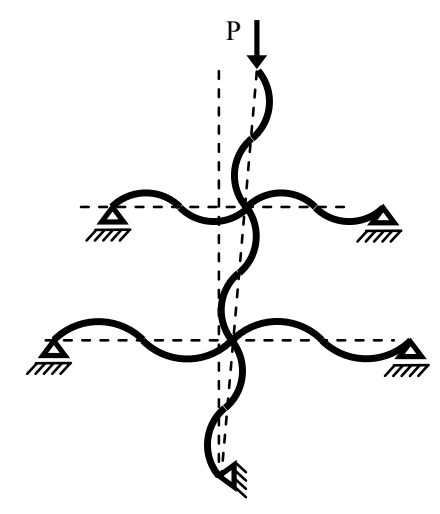

Figura 2.6 - Modelo estrutural para cálculo do coeficiente K em estruturas deslocáveis (AISC, 2005b).

A solução apresentada para o problema da estabilidade dessa subestrutura está sujeita às seguintes simplificações:

- $\quad$ todos os pilares são contínuos;

- comportamento elástico;

- cada barra da estrutura tem seção transversal constante;

- todas as ligações são rígidas;

- nas estruturas indeslocáveis, as rotações nas extremidades opostas das vigas rigidamente conectadas são iguais em intensidade, produzindo curvatura simples;

- nas estruturas deslocáveis, as rotações nas extremidades opostas das vigas rigidamente conectadas são iguais em intensidade, produzindo curvatura reversa;

- o parâmetro de rigidez $L \sqrt{N_{S d} /(E I)}$ de todos os pilares são iguais;

- a rigidez do nó é distribuída para os pilares imediatamente acima e abaixo do mesmo, na proporção do parâmetro I/L desses dois pilares;

- todos os pilares atingem a força crítica simultaneamente;

- não ocorre força normal de compressão significativa nas vigas. 
A partir dessas idealizações, é possível determinar a força normal no pilar correspondente à bifurcação do equilíbrio, que é igual à carga crítica de flambagem da subestrutura. Em seguida, calcula-se o comprimento efetivo de flambagem (KL) correspondente ao esforço normal atuante no pilar. Para estruturas deslocáveis, a solução do problema é dada pela expressão que segue:

$$
\begin{gathered}
K=\sqrt{\frac{7,5+4\left(G_{A}+G_{B}\right)+1,6 G_{A} G_{B}}{7,5+G_{A}+G_{B}}} \\
G=\frac{\sum \frac{I_{p}}{L_{p}}}{\sum \frac{I_{v}}{L_{v}}}
\end{gathered}
$$

onde os índices $A$ e $B$ referem-se aos nós inferior e superior do pilar e os índices $p$ e $v$ referem-se aos pilares e vigas rigidamente conectados ao nó considerado. A mesma solução do problema pode ser obtida empregando-se o diagrama de alinhamento apresentado na Figura 2.7 cujos parâmetros de entrada são $G_{A}$ e $G_{B}$.

A utilização da subestrutura torna o procedimento de cálculo da carga crítica mais fácil e passível de parametrização, mas limita significativamente a capacidade de representação da estrutura original. Além disso, de acordo com a ASCE (1997), para os casos onde as simplificações apresentadas não são atendidas, o método do diagrama de alinhamento pode conduzir a erros significativos contra a segurança. 


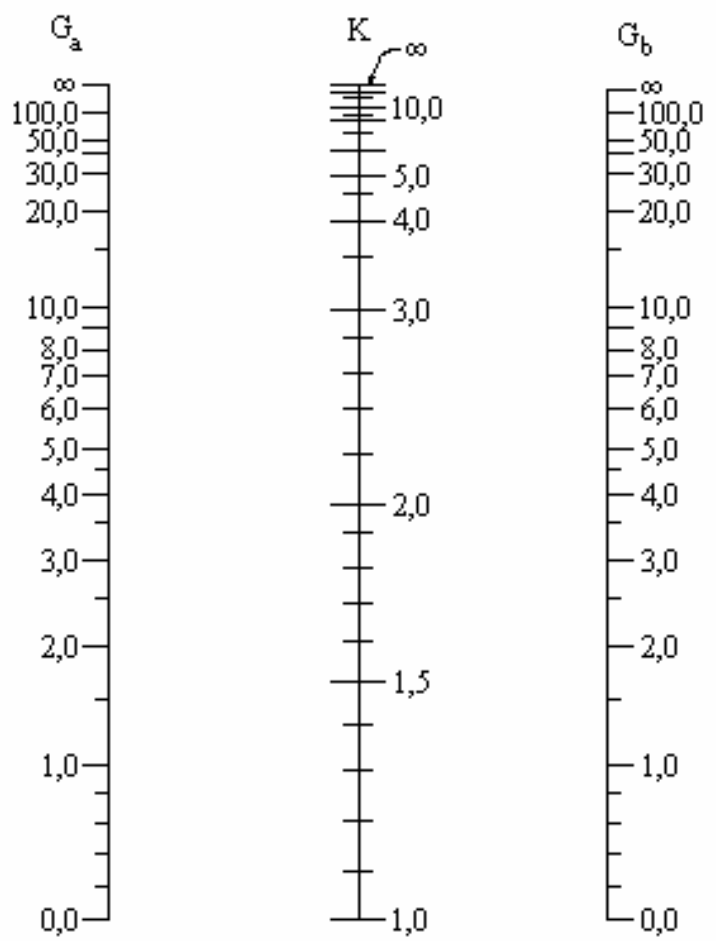

Figura 2.7 - Diagrama de alinhamento para estruturas deslocáveis (AISC, 2005b).

De acordo com Girgin et al. (2006), a principal desvantagem do método do diagrama de alinhamento é a falta de sensibilidade à configuração de forças que a estrutura está submetida. A expressão (2.4) não contém informações sobre o nível de solicitação e a contribuição de rigidez aos deslocamentos laterais dos pilares próximos.

Num grupo de pórticos planos analisados em regime elástico por dois procedimentos diferentes de determinação do coeficiente $K$, o método do diagrama de alinhamento apresentou erros considerados intoleráveis, entre $-55 \%$ e $77 \%$. O outro método, proposto no trabalho e baseado num conceito energético para obtenção de forças horizontais virtuais que representem o primeiro modo de flambagem foi capaz de reduzir o erro para $3 \%$, sempre a favor da segurança.

Antunes (2001) fez um estudo sobre o cálculo do coeficiente K em pilares pertencentes a pórticos não-contraventados. Verificou-se que a rigidez do pórtico é uma propriedade que influencia o comprimento efetivo de flambagem. Por isso, foram 
desenvolvidos ábacos semelhantes ao apresentado pela norma brasileira específicos para alguns valores de rigidez do pórtico.

Outros métodos mais sofisticados para avaliação do coeficiente K para pilares sujeitos à instabilidade em regime inelástico podem ser encontrados na literatura e apresentam resultados mais precisos (ASCE, 1997; DUAN e CHEN, 1999). Entretanto, os ajustes necessários para contabilizar esses efeitos tornam os procedimentos pouco práticos e abrangentes (HAJJAR e WHITE, 2000; MALECK e WHITE, 2004).

\subsubsection{EFEITOS DE SEGUNDA ORDEM}

Os efeitos de segunda ordem compreendem a amplificação dos momentos fletores e deslocamentos devido à presença de uma força axial associada a deslocamentos transversais, devido à curvatura da barra e rotação da corda, $\mathrm{P}-\delta$ e $\mathrm{P}-\Delta$, respectivamente.

Serão apresentados os métodos aproximados propostos mais difundidos na literatura para avaliação dos efeitos P- $\delta$ e P- $\Delta$. Embora esses efeitos também envolvam a amplificação dos deslocamentos laterais, a apresentação que segue será restrita à amplificação de momentos fletores.

\subsubsection{EFEITO P- $\delta$}

A influência desse efeito pode ser avaliada para uma barra isolada bi-rotulada, solicitada por carregamentos transversais ou momentos de extremidade e a uma força axial de compressão. A dedução das equações de amplificação do momento fletor para os dois casos é apresentada na literatura (ENGLEKIRK, 1994; SALMON e JOHNSON, 1996).

Considerando-se a presença de carregamento transversal e da força axial de compressão $\left(\mathrm{N}_{\mathrm{Sd}}\right)$ é possível determinar a expressão analítica para a amplificação do momento 
fletor de primeira ordem, admitindo-se que o diagrama de momento fletor de segunda ordem, provocado pela presença da força axial de compressão associada aos deslocamentos transversais de primeira ordem, assume uma forma senoidal. Assim, obtém-se a seguinte expressão:

$$
M_{S d}=B_{1} M_{n t}
$$

onde $\mathrm{M}_{\mathrm{nt}}$ é o momento fletor solicitante de cálculo, obtido em análise elástica de primeira ordem, provocado pelo carregamento transversal e $\mathrm{B}_{1}$ é o coeficiente de amplificação devido ao efeito P- $\delta$, dado pela seguinte expressão:

$$
B_{1}=\frac{C_{m}}{1-\frac{N_{S d}}{N_{e}}}
$$

onde $\mathrm{N}_{\mathrm{e}}$ é força normal crítica de flambagem elástica da barra, no plano em que atua a força transversal, calculada com o comprimento efetivo de flambagem considerando a barra contida numa estrutura indeslocável, ou seja, $\mathrm{K} \leq 1$. O coeficiente $\mathrm{C}_{\mathrm{m}}$ é dado por:

$$
C_{m}=1+\left(\frac{\pi^{2} E I \delta_{1}}{M_{n t} L^{2}}-1\right) \frac{N_{S d}}{N_{e}}
$$

onde $\delta_{1}$ é o deslocamento transversal no meio do vão, obtido em análise elástica de primeira ordem, devido ao carregamento transversal. O termo entre parênteses da equação (2.8) vale 0,028 para uma força distribuída constante. Por isso, algumas normas permitem a utilização de $\mathrm{C}_{\mathrm{m}}$ igual a 1,00 nesse caso (NBR 8800:1986; AISC, 2005).

Para o caso da barra estar submetida a momentos aplicados nas extremidades e à força axial de compressão (sem carregamento transversal), é possível determinar uma expressão 
idêntica à equação (2.7), variando-se apenas a definição do parâmetro $C_{m}$, cuja expressão aproximada é dada por:

$$
C_{m}=0,60-0,40 \frac{M_{1}}{M_{2}}
$$

onde $M_{1}$ e $M_{2}$ são, respectivamente, o menor e maior dos momentos fletores solicitantes nas extremidades da barra, em valor absoluto. A razão entre esses momentos é tomada positiva quando provocam curvatura reversa e negativa quando provocarem curvatura simples. $\mathrm{O}$ momento de referência $\left(\mathrm{M}_{\mathrm{nt}}\right)$ é igual a $\mathrm{M}_{2}$.

Para barras sob força transversal, $\mathrm{C}_{\mathrm{m}}$ é parte integrante do coeficiente de amplificação $B_{1}$. Para barras sem força transversal e sob momentos aplicados nas extremidades, $C_{m}$ é um fator de uniformização de momentos, isto é, $\mathrm{C}_{\mathrm{m}} \mathrm{M}_{2}$ indica $\mathrm{o}$ momento constante correspondente.

\subsubsection{EFEITO P- $\Delta$}

Salmon e Johnson (1996) apresentam a dedução de uma equação aproximada para amplificação de momentos fletores devido ao efeito P- $\Delta$. Para o estudo do efeito de segunda ordem, admite-se uma barra que representa um pavimento da estrutura. Essa barra é submetida a uma força axial com intensidade igual ao somatório de todas as forças normais nos pilares contidos no pavimento $\left(\Sigma \mathrm{N}_{\mathrm{Sd}}\right)$ e a uma força horizontal igual ao somatório das forças cortantes nos referidos pilares $\left(\Sigma \mathrm{H}_{\mathrm{Sd}}\right)$. 

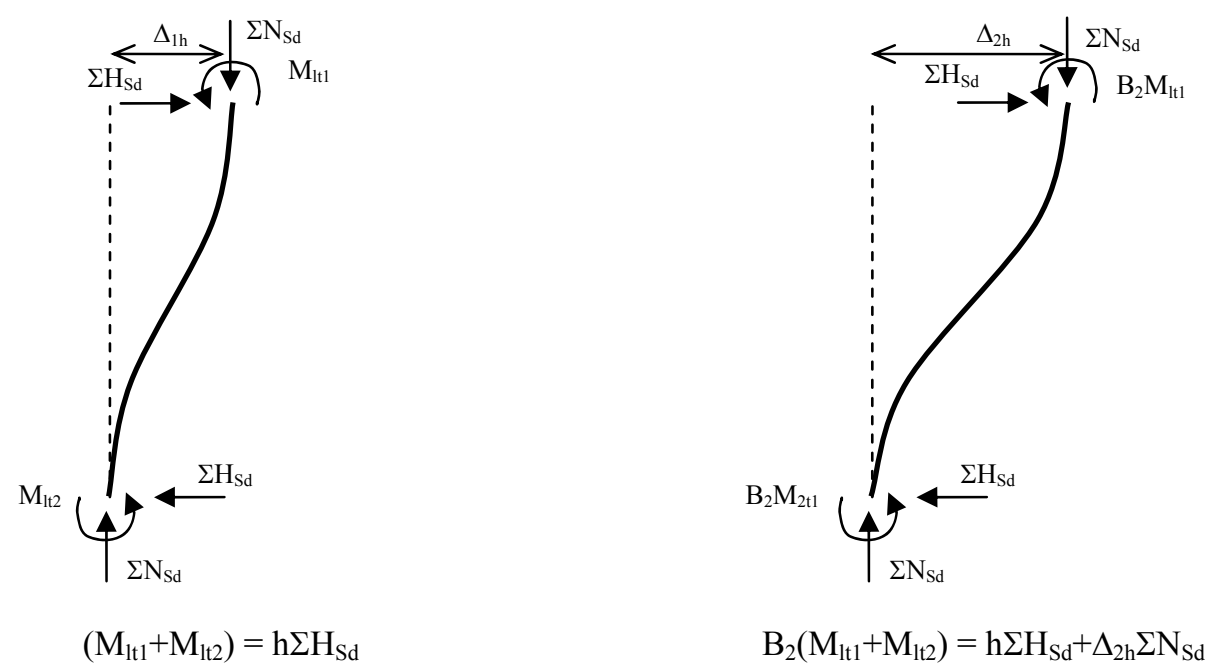

Figura 2.8 - Efeitos P- $\Delta$ (SALMON e JONHSON, 1996).

$\mathrm{O}$ estudo do equilíbrio dos esquemas estruturais sem efeito de segunda ordem e considerando esse efeito permite escrever:

$$
B_{2}=1+\frac{\Delta_{2 h} \sum N_{S d}}{h \sum H_{S d}}
$$

Admitindo-se que a rigidez da estrutura avaliada em primeira e segunda ordem é a mesma, é possível relacionar os deslocamentos relativos de segunda e primeira ordem. Após várias manipulações algébricas, é possível obter a seguinte expressão para o fator de amplificação dos momentos:

$$
B_{2}=\frac{1}{1-\frac{\Delta_{1 h} \sum N_{S d}}{h \sum H_{S d}}}
$$

onde $\Delta_{1 \mathrm{~h}}$ é o deslocamento relativo entre pavimentos, obtido em análise elástica de primeira ordem, $\mathrm{H}_{\mathrm{Sd}}$ é o somatório das forças horizontais no pavimento considerado que produzem $\Delta_{1 \mathrm{~h}}$ e h é a altura do pavimento. De acordo com Englekirk (1994), a equação seguinte também pode ser utilizada como alternativa à equação (2.11). 


$$
B_{2}=\frac{1}{1-\frac{\sum N_{S d}}{\sum N_{e}}}
$$

Nesse caso, a força normal de flambagem elástica no plano de flexão considerado é obtida utilizando o comprimento efetivo de flambagem referente à estrutura deslocável $(\mathrm{K} \geq 1)$. Segundo Kanchanalai e Le-Wu (1979), as equações (2.12) e (2.11) foram propostas em 1971 e 1976, respectivamente.

De acordo com Gomes (2005), a avaliação do parâmetro $\mathrm{B}_{2}$ por meio da expressão (2.12) pode causar confusão, devido à necessidade de se avaliar o coeficiente de flambagem K. Por isso, recomendou-se a eliminação desta equação, ficando apenas com a equação (2.11). Essa recomendação está sendo seguida pelo Projeto de Revisão da NBR 8800 (set. 2006).

Para pórticos planos deslocáveis, o momento fletor de segunda ordem considerando-se apenas o efeito P- $\Delta$ é dado por:

$$
M_{S d}=B_{2} M_{l t}
$$

onde $\mathrm{M}_{1 \mathrm{t}}$ é o momento fletor solicitante de cálculo, obtido em análise elástica de primeira ordem, considerando-se apenas as forças laterais.

$\mathrm{O}$ parâmetro $\mathrm{B}_{2}$ depende da intensidade das forças laterais aplicadas na estrutura. Em combinações de ações em que só atuem forças gravitacionais, o cálculo de $\mathrm{B}_{2}$ pela equação (2.11) não é possível, ainda que o efeito P- $\Delta$ exista e deva ser considerado. Nesses casos, Kanchanalai e Le-Wu (1979) recomendam a utilização de forças horizontais fictícias aplicadas aos pavimentos com intensidade igual a $0,5 \%$ do total das forças verticais atuantes no respectivo pavimento. 
A expressão (2.11) é apresentada pelas normas de estruturas de aço canadense (CSA, 1994), americana (AISC, 2005) e foi proposta para pelo Projeto de Revisão da NBR 8800 (set. 2006). Nestas duas últimas, foi introduzido um coeficiente $\mathrm{R}_{\mathrm{m}}$, como segue:

$$
B_{2}=\frac{1}{1-\frac{\Delta_{1 h} \sum N_{S d}}{R_{m} h \sum H_{S d}}}
$$

O coeficiente $R_{m}$ é igual a 1,0 quando toda a rigidez da estrutura é garantida por elementos de contraventamento e 0,85 quando a rigidez é garantida pela rigidez à flexão dos pilares e vigas. Esse valor $(0,85)$ representa um acréscimo em $\mathrm{B}_{2}$ devido à influência do efeito $\mathrm{P}-\delta$ no efeito P- $\Delta$ (AISC, 2005b).

A norma brasileira de estruturas de concreto NBR 6118:2003 apresenta o coeficiente $\gamma_{\mathrm{z}}$ como parâmetro para classificação da estrutura quanto à deslocabilidade e permite que seja utilizado para amplificação dos esforços globais finais de $1^{\mathrm{a}}$ ordem para obtenção dos finais de $2^{\mathrm{a}}$ ordem. Esse parâmetro foi proposto por Franco e Vasconcelos $\left(1991^{2}\right.$ apud PINTO, 1997) e apresenta alguma semelhança com a expressão do coeficiente $B_{2}$ :

$$
\gamma_{z}=\frac{1}{1-\frac{\Delta M_{t o t, d}}{M_{1, t o t, d}}}
$$

onde $\Delta \mathrm{M}_{\mathrm{tot}, \mathrm{d}}$ é a soma do produto de todas as forças verticais atuantes na estrutura, na combinação considerada, com seus valores de cálculo, pelos deslocamentos horizontais de seus respectivos pontos de aplicação, obtidos na análise de $1^{\mathrm{a}}$ ordem. $\mathrm{M}_{1, \mathrm{tot}, \mathrm{d}}$ é o momento de tombamento, ou seja, a soma dos momentos de todas as forças horizontais da combinação considerada, com seus valores de cálculo, em relação à base da estrutura.

\footnotetext{
${ }^{2}$ FRANCO, M.; VASCONCELOS, A.C. Pratical Assessment of second order effects in tall buildings. In: COLLOQUIUM ON THE CEB-FIP MC 90, Rio de Janeiro, 1991, p.307-324.
} 
A amplificação dos momentos de primeira ordem é dada por:

$$
M_{S d}=0,95 \gamma_{z} M_{1}
$$

onde $\mathrm{M}_{1}$ é o momento fletor solicitante de cálculo de primeira ordem, considerando-se todas as ações verticais e horizontais.

A majoração dos momentos fletores de primeira ordem é válida apenas para $\gamma_{\mathrm{z}} \leq 1,30$. Além disso, a análise estrutural deve ser realizada adotando-se a redução de rigidez dos elementos definida nessa norma para representação aproximada da não-linearidade física do concreto.

Pinto (1997) realizou um estudo comparativo entre o procedimento de amplificação dos esforços de primeira ordem utilizando o coeficiente $\gamma_{z}$ e uma análise de segunda ordem. Foram analisados 25 edifícios usuais de concreto armado submetidos a forças verticais e a ação do vento em duas direções ortogonais. Os parâmetros de comparação foram os esforços internos solicitantes nas vigas e pilares.

Os desvios médios encontrados nos valores estimados dos esforços internos solicitantes foram inferiores a 5\% para valores de $\gamma_{\mathrm{z}}$ inferiores a 1,20. O estudo apontou esse valor como limite para a utilização do coeficiente $\gamma_{\mathrm{z}}$. Os desvios médios apresentaram valores superiores a $7 \%$ quando $\gamma_{\mathrm{Z}}>1,30$.

A questão é que esse estudo foi realizado tomando-se como parâmetro de comparação a média dos desvios entre o procedimento aproximado e a análise de segunda ordem e esse não é um parâmetro estatístico interessante, pois pode induzir a conclusões equivocadas. $\mathrm{O}$ desvio padrão também deve ser estudado para avaliar a dispersão dos resultados.

Os coeficientes $\mathrm{B}_{2}$ e $\gamma_{\mathrm{z}}$ são empregados como procedimentos simplificados para classificar a estrutura quanto à deslocabilidade e avaliar a influência dos efeitos de segunda 
ordem. A dedução da expressão de cada coeficiente segue uma idéia semelhante de avaliar o momento de tombamento devido às forças horizontais e verticais. A diferença é que o coeficiente $B_{2}$ é aplicado a um pavimento, enquanto que o $\gamma_{z}$ é aplicado à estrutura como um todo.

Embora não tenha sido encontrada na literatura nenhuma relação entre esses parâmetros, é possível mostrar que sob algumas condições, essa relação existe. As expressões para os coeficientes $B_{2, \mathrm{i}}$ (relativo ao $i$-ésimo pavimento) e $\gamma_{\mathrm{z}}$ são:

$$
\begin{gathered}
B_{2, i}=\frac{1}{1-\frac{\Delta u_{i}\left(\sum N_{S d}\right)_{i}}{h_{i}\left(\sum H_{S d}\right)_{i}}} \\
\gamma_{z}=\frac{1}{1-\frac{\Delta M_{\text {tot }, d}}{M_{1, t o t, d}}}
\end{gathered}
$$

É possível escrever o momento de tombamento devido às forças verticais como segue:

$$
\Delta M_{t o t, d}=\sum_{i=1}^{n} P_{i} u_{i}
$$

onde $\mathrm{P}_{\mathrm{i}}$ é carregamento total no pavimento na combinação de ações considerada, $\mathrm{u}_{\mathrm{i}} \mathrm{e}$ o deslocamento do pavimento em relação à base e n é o número de pavimentos. O deslocamento do pavimento i em relação à base pode ser obtido pela soma dos deslocamentos relativos dos pavimentos inferiores, ou seja:

$$
u_{i}=\sum_{j=1}^{i} \Delta u_{j}
$$

Portanto, 


$$
\Delta M_{\text {tot }, d}=\Delta u_{1}\left(P_{1}+P_{2}+\ldots+P_{n}\right)+\Delta u_{2}\left(P_{2}+\ldots+P_{n}\right)+\ldots+\Delta u_{n} P_{n}=\sum_{i=1}^{n} \Delta u_{i}\left(\sum N_{S d}\right)_{i}
$$

Agrupando-se os deslocamentos relativos entre pavimentos $\Delta \mathrm{u}_{\mathrm{i}}$ e considerando-se que o somatório das forças que atuam acima do pavimento é igual ao somatório dos esforços normais no pilares do respectivo pavimento $\left(\Sigma \mathrm{N}_{\mathrm{Sd}}\right)_{\text {i }}$, tem-se:

$$
\Delta M_{\text {tot }, d}=\Delta u_{1}\left(P_{1}+P_{2}+\ldots+P_{n}\right)+\Delta u_{2}\left(P_{2}+\ldots+P_{n}\right)+\ldots+\Delta u_{n} P_{n}
$$

ou seja,

$$
\Delta M_{t o t, d}=\sum_{i=1}^{n} \Delta u_{i}\left(\sum N_{S d}\right)_{i}
$$

Nota-se que o termo do somatório da equação (2.21) também aparece na expressão (2.17).

Adotando um procedimento semelhante para o momento de tombamento devido às ações horizontais, tem-se:

$$
M_{1, t o t, d}=\sum_{i=1}^{n} F_{i} \bar{h}_{i}
$$

Onde $\overline{\mathrm{h}}$ é a distância do pavimento até a base da estrutura, dada pelo somatório das alturas dos pavimentos inferiores. Deste modo:

$$
\sum_{i=1}^{n} F_{i} \bar{h}_{i}=F_{1} h_{1}+F_{2}\left(h_{1}+h_{2}\right)+\ldots+F_{n}\left(h_{1}+h_{2}+\ldots+h_{n}\right)
$$

Agrupando os termos $h_{i}$ e considerando-se que a força horizontal que atua acima do pavimento é igual ao somatório das forças cortantes solicitantes nos pilares do pavimento, tem-se: 


$$
M_{1, t o t, d}=h_{1}\left(F_{1}+F_{2}+\ldots+F_{n}\right)+h_{2}\left(F_{2}+\ldots+F_{n}\right)+\ldots+h_{n} F_{n}
$$

Ou seja,

$$
M_{1, t o t, d}=\sum_{i=1}^{n} h_{i}\left(\sum H_{S d}\right)_{i}
$$

Novamente, o termo do somatório em (2.23) aparece na expressão (2.17). Isolando-se o termo $\Delta u_{i}\left(\sum N_{S d}\right)_{i}$ na expressão (2.17) tem-se.

$$
\Delta u_{i}\left(\sum N_{S d}\right)_{i}=\left(1-\frac{1}{B_{2, i}}\right) h_{i}\left(\sum H_{S d}\right)_{i}
$$

Somando-se o resultado anterior em todos os pavimentos da estrutura, chega-se a:

$$
\sum_{i=1}^{n} \Delta u_{i}\left(\sum N_{S d}\right)_{i}=\sum_{i=1}^{n} h_{i}\left(\sum H_{S d}\right)_{i}-\sum_{i=1}^{n} \frac{h_{i}\left(\sum H_{S d}\right)_{i}}{B_{2, i}}
$$

Substituindo-se os resultados obtidos em (2.21) e (2.23) na expressão anterior, tem-se:

$$
\Delta M_{t o t, d}=M_{1, t o t, d}-\sum_{i=1}^{n} \frac{h_{i}\left(\sum H_{S d}\right)_{i}}{B_{2, i}}
$$

Uma hipótese razoável em estruturas com geometria e distribuição de carregamentos regulares é que o parâmetro $\mathrm{B}_{2}$ não varia de forma significativa entre os pavimentos, o que permite ajustar o resultado da expressão anterior. Assim, é possível substituir o valor do coeficiente $\mathrm{B}_{2, \mathrm{i}}$ em cada pavimento, pelo seu valor médio $\overline{\mathrm{B}}_{2}$, que é constante, portanto, pode ser retirado do somatório.

$$
\Delta M_{\text {tot, },}=M_{1, t o t, d}-\frac{1}{\bar{B}_{2}} \sum_{i=1}^{n} h_{i}\left(\sum H_{S d}\right)_{i}
$$


Avaliando-se a expressão (2.23), nota-se que o somatório da expressão anterior é o momento de tombamento devido às forças horizontais. Deste modo:

$$
\frac{\Delta M_{\text {tot }, d}}{M_{1, t o t, d}}=1-\frac{1}{\bar{B}_{2}}
$$

Escrevendo o primeiro membro da expressão anterior em função do parâmetro $\gamma_{\mathrm{z}}$, obtém-se:

$$
1-\frac{1}{\gamma_{z}}=1-\frac{1}{\bar{B}_{2}}
$$

ou seja:

$$
\gamma_{z}=\bar{B}_{2}
$$

Portanto, admitindo válida a hipótese que o parâmetro $\mathrm{B}_{2}$ não varia de forma significativa entre os pavimentos, a expressão (2.24) estabelece uma relação entre os parâmetros $B_{2}$ e $\gamma_{z}$.

Essa demonstração ainda pode ser desenvolvida considerando-se o coeficiente $R_{m}$ Naturalmente, para estruturas onde o sistema de contraventamento não é composto por vigas e pilares rigidamente conectados entre si, $\mathrm{R}_{\mathrm{m}}$ é igual a 1,0 e o resultado será o mesmo.

\subsubsection{COMPOSIÇÃO DOS EFEITOS}

Para estruturas deslocáveis, ambos os efeitos supracitados são importantes. Por isso, é preciso definir como será composto o momento fletor solicitante de segunda ordem proveniente do cálculo aproximado dos efeitos locais e globais. 
Kanchanalai e Le-Wu (1979) propuseram que o momento fletor final fosse o produto do momento fletor solicitante de primeira ordem pelos coeficientes de amplificação $\mathrm{B}_{1}$ e $\mathrm{B}_{2}$.

$$
M_{S d}=B_{1} B_{2} M_{1}
$$

A especificação do AISC (2005) e o Projeto de Revisão da NBR 8800 (set. 2006) adotam a seguinte expressão para o momento fletor total:

$$
M_{S d}=B_{1} M_{n t}+B_{2} M_{l t}
$$

A estrutura é entendida como a superposição de duas estruturas (Figura 2.9), as quais são empregadas para avaliação dos coeficientes $\mathrm{B}_{1}$ e $\mathrm{B}_{2}$. Uma delas é contraventada por contenções nodais dispostas em cada nível (pavimento) e serve como modelo para o cálculo dos momentos fletores solicitantes $\mathrm{M}_{\mathrm{nt}}$ (o índice nt significa no translation). Os momentos fletores $\mathrm{M}_{\mathrm{lt}}$ (o índice lt significa lateral translation) são obtidos a partir da segunda estrutura, na qual as contenções nodais são removidas e aplicam-se as respectivas reações obtidas na análise da primeira estrutura, em sentido contrário.

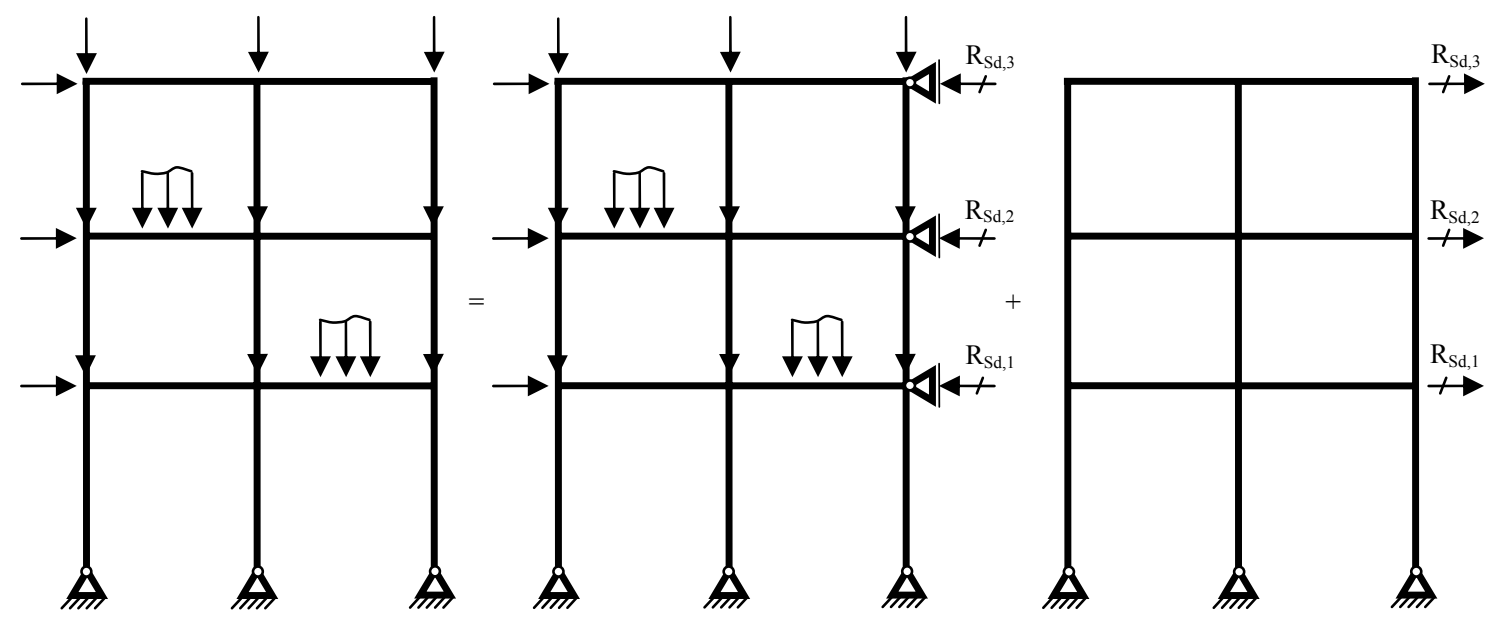

Figura 2.9 - Modelo de análise estrutural para cálculo de $\mathrm{M}_{\mathrm{nt}}$ e $\mathrm{M}_{\mathrm{lt}}$ (Projeto de Revisão da NBR 8800, set. 2006). 
Al-Mashray e Chen (1990) citam algumas desvantagens do método de amplificação pelos coeficientes $\mathrm{B}_{1}$ e $\mathrm{B}_{2}$ :

- o método é restrito a pórticos retangulares;

- não considera redistribuição de esforços;

- dificuldade de avaliação dos pontos onde serão aplicadas as contenções nodais de cálculo e interpretação dos parâmetros $\mathrm{C}_{\mathrm{m}} \mathrm{e} \mathrm{K}$.

- os momentos fletores totais são obtidos como a soma dos momentos fletores de segunda ordem para cada efeito e nem sempre esses momentos solicitantes atuam na mesma seção;

- duas análises de primeira ordem são necessárias para cada combinação de ações.

Certamente, a principal desvantagem apresentada é a duplicação do número de análises estruturais a realizar.

\subsubsection{MÉTODOS DAS FORÇAS HORIZONTAIS FICTÍCIAS}

Uma das técnicas de avaliação das imperfeições iniciais globais que dispensa a modelagem da estrutura na configuração imperfeita é a utilização de forças horizontais fictícias aplicadas aos pavimentos da estrutura. Essa metodologia também já foi empregada como técnica aproximada para capturar o efeito P- $\Delta$ (WILSON e HABIBULLAH, 1987 apud

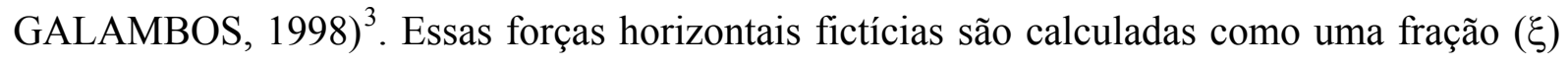
do somatório das forças verticais $\left(\mathrm{P}_{\mathrm{i}}\right)$ que atuam no pavimento considerado (Figura 2.10).

${ }^{3}$ WILSON, E.L.; HABIBULlAH, A. (1987). Static and Dynamic Analysis of Multi-story Building Including P- $\triangle$ Effects. Earthquake Spectra, Vol. 3, No. 2, pp. 289-298. 


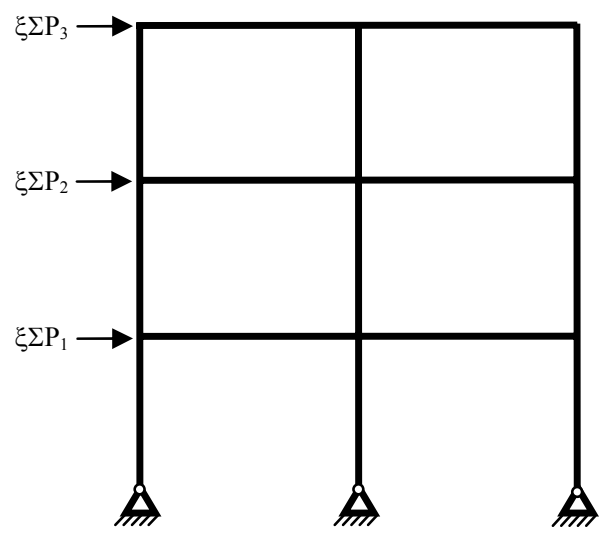

Figura 2.10 - Esquema de forças horizontais.

As variações propostas na literatura para o método das forças horizontais fictícias diferem essencialmente pela intensidade da força horizontal e pelo fenômeno representado. A nomenclatura aqui apresentada pode variar entre autores, mas o conceito envolvido é preservado.

\subsubsection{MÉTODO SIMPLIFICADO}

O método simplificado consiste em aplicar um coeficiente constante $\left(\xi_{0}\right)$ e igual a $0,5 \%$ da força vertical total do pavimento. Esse valor foi calibrado para representar o efeito da imperfeição global equivalente a L/500, que corresponde a um coeficiente de força horizontal igual a 0,002 , além das tensões residuais e do comportamento inelástico da estrutura, que correspondem ao restante do coeficiente proposto $(0,003)$. A calibração do método foi realizada para um modelo de plastificação concentrada (item 2.5.5). Para os casos estudados foram encontrados erros máximos de 5 e $26 \%$ quando considerados pilares pertencentes a pórticos e submetidos à flexão em torno do eixo de maior e menor inércia, respectivamente, (LIEW; WHITE; CHEN, 1994). Esse método já era apresentado pela norma canadense (CSA, 1994). 
A aplicação do método simplificado em edifícios de múltiplos andares não se mostrava interessante, porque a intensidade da força horizontal fictícia não considerava o número de pilares nem o número de pavimentos. Por isso, os fatores de correção desses parâmetros apresentados pelo regulamento europeu já se mostravam uma alternativa atraente.

Diante da validade e, principalmente, praticidade do método, esperava-se que a norma americana incorporasse algum procedimento nesse sentido, uma vez que a especificação do AISC ainda abordava unicamente o método do comprimento efetivo de flambagem (SCHMITH, 1999). Entretanto, estudos posteriores mostraram que, no contexto da norma americana, o método simplificado era muito conservador para os fenômenos representados (MALECK; WHITE, 2004; ASCE, 1997).

\subsubsection{MÉTODO MODIFICADO}

Segundo a ASCE (1997), a intensidade da força horizontal fictícia necessária para representar os efeitos inelásticos varia até $25 \%$ quando a razão $\mathrm{f}_{\mathrm{y}} / \mathrm{E}$ é alterada. Por isso, foi proposta uma modificação ao método simplificado em função dessa razão, que preserva a simplicidade do método das forças horizontais fictícias e reduz os erros apresentados pelo método simplificado. O coeficiente da força horizontal é dado pela seguinte expressão:

$$
\xi=\xi_{0} k_{y}
$$

onde

$$
k_{y}=22 \sqrt{\frac{f_{y}}{E}}
$$

$\mathrm{f}_{\mathrm{y}}$ é a resistência ao escoamento e E é o módulo de elasticidade do aço. Essa expressão resulta em coeficientes de força horizontal iguais a $0,4 \%$ para $f_{y}=250 \mathrm{MPa}$ e $0,5 \%$ para $\mathrm{f}_{\mathrm{y}}=450 \mathrm{MPa}$. 
Note-se que para a resistência ao escoamento igual a 250MPa, o método modificado já apresenta uma redução de $20 \%$ na intensidade da força horizontal em relação ao método simplificado.

\subsubsection{MÉTODO REFINADO (ASCE, 1997)}

A aplicação de um coeficiente único em toda estrutura apresenta bons resultados para pórticos simples, com um pavimento. Entretanto, a análise de pilares com esbeltez mediana ou baixa, submetidos à curvatura reversa e com contribuição de rigidez à flexão significativa nas extremidades devido a outros elementos conectados, mostrou que os métodos anteriores forneciam resultados muito conservadores. Pilares com essas características são comuns em edifícios de múltiplos pavimentos, principalmente nos pavimentos inferiores. Por isso, algumas modificações foram sugeridas e deram origem ao método refinado.

Nessa nova proposta, buscou-se uma expressão que avaliasse melhor a esbeltez e rigidez do elemento isolado ou do pavimento, permitindo inclusive variação na intensidade da força horizontal entre os pavimentos. Apresentou-se, enfim, a seguinte expressão:

$$
\xi=\xi_{0} k_{y} k_{s} k_{\lambda} k_{n p}
$$

com

$$
\begin{aligned}
& k_{s}=\left\{\begin{array}{cc}
1,0 & \text { se } 0,0 \leq \sqrt{S} \leq 0,5 \\
2(1-\sqrt{S}) & \text { se } 0,5<\sqrt{S} \leq 1,0
\end{array}\right. \\
& k_{\lambda}=\frac{\lambda_{(L)}}{\sqrt{S}} \\
& k_{n p}=\sqrt{0,5+\frac{1}{n p}} \leq 1,0
\end{aligned}
$$


onde np é o número de pilares do pavimento contidos no plano do pórtico em estudo, $\lambda_{(\mathrm{L})}$ é a esbeltez reduzida do pilar, calculada com o comprimento real:

$$
\lambda_{(L)}=\frac{L}{r \pi} \sqrt{\frac{f_{y}}{E}}
$$

S é um parâmetro associado à rigidez do pavimento e, para pilares pertencentes a pórticos deslocáveis, pode ser calculado de forma aproximada da seguinte forma:

$$
S=\frac{1}{K^{2}}
$$

e K é o coeficiente de flambagem do pilar, portanto:

$$
k_{\lambda}=\frac{\lambda_{(L)}}{\sqrt{S}}=\frac{K L}{r \pi} \sqrt{\frac{f_{y}}{E}}
$$

A expressão (2.31) é aplicável apenas a pilares isolados, os quais são utilizados inicialmente para a calibração e validação do método. Para edifícios cujos pavimentos possuem vários pilares o parâmetro $\mathrm{S}$ é redefinido como segue:

$$
S=\frac{\sum\left(M_{1}+M_{2}\right)}{2 \sum M_{f 00}}
$$

onde $M_{1}$ e $M_{2}$ são os momentos fletores nas extremidades inferior e superior de cada pilar, obtidos numa análise elástica de primeira ordem contendo apenas forças horizontais fictícias. Essas forças laterais fictícias são aplicadas em cada pavimento com intensidade igual a uma fração constante (qualquer) das forças gravitacionais atuantes no respectivo pavimento. Os somatórios estendem-se para todos os pilares do pavimento, inclusive aqueles que não contribuem com rigidez. $\mathrm{O}$ parâmetro $\mathrm{M}_{\mathrm{f} 00}$ é definido pela seguinte expressão: 


$$
M_{f 00}=\frac{6 E I \Delta_{1 h}}{L^{2}}
$$

onde os parâmetros físicos e geométricos referem-se ao pilar considerado e $\Delta_{1 \mathrm{~h}}$ é o deslocamento relativo entre as extremidades do pilar, obtido na análise de primeira ordem supracitada. Finalmente, o parâmetro $\mathrm{k}_{\lambda}$ é definido por:

$$
k_{\lambda}=\frac{1}{c_{r} \sqrt{S}} \sum_{j=1}^{c_{r}} \lambda_{(L) j}
$$

onde o somatório estende-se apenas aos $\mathrm{c}_{\mathrm{r}}$ pilares que contribuem para a rigidez do pavimento.

É interessante citar que os parâmetros $\mathrm{k}_{\mathrm{s}}$ e $\mathrm{k}_{\lambda}$ permitem reduzir significativamente a intensidade da força horizontal nos pavimentos que apresentarem rigidez elevada e/ou esbeltez baixa. De fato, em um pavimento com alta rigidez, os deslocamentos relativos entre as extremidades dos pilares são menores e, portanto, o efeito das imperfeições geométricas referente ao respectivo pavimento na resposta global da estrutura é reduzido. Além disso, estruturas que possuem elementos de contraventamento, mas classificadas como deslocáveis, terão a força horizontal fictícia reduzida, refletindo a contribuição do contraventamento.

O parâmetro $\mathrm{k}_{\mathrm{np}}$ depende do número de pilares contidos no plano do pórtico analisado. Em pórticos tridimensionais, basta repetir o procedimento para cada fila, aplicando a força horizontal nas extremidades dos pilares correspondentes. A variação decrescente desse parâmetro é bastante plausível quando se remete às imperfeições geométricas que estão sendo modeladas. O fato é que a probabilidade que todos os pilares apresentem imperfeições geométricas com a intensidade máxima e mesmo sentido é reduzida à medida que o número de pilares aumenta. 
O método das forças horizontais fictícias foi apresentado como alternativa ao método do diagrama de alinhamento, o qual utiliza o conceito de comprimento efetivo de flambagem. Em uma investigação inicial, o método simplificado apresentou-se conservador, por isso foram propostos os métodos modificado e refinado.

Parece estranho que este resgate o conceito de comprimento efetivo e a necessidade de cálculo do coeficiente K. Acontece que no contexto do método refinado das forças horizontais fictícias, o coeficiente $K$ pode ser calculado diretamente pela equação (2.4), sem a necessidade dos ajustes indesejáveis necessários para contabilizar os efeitos inelásticos, os quais estão embutidos na intensidade das forças horizontais.

O grande problema da expressão proposta é que o cálculo dos parâmetros $\mathrm{k}$ não é imediato e a praticidade do método outrora ressaltada deixou de ser uma vantagem. A ASCE (1997) recomenda que os parâmetros $k_{\lambda}$ e $k_{s}$ sejam adotados de forma conservadora iguais a 1,0. Particularmente, esta simplificação pode levar a resultados contra a segurança, porém considerados aceitáveis, para pilares com esbeltez elevada.

A Tabela 2.2 apresenta a variação do coeficiente $\xi$ em função do número de pilares (np) e da resistência de escoamento. Essa calibração apresenta valores bem inferiores aos 0,5\% propostos pelo método simplificado, quando considerados apenas os dois parâmetros mais simples de serem obtidos ( $\mathrm{k}_{\mathrm{y}}$ e $\left.\mathrm{k}_{\mathrm{np}}\right)$.

Tabela 2.2 - Parâmetro $\xi(\%)$ para o método refinado.

\begin{tabular}{cccc}
\hline & \multicolumn{3}{c}{$\mathrm{f}_{\mathrm{y}}(\mathrm{MPa})$} \\
$\mathrm{np}$ & 250 & 350 & 450 \\
\hline 2 & 0,384 & 0,455 & 0,515 \\
4 & 0,333 & 0,394 & 0,446 \\
6 & 0,314 & 0,371 & 0,421 \\
8 & 0,304 & 0,359 & 0,407 \\
10 & 0,298 & 0,352 & 0,399 \\
\hline
\end{tabular}




\subsubsection{MÉTODO R-N (ASCE, 1997)}

A proposta do método das forças horizontais fictícias é modelar as imperfeições iniciais. Esses efeitos alteram os esforços internos solicitantes e os deslocamentos. Entretanto, a aplicação das forças horizontais fictícias pode alterar os esforços normais da estrutura. Os pilares de um lado do pórtico apresentam um alívio de esforço normal e os pilares opostos, aumento. Isso não é verificado como conseqüência dos referidos efeitos na intensidade que surge com o emprego das forças horizontais fictícias e é mais acentuado nos pilares dos andares inferiores de edifícios de múltiplos pavimentos com alta relação entre a altura total e a largura.

Uma alternativa encontrada para solucionar o problema é realizar a análise estrutural considerando-se duas situações, denominadas $\mathrm{R}$ e N. A análise R é realizada com todas as ações reais da estrutura, incluindo as forças horizontais $\left(\mathrm{F}_{\mathrm{i}}\right)$, se houver, e desprezando-se as imperfeições geométricas. Portanto, sem aplicar forças horizontais fictícias (Figura 2.11a). Desta análise extraem-se as forças normais e os momentos fletores $\mathrm{M}_{\mathrm{Sd},(\mathrm{R}) \text {. }}$

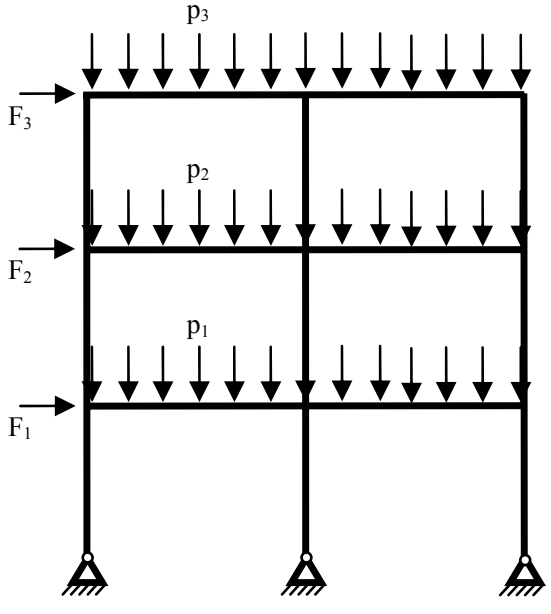

(a) análise $\mathrm{R}$

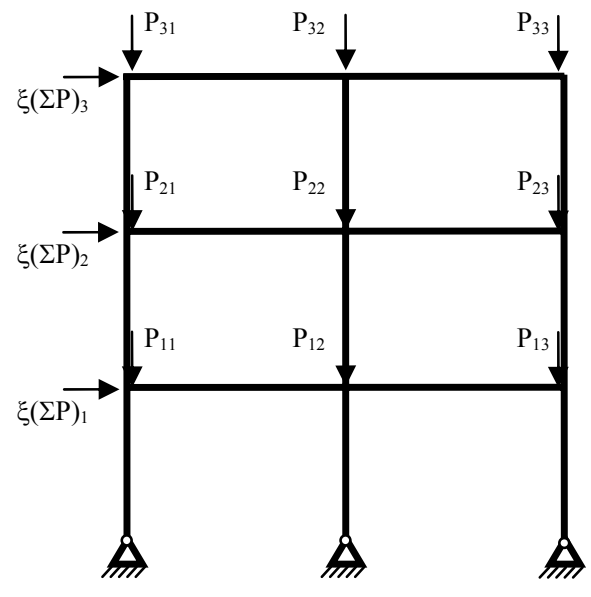

(b) análise $\mathrm{N}$

Figura 2.11 - Método R-N. (Adaptação de ASCE, 1997) 
A análise $\mathrm{N}$ é realizada sem as forças horizontais reais da estrutura e considerando-se as imperfeições, aplicando-se as forças horizontais fictícias aos pavimentos da estrutura (Figura 2.11b). Além disso, as forças verticais distribuídas provenientes das ações gravitacionais $\left(\mathrm{p}_{\mathrm{j}}\right)$ são convertidas em forças nodais equivalentes aplicadas nas extremidades dos pilares $\left(\mathrm{P}_{\mathrm{ij}}\right)$. Dessa análise extraem-se apenas os momentos fletores $\mathrm{M}_{\mathrm{Sd},(\mathrm{N})}$, os quais são somados aos momentos fletores da análise $\mathrm{R}\left(\mathrm{M}_{\mathrm{Sd},(\mathrm{R})}\right)$ para obtenção do esforço final $\left(\mathrm{M}_{\mathrm{Sd}}\right)$. As forças normais a serem verificados são as obtidas na análise $\mathrm{R}$, sem qualquer alteração.

É interessante perceber que o momento fletor final, obtido como a soma dos momentos fletores pontuais das análises $\mathrm{R}$ e $\mathrm{N}$, não necessariamente ocorrerá nos mesmos pontos de momentos máximos obtido pela soma dos diagramas de momentos fletores, porque as seções mais solicitadas em cada análise podem estar em posições diferentes. Entretanto, para a maior parte dos casos práticos, os pontos de momentos máximos coincidem e atuam nas seções de extremidade dos pilares.

O Método R-N é uma estratégia empregada para a redução da influência das forças horizontais fictícias nas forças normais dos pilares e pode ser utilizado em conjunto com os métodos simplificado, modificado ou refinado.

\subsubsection{MÉTODO ELÁSTICO MODIFICADO}

Os resultados conservadores observados e a dificuldade de encontrar um procedimento prático que fosse abrangente levaram à separação da modelagem dos conceitos da seguinte forma: a imperfeição geométrica inicial seria modelada com forças horizontais $(\xi=0,2 \%)$, enquanto que as tensões residuais e o regime inelástico seriam representados pela redução na rigidez dos pilares. De acordo com Maleck e White (2004a), os valores para a rigidez à flexão reduzida dos elementos são $\mathrm{EI}_{\mathrm{red}}=0,9 \tau \mathrm{EI}$ e $\mathrm{EI}_{\mathrm{red}}=0,8 \tau \mathrm{EI}$, respectivamente, para os eixos de maior e menor inércia e o parâmetro $\tau$ é dado por: 


$$
\tau=\left\{\begin{array}{cc}
1,0 & \text { se } N_{S d} / N_{y} \leq 0,39 \\
-2,724 \frac{N_{S d}}{N_{y}} \ln \left(\frac{N_{S d}}{N_{y}}\right) & \text { se } N_{S d} / N_{y}>0,39
\end{array}\right.
$$

Segundo os autores, nas estruturas em que a estabilidade é garantida pela rigidez das ligações viga-pilar, o efeito das tensões residuais na rigidez axial é menos importante em relação à rigidez à flexão, por isso foi proposta uma redução constante igual a $\mathrm{EA}_{\text {red }}=0,8 \mathrm{EA}$.

Uma idéia semelhante, que propõe a redução das rigidezes à flexão dos pilares, vigas e lajes por coeficientes distintos, é sugerida pela NBR 6118:2003 para a consideração da nãolinearidade física do concreto.

Maleck e White (2004b) fizeram um estudo comparativo entre o procedimento recomendado pelo AISC (1999), o qual utilizava o diagrama de alinhamento para cálculo do coeficiente de flambagem $\mathrm{K}$, o método simplificado das forças horizontais fictícias $(\xi=0,005)$ apresentado pela ASCE (1997) e o método elástico modificado. As estratégias de modelagem das imperfeições geométricas e tensões residuais propostas por cada método são apresentadas na Tabela 2.3.

Tabela 2.3 - Modelos simplificados de avaliação de estabilidade.

\begin{tabular}{|c|c|c|c|c|}
\hline & Imperfeição global & Imperfeição local & $\begin{array}{l}\text { Tensões } \\
\text { residuais }\end{array}$ & $\begin{array}{l}\text { Comprimento da } \\
\text { barra }\end{array}$ \\
\hline $\begin{array}{l}\text { Comprimento efetivo } \\
\text { de flambagem }\end{array}$ & - & Curva de resistência & $\begin{array}{l}\text { Curva de } \\
\text { resistência }\end{array}$ & KL \\
\hline $\begin{array}{l}\text { Forças horizontais } \\
\text { fictícias }\end{array}$ & $\begin{array}{l}\text { Força horizontal } \\
\qquad(\xi=0,002)\end{array}$ & $\begin{array}{c}\text { Curvas de resistência } \\
\text { ou força horizontal } \\
\text { transversal à barra }\end{array}$ & $\begin{array}{l}\text { Força horizontal } \\
\text { adicional e curva } \\
\text { de resitência }\end{array}$ & $\mathrm{L}$ \\
\hline Elástico modificado & $\begin{array}{l}\text { Força horizontal } \\
\qquad(\xi=0,002)\end{array}$ & Curvas de resistência & $\begin{array}{l}\text { Redução de } \\
\text { rigidez e curvas } \\
\text { de resistência }\end{array}$ & $\mathrm{L}$ \\
\hline
\end{tabular}

Os resultados foram comparados a valores de referência fornecidos por um modelo explícito de plastificação distribuída e imperfeições geométricas. O método elástico modificado foi o que apresentou melhores resultados, reduzindo o caráter conservador 
apresentado pelo método simplificado das forças horizontais fictícias e eliminando o cálculo do comprimento efetivo de flambagem. Uma proposta semelhante ao método elástico modificado foi introduzida pelo AISC (2005a), nesse caso denominada Método da Análise Direta (item 2.7.4), e também consta no Projeto de Revisão da NBR 8800:1986.

\subsubsection{EFEITOS DE PLASTIFICAÇÃO DA SEÇÃO TRANSVERSAL}

Basicamente, existem dois modelos para avaliar a plastificação da seção transversal: o modelo da zona plástica, ou plastificação distribuída, e o modelo das rótulas plástica, ou plastificação concentrada.

De acordo com Machado (2005), existem duas formulações para definir um modelo de plastificação concentrada: a elasto-plástica e a plástica-refinada. Na formulação elastoplástica, a seção assume dois comportamentos: perfeitamente elástica, quando os esforços internos ainda não atingiram a capacidade resistente da seção, e perfeitamente plástico, quando a capacidade resistente é atingida. $\mathrm{Na}$ formulação plástica-refinada, permite-se uma degradação da rigidez da seção transversal à medida que os esforços internos se aproximam da capacidade limite da seção.

Landesman e Batista (2005) empregaram uma formulação plástica-refinada para análise de pórticos de aço em situação de incêndio. Foi definido um limite elástico correspondente a uma contração da superfície que define a capacidade limite da seção por um fator igual a 0,50 . Quando o estado de solicitação da seção ultrapassa esse limite elástico, a rigidez associada ao elemento é reduzida seguindo uma função parabólica.

Uma modelo de zona plástica foi apresentado por Jiang et al. (2002). O estudo propõe uma formulação para o método dos elementos finitos capaz de captar esses efeitos em pontos internos ao elemento. Em cada ponto interno do elemento é feita uma integração das tensões 
atuantes na seção transversal (Figura 2.12), permitindo inserir o efeito das tensões residuais de forma explícita e captar a redução de rigidez ao longo da barra.

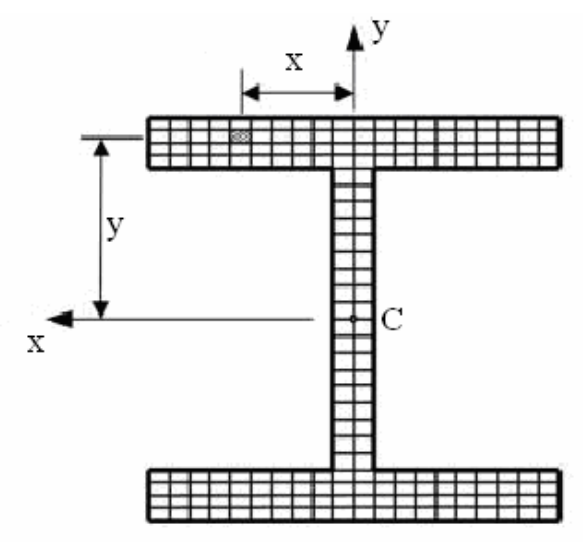

Figura 2.12 - Discretização da seção transversal de um perfil I (JIANG et al., 2002).

Esse procedimento mostrou-se preciso, porém com elevado custo computacional. Por isso, foi utilizada uma discretização adaptativa para as barras. Inicialmente cada barra foi discretizada por um elemento finito convencional para análise de pórticos tridimensionais. À medida que os incrementos de força são inseridos, as barras mais solicitadas são detectadas, os respectivos elementos finitos são substituídos por elementos contendo pontos internos e a discretização ao longo da barra é refinada.

Um procedimento de divisão da seção transversal em poligonais foi empregado por Caldas (2004) e Muniz (2005) para avaliação de estruturas mistas aço-concreto. Cada poligonal representa um tipo de material com sua respectiva relação constitutiva. Os esforços resistentes e rigidezes da seção são calculados com o auxílio do Teorema de Green, que relaciona integrais de área com integrais de linha ao longo do perímetro das poligonais.

A análise avançada apresentada por Gomes (2005), emprega elementos planos de casca para discretizar a estrutura. Esse procedimento gera um modelo tridimensional mais fiel à realidade e capaz de capturar melhor a plastificação da seção e efeitos localizados, como instabilidade local de alma e mesa. Entretanto, o custo computacional para a solução do problema é bem maior quando comparado com a discretização por elementos de pórtico. Por 
isso, essa metodologia torna-se pouco interessante para estruturas onde o número de barras é grande. Além disso, o efeito das instabilidades locais não é relevante quando a seção dos perfis é compacta.

Diante da variedade de ferramentas disponíveis para avaliação dos efeitos desestabilizantes da estrutura é necessário que o projetista entenda o escopo de aplicação de cada método - análise estrutural ou dimensionamento - para evitar que um efeito seja considerado duas vezes. A Tabela 2.4 traz um resumo dessas ferramentas e o contexto em que estão inseridas.

Tabela 2.4 - Estratégias para avaliação da estabilidade de pórticos.

\begin{tabular}{|c|c|c|}
\hline & Análise estrutural & Dimensionamento \\
\hline Efeito $\mathrm{P}-\delta$ & $\begin{array}{c}\text { Análise de segunda ordem } \\
\text { Amplificação de momentos }\left(\mathrm{B}_{1}\right)\end{array}$ & - \\
\hline Efeito P- $\Delta$ & $\begin{array}{c}\text { Análise de segunda ordem } \\
\text { Amplificação de momentos }\left(\mathrm{B}_{2}, \gamma_{\mathrm{z}}\right)\end{array}$ & - \\
\hline Imperfeição local & $\begin{array}{c}\text { Elementos curvos } \\
\text { Forças transversais à barra }\end{array}$ & Curvas de resistência \\
\hline Imperfeição global & $\begin{array}{c}\text { Forças horizontais fictícias } \\
\text { Modelagem explícita } \\
\text { Modo de flambagem da estrutura } \\
\text { Redução de rigidez à flexão }\end{array}$ & - \\
\hline Tensões residuais & $\begin{array}{c}\text { Tensões iniciais na seção transversal } \\
\text { Redução de rigidez }\end{array}$ & Curvas de resistência \\
\hline Plastificação do material & $\begin{array}{c}\text { Forças horizontais fictícias } \\
\text { Redução de rigidez } \\
\text { Análise não-linear física }\end{array}$ & $\begin{array}{c}\text { Curvas de resistência associadas à } \\
\text { correção do fator } \mathrm{K}\end{array}$ \\
\hline Critério de escoamento & $\begin{array}{l}\text { Superfície de escoamento em } \\
\text { esforços/tensões }\end{array}$ & Expressões de interação \\
\hline
\end{tabular}

Os procedimentos descritos para avaliação dos efeitos que contribuem para a instabilidade do pórtico são apresentados na Tabela 2.4 com as respectivas estratégias de avaliação e a etapa do projeto estrutural em que estão inseridas. A análise numérica avançada 
empregada neste trabalho envolve os procedimentos apresentados na segunda coluna, enquanto que os métodos da força horizontal fictícia e da análise direta propõem uma combinação entre os procedimentos da segunda e terceira coluna.

\subsection{CALIBRAÇÃO DOS MÉTODOS SIMPLIFICADOS}

Para calibrar os métodos simplificados define-se uma estrutura padrão e representativa de outras estruturas mais complexas. Por exemplo, um pilar bi-rotulado com molas de rotação nas extremidades representa os pilares de pórticos de múltiplos pavimentos. Um pórtico retangular simples pode representar subestruturas de contraventamento contidas em edifícios de múltiplos andares.

Definida a estrutura padrão, a configuração das imperfeições geométricas, tensões residuais e condições de vínculo, adotam-se as grandezas de referência para comparação dos resultados. Os deslocamentos laterais são parâmetros interessantes para a avaliação dos efeitos de segunda ordem. Entretanto, são os esforços solicitantes, portanto, os momentos fletores e forças normais que mais interessam.

A mesma estrutura é estudada com base nos diferentes procedimentos simplificados. Uma análise numérica avançada também é empregada, da qual se extraem os resultados “exatos” dessa estrutura que serão empregados na calibração dos procedimentos aproximados.

A Figura 2.13 apresenta os modelos simplificados empregados no estudo de pilares pertencentes a pórticos deslocáveis. O pilar está submetido a uma força horizontal (F) e uma vertical $(\mathrm{P})$, ambas provenientes de ações reais (atuantes). 


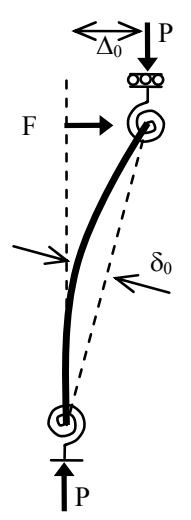

(a)

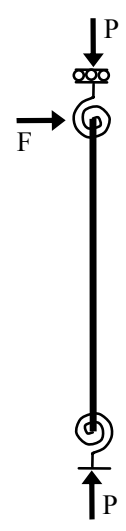

(b)

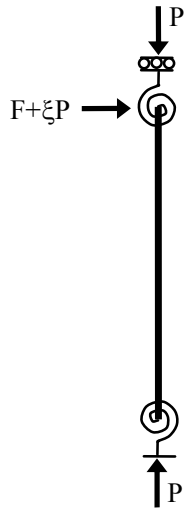

(c)

Figura 2.13 - Modelos utilizados para calibrar os métodos simplificados (ASCE, 1997).

Para análise numérica avançada, as imperfeições geométricas iniciais são inseridas diretamente no modelo e uma análise não-linear física e geométrica é empregada (Figura 2.13a). Uma prática comum (KANCHANALAI e LE-WU, 1979; ASCE, 1997) na análise numérica avançada é aplicar as forças verticais na estrutura e, em seguida, introduzir as forças laterais. Esse procedimento é mais coerente com a situação real de solicitação da estrutura.

O incremento de forças laterais é efetuado até a estrutura "perder a rigidez" e apresentar deslocamentos exagerados, caracterizando a falha. Obtém-se um par de forças (P e F) correspondente à capacidade da barra. Variando-se a intensidade da força $\mathrm{P}$ obtêm-se novos pares de forças, definindo uma envoltória.

A Figura 2.13b ilustra o modelo utilizado para análise estrutural do pilar com base em procedimentos aproximados que utilizam o conceito do comprimento efetivo de flambagem. É empregada uma análise elástica linear e a imperfeição local, as tensões residuais e a nãolinearidade física são consideradas na avaliação do esforço normal resistente à compressão por meio das curvas de resistência. É feita uma correção no comprimento da barra, pelo coeficiente de flambagem $\mathrm{K}$, dando origem ao comprimento efetivo de flambagem (KL), para levar em consideração a rigidez à rotação das molas de extremidade. 
O método das forças horizontais fictícias propõe que a imperfeição geométrica global seja modelada por meio da aplicação de uma força horizontal adicional obtida como uma fração da força axial (乡P), que é somada à força horizontal real (F). Nesse caso, a avaliação do esforço normal resistente é feita considerando-se o comprimento real da barra $(K=1,0)$.

Para os procedimentos simplificados, efetua-se uma análise de segunda ordem para uma determinada intensidade de força axial, aumentando-se a força horizontal até atingir o momento fletor solicitante de segunda ordem correspondente ao esgotamento da capacidade resistente do perfil. Essa capacidade resistente é definida pela expressão (2.2) ou (2.3). A repetição desse procedimento para diferentes intensidades de $\mathrm{P}$ fornece a envoltória de forças aplicadas (P e F) correspondente à análise simplificada.

As envoltórias obtidas pelas análises numérica avançada e simplificada são comparadas adotando-se um critério de aceitação. A ASCE (1997) admite como aceitáveis erros inferiores a 5\% contra a segurança em relação aos procedimentos avançados. As envoltórias são apresentadas e comparadas em diagramas normalizados em relação aos respectivos esforços correspondentes à plastificação da seção. Assim, evita-se trabalhar com grandezas elevadas e a comparação é mais imediata.

Portanto, calibra-se o parâmetro $\xi$ com a análise numérica. Essa metodologia pode ainda ser estendida para uma análise paramétrica, definindo expressões para $\xi$ em função de propriedades físicas e geométricas de interesse, tais como, resistência ao escoamento do aço e rigidez da barra. Daí o surgimento dos diferentes métodos de avaliação da intensidade da força horizontal fictícia. 


\subsection{RECOMENDAÇÕES NORMATIVAS}

Serão apresentadas as recomendações normativas para avaliação das imperfeições geométricas iniciais, tensões residuais e regime inelástico. As recomendações serão expostas à luz dos métodos de aplicação de forças horizontais fictícias. Outros procedimentos alternativos disponíveis pelas normas para avaliação desses efeitos serão apenas citados. O objetivo desta apresentação é simplesmente tornar evidente a variação dos métodos de forças horizontais. Logo, qualquer conclusão sobre a precisão de cada procedimento fora do contexto das expressões de dimensionamento à flexo-compressão e de exemplos de projeto é precipitada.

\subsubsection{PROCEDIMENTO DA NORMA CANADENSE CSA S16.1-94 ${ }^{4}$}

Esta versão da norma canadense exige que os efeitos desestabilizantes provocados pela assimetria do carregamento, da estrutura ou de ambos devem ser considerados em todas as combinações de ações que contenham apenas forças gravitacionais. Por isso, em todas as combinações de ações em que só atuem forças gravitacionais, esses efeitos desestabilizantes não devem ser inferiores aos provocados por forças horizontais fictícias, aplicadas em cada pavimento, iguais a $0,5 \%$ do total de forças gravitacionais atuantes no pavimento. Segundo Kennedy et al. (1993), a norma canadense exige a aplicação de forças horizontais fictícias desde 1974 e nas três versões anteriores a intensidade das forças era igual a $0,2 \%$ do total de forças verticais atuantes no pavimento.

O cálculo do comprimento efetivo de flambagem é previsto apenas para as verificações da estabilidade fora do plano do pórtico. Nesse caso, o coeficiente de flambagem K é determinado considerando-se a estrutura indeslocável. Na verificação da estabilidade no

\footnotetext{
${ }^{4}$ Substituída pela CSA S16.1-01.
} 
plano, o coeficiente $\mathrm{K}$ é sempre adotado igual a 1, uma vez que os efeitos da deslocabilidade da estrutura são inseridos pelas forças horizontais fictícias.

Esse é um procedimento semelhante ao método simplificado das forças horizontais, com uma diferença: neste último, as forças horizontais devem ser aplicadas em todas as combinações de ações, inclusive naquelas que contêm forças laterais.

Essa e Kennedy (2000) realizaram um estudo sobre o dimensionamento de pilares de acordo com a CSA S16.1-94 com o objetivo de propor alterações para a nova versão dessa norma que estava em revisão. O estudo de um pórtico retangular com um pavimento mostrou que as forças horizontais fictícias deviam ser aplicadas em todas as combinações de ações, inclusive naquelas que continham forças horizontais reais, porque a função dessas forças fictícias é compensar o fato do dimensionamento ser efetuado com o comprimento real do pilar $(\mathrm{K}=1)$.

Outra questão interessante abordada por Essa e Kennedy (2000) diz respeito ao efeito das forças horizontais fictícias no dimensionamento das ligações. A norma canadense utiliza as forças horizontais fictícias para permitir o dimensionamento com o comprimento real da barra. Considerando que o comprimento efetivo de flambagem não altera em nada a configuração de esforços para o dimensionamento das ligações, é coerente admitir que as forças horizontais fictícias também não devam alterá-lo. Uma opção para este caso é utilizar o método R-N e dimensionar as ligações com os esforços obtidos na análise R.

\subsubsection{PROCEDIMENTO DA NORMA AUTRALIANA AS 4100/1990}

A recomendação da norma australiana (AS, 1990 apud CLARKE e WHITE, 1997a) ${ }^{5}$ é que devem ser incluídas forças horizontais fictícias no valor de $0,2 \%$ da carga total do

\footnotetext{
${ }^{5}$ STANDARDS AUSTRALIA (1990). Steel Structures. AS4100-1990. Sydney.
} 
pavimento em análises de estruturas com mais de um pavimento e sujeitas a combinações de ações em que atuem apenas forças gravitacionais. Esse efeito é considerado representativo das imperfeições geométricas globais.

\subsubsection{PROCEDIMENTO DO EUROCÓDIGO prEN 1993:3/2003}

O regulamento europeu exige que as imperfeições geométricas globais e locais sejam consideradas na análise estrutural ou no dimensionamento das barras. As imperfeições geométricas globais são definidas pela rotação da corda do pilar ( $\xi$ ), cuja intensidade é dada pela expressão (2.36).

$$
\xi=\xi_{0} k_{h} k_{n p}
$$

com

$$
\begin{gathered}
k_{h}=\frac{2}{\sqrt{H}} \quad \text { e } \frac{2}{3} \leq k_{h} \leq 1,0 \\
k_{n p}=\sqrt{\frac{1}{2}\left(1+\frac{1}{n p}\right)}
\end{gathered}
$$

onde $\mathrm{H}$ é a altura total do edifício, em metros, e np é o número de pilares do pavimento que estão solicitados por uma força normal igual ou superior a $50 \%$ da média das forças normais atuantes nos pilares pertencentes ao pavimento. Uma simulação da variação do parâmetro $\xi$ em função de np e H é apresentada na Tabela 2.5. 
Tabela 2.5 - Variação do parâmetro $\xi$ (\%) segundo o prEN 1993:3 (2003).

\begin{tabular}{cccc}
\hline & \multicolumn{3}{c}{$\mathrm{H}$ (metros) } \\
$\mathrm{np}$ & 3,0 & 6,0 & $>9,0$ \\
\hline 2 & 0,433 & 0,354 & 0,289 \\
4 & 0,395 & 0,323 & 0,264 \\
6 & 0,382 & 0,312 & 0,255 \\
8 & 0,375 & 0,306 & 0,250 \\
10 & 0,371 & 0,303 & 0,247 \\
\hline
\end{tabular}

Alternativamente à introdução direta destas imperfeições globais na estrutura, é permitido aplicar forças horizontais fictícias aos pavimentos da estruturas com intensidade igual a $\xi \Sigma \mathrm{P}_{\mathrm{i}}$.

O método apresentado pelo regulamento europeu apresenta semelhança com o método refinado das forças horizontais fictícias (equação (2.28)) para consideração do número de pilares do pavimento contidos no plano do pórtico.

Além das forças horizontais fictícias aplicadas aos pavimentos, permite-se aplicar forças distribuídas transversais ao eixo do pilar para representar o efeito das imperfeições locais. A intensidade da força distribuída é dada por:

$$
p=\frac{8 N_{S d} \delta_{0}}{L^{2}}
$$

onde $\mathrm{N}_{\mathrm{Sd}}$ é a força normal de cálculo do pilar e $\delta_{0}$ é a imperfeição geométrica inicial da barra, cujos valores são apresentados na Tabela 2.6.

A consideração das imperfeições geométricas, seja por modelagem direta ou forças horizontais fictícias, permite ao projetista dimensionar os pilares com o comprimento real $(\mathrm{K}=1)$. 
Tabela 2.6 - Imperfeição local $\delta_{0} / \mathrm{L}$.

\begin{tabular}{ccc}
\hline Curva de resistência & Análise elástica & Análise inelástica \\
\hline $\mathrm{a}_{0}$ & $1 / 350$ & $1 / 300$ \\
$\mathrm{a}$ & $1 / 300$ & $1 / 250$ \\
$\mathrm{~b}$ & $1 / 250$ & $1 / 200$ \\
$\mathrm{c}$ & $1 / 200$ & $1 / 150$ \\
$\mathrm{~d}$ & $1 / 150$ & $1 / 100$ \\
\hline & & FONTE: prEN $1993: 3 / 2003$.
\end{tabular}

As imperfeições geométricas das barras (locais) são consideradas na verificação da estabilidade dos elementos comprimidos por meio das curvas de resistência. Portanto, caso o projetista opte por introduzir as imperfeições da barra utilizando elementos curvos ou inserindo forças transversais, a verificação da estabilidade da barra torna-se desnecessária. Nesse caso, basta verificar a resistência ao escoamento da seção transversal.

\subsubsection{ESPECIFICAÇÃO DO AISC LRFD (2005a,b)}

A versão mais recente da especificação do AISC manteve o método do diagrama de alinhamento para avaliação do comprimento efetivo de flambagem. Para estruturas que apresentam a razão entre os deslocamentos laterais de segunda e primeira ordem superior a 1,5 em pelo menos uma combinação de ações, a análise estrutural deve ser realizada considerando-se imperfeições geométricas globais. Essas imperfeições podem ser representadas, quando considerados os efeitos de segunda ordem, por forças horizontais fictícias de $0,2 \%$ do total das forças verticais do pavimento.

Para estruturas que apresentam a razão entre os deslocamentos laterais de segunda e primeira ordem inferior a 1,5 em todas as combinações de ações, permite-se que as forças horizontais fictícias sejam consideradas como forças horizontais mínimas a serem aplicadas na estrutura. 
Uma estimativa permitida para avaliação da razão ente os deslocamentos de segunda e primeira ordem são os coeficientes de amplificação de momentos fletores $\left(\mathrm{B}_{2}\right)$. A verificação pode ser feita diretamente com esses coeficientes para determinar a necessidade de incluir as imperfeições geométricas.

A exigência da consideração das imperfeições iniciais através da modelagem explícita ou de forças horizontais foi introduzida na versão de 2005 da especificação do AISC. Os efeitos de segunda ordem e o comprimento efetivo de flambagem já eram considerados em versões anteriores e não sofreram alterações (AISC, 1999).

É permitido verificar a estabilidade de estrutura por meio do método da análise direta, ou seja, reduzindo a rigidez axial $\left(\mathrm{EA}_{\mathrm{red}}=0,8 \mathrm{EA}\right)$ e à flexão $\left(\mathrm{EI}_{\mathrm{red}}=0,8 \tau_{\mathrm{b}} \mathrm{EI}\right)$ das barras que compõem a estrutura e introduzindo forças horizontais fictícias.

Essa redução possui duas interpretações. Primeiro, para pórticos contendo pilares esbeltos, propensos à instabilidade elástica, a redução é entendida como limitação da capacidade resistente em $80 \%$ da carga crítica elástica do pilar. Segundo, para pilares com esbeltez média ou baixa, a redução é interpretada como influência dos efeitos inelásticos. A redução da rigidez deve ser feita apenas nas barras que contribuem para a estabilidade do pórtico.

Esse conceito é diferente daquele proposto para o método elástico modificado. Neste último, a redução de rigidez foi apresentada para representar os efeitos inelásticos e as tensões residuais. $\mathrm{Na}$ especificação do AISC, o efeito das tensões residuais está incluído na força horizontal fictícia.

$\mathrm{O}$ parâmetro $\tau_{\mathrm{b}}$ depende da força normal $\left(\mathrm{N}_{\mathrm{Sd}}\right)$ atuante na barra e da força de compressão correspondente ao escoamento da seção transversal $\left(\mathrm{N}_{\mathrm{y}}=\mathrm{Af}_{\mathrm{y}}\right)$, como segue: 


$$
\tau_{b}=\left\{\begin{array}{cc}
1,0 & \text { se } N_{S d} / N_{y} \leq 0,5 \\
4,0 \frac{N_{S d}}{N_{y}}\left(1-\frac{N_{S d}}{N_{y}}\right) & \text { se } N_{S d} / N_{y}>0,5
\end{array}\right.
$$

Permite-se adotar um valor constante igual a 1,0 para o parâmetro $\tau_{\mathrm{b}}$ desde que a força horizontal fictícia seja aumentada em $0,1 \%$ das forças verticais do pavimento, ou seja, $\xi=0,003$. Este é um procedimento mais prático, uma vez que a redução das rigidezes axial e à flexão pode ser entendida unicamente como uma redução do módulo de elasticidade $\left(\mathrm{E}_{\mathrm{red}}=0,8 \mathrm{E}\right)$.

A redução das rigidezes axial e à flexão permite dimensionar as barras utilizando os comprimentos reais $(\mathrm{K}=1,0)$. De acordo com o AISC (2005b), este procedimento associado às forças horizontais fictícias é considerado o maior avanço na análise estrutural de pórticos em relação às edições anteriores desta norma.

Um procedimento semelhante ainda é apresentado para estruturas analisadas em primeira ordem. Neste caso, a intensidade da força horizontal fictícia é aumentada para incluir os efeitos de segunda ordem e deve ser aplicada em todas as combinações de ações. O coeficiente de força horizontal é dado por:

$$
\xi=2,1 \frac{\Delta_{1 h}}{L} \geq 0,0042
$$

onde a razão entre o deslocamento horizontal de primeira ordem entre pavimentos $\left(\Delta_{1 \mathrm{~h}}\right)$ e o comprimento do pilar (L) deve ser a maior da estrutura. Além disso, só é permitido o emprego desse procedimento se as forças normais de cálculo em cada pilar dos sistemas resistentes a forças laterais, em todas as combinações de ações, não forem superiores a $50 \%$ da força normal de escoamento $\left(\mathrm{N}_{\mathrm{y}}\right)$ desses pilares.

Nota-se que o procedimento do AISC é bastante eclético. Fundamentalmente, as forças horizontais fictícias são utilizadas para modelar as imperfeições iniciais, porém 
permitem-se adaptações para representar os efeitos de segunda ordem e a não-linearidade física do material por meio da alteração da intensidade da força horizontal fictícia.

\subsubsection{PROJETO DE REVISÃO DA NBR 8800 (SET. 2006)}

O Projeto de Revisão da norma brasileira de estruturas de aço propõe um procedimento idêntico ao da especificação americana. A principal diferença está na classificação das estruturas, as quais podem ser classificadas em pequena, média e grande deslocabilidade.

\subsubsection{ESTRUTURAS DE PEQUENA DESLOCABILIDADE}

Os efeitos das imperfeições geométricas iniciais da estrutura devem ser levados em conta diretamente na análise por meio da consideração, em cada andar, de um deslocamento horizontal relativo entre pavimentos de $\mathrm{h} / 500$, sendo $\mathrm{h}$ a altura do andar. Admite-se também que sejam levados em conta por meio da aplicação, em cada andar, de uma força horizontal fictícia, igual a $0,2 \%$ do valor das cargas gravitacionais de cálculo aplicadas em todos os pilares e outros elementos resistentes a cargas verticais, no andar considerado.

Os efeitos das imperfeições de material não precisam ser considerados na análise.

\subsubsection{ESTRUTURAS DE MÉDIA E GRANDE DESLOCABILIDADE}

Os efeitos das imperfeições geométricas iniciais da estrutura devem ser levados em conta aumentando o deslocamento interpavimento para $\mathrm{h} / 333$ ou a força horizontal fictícia para $0,3 \%$ do valor das cargas gravitacionais de cálculo. 
Os efeitos das imperfeições iniciais de material devem ser levados em conta na análise reduzindo-se a rigidez à flexão (EI) e a rigidez axial (EA) das barras para $80 \%$ dos valores originais.

Nas estruturas de pequena deslocabilidade e média deslocabilidade, os efeitos das imperfeições geométricas iniciais podem ser entendidos como uma força horizontal mínima atuante na estrutura, não sendo necessário que sejam considerados nas combinações em que atuem ações variáveis devidas ao vento. Entretanto, devem ser consideradas nas combinações em que atuem apenas ações permanentes diretas e ações variáveis constituídas pelas cargas acidentais previstas para o uso da construção. Nas estruturas de grande deslocabilidade, os efeitos das imperfeições geométricas iniciais deverão ser adicionadas também às combinações de ações em que atuem ações variáveis devidas ao vento.

A Tabela 2.7 apresenta os procedimentos do AISC (2005) para análise de estruturas deslocáveis, de acordo com a classificação quanto à deslocabilidade. A Tabela 2.8 apresenta um resumo comparativo entre os procedimentos das demais normas estrangeiras supracitadas e da NBR 8800:1986.

Tabela 2.7 - Procedimentos do AISC (2005) para análise de estruturas deslocáveis.

\begin{tabular}{|c|c|c|c|}
\hline & \multicolumn{3}{|c|}{ Deslocabilidade } \\
\hline & Pequena & Média & $\operatorname{Alta}^{(a)}$ \\
\hline $\begin{array}{l}\text { Procedimento simplificado de } \\
\text { análise de segunda ordem }\end{array}$ & $\begin{array}{c}\text { amplificação com } \mathrm{B}_{1} \mathrm{e} \\
\mathrm{B}_{2}\end{array}$ & $\begin{array}{c}\text { amplificação com } \mathrm{B}_{1} \mathrm{e} \\
\mathrm{B}_{2}\end{array}$ & - \\
\hline Comprimento efetivo & $\mathrm{K}=1$ & $\mathrm{~K} \geq 1^{(\mathrm{b})}$ & $\mathrm{K}=1$ \\
\hline Força horizontal fictícia & $\begin{array}{c}\xi=0,002 \text {; força } \\
\text { horizontal mínima }\end{array}$ & $\begin{array}{c}\xi=0,002 ; \text { força } \\
\text { horizontal mínima }\end{array}$ & $\begin{array}{c}\xi=0,002 ; \text { adicionada às } \\
\text { forças reais }\end{array}$ \\
\hline Redução de rigidez & - & $\begin{array}{c}\mathrm{EI}_{\mathrm{red}}=0,8 \tau \mathrm{EI}^{(\mathrm{c})} \\
\mathrm{EA}_{\mathrm{red}}=0,8 \mathrm{EA}\end{array}$ & $\begin{array}{l}\mathrm{EI}_{\mathrm{red}}=0,8 \tau \mathrm{E}^{(\mathrm{c})} \\
\mathrm{EA}_{\mathrm{red}}=0,8 \mathrm{EA}\end{array}$ \\
\hline \multicolumn{4}{|c|}{$\begin{array}{l}\text { (a) o método da análise direta deve se empregado. } \\
\text { (b) } \mathrm{K}=1 \text { quando o método da análise direta for empregado, ou seja, } \xi=0,002 \text { e redução de rigidez. } \\
\text { (c) Permite-se adotar } \tau_{\mathrm{b}}=1 \text {, desde que } \xi=0,003 \text {. }\end{array}$} \\
\hline
\end{tabular}


Os procedimentos apresentados pelo AISC (2005) são semelhantes àqueles apresentados pelo Projeto de Revisão da NBR 8800 (set. 2006). A diferença é que este último eliminou definitivamente o coeficiente de flambagem $\mathrm{K}$, ou seja, $\mathrm{K}=1$ em todos os casos. $\mathrm{O}$ parâmetro $\tau_{\mathrm{b}}$ também foi eliminado, ou seja, $\xi=0,003$ quando aplicável.

Tabela 2.8 - Procedimentos normativos para análise de estruturas deslocáveis.

\begin{tabular}{|c|c|c|c|c|}
\hline & NBR 8800:1986 & CSA 16.1-1994 & prEN 1993:3/2003 & AS $4100 / 1990$ \\
\hline $\begin{array}{l}\text { Método de análise } \\
\text { sugerido }\end{array}$ & $\begin{array}{c}\text { Elástico de primeira } \\
\text { ordem }\end{array}$ & $\begin{array}{l}\text { Elástico de segunda } \\
\text { ordem }\end{array}$ & $\begin{array}{l}\text { Elástico de primeira } \\
\text { ou segunda ordem }\end{array}$ & $\begin{array}{c}\text { Elástico de segunda } \\
\text { ordem }\end{array}$ \\
\hline $\begin{array}{l}\text { Limitação dos métodos } \\
\text { simplificados de } \\
\text { segunda ordem }\end{array}$ & - & $\Delta_{2 \mathrm{~h}} / \Delta_{1 \mathrm{~h}}<1,4$ & $\Delta_{2 h} / \Delta_{1 h}<1,33$ & $\Delta_{2 \mathrm{~h}} / \Delta_{1 \mathrm{~h}}<1,4$ \\
\hline Comprimento efetivo & $\begin{array}{l}\mathrm{K} \geq 1 \text { se análise de } \\
\text { primeira ordem } \\
\mathrm{K} \leq 1 \text { se análise de } \\
\text { segunda ordem. }\end{array}$ & $\mathrm{K}=1$ & $\begin{array}{l}\mathrm{K} \geq 1 \text { se análise de } \\
\text { primeira ordem } \\
\mathrm{K}=1 \text { se análise de } \\
\text { segunda ordem }\end{array}$ & $\mathrm{K}=1$ \\
\hline $\begin{array}{l}\text { Força horizontal } \\
\text { fictícia }\end{array}$ & - & $\begin{array}{c}\xi=0,005 \text { apenas nas } \\
\text { combinações de } \\
\text { ações em que só } \\
\text { atuem forças } \\
\text { gravitacionais }\end{array}$ & $\begin{array}{c}\xi \text { é variável }^{(\mathrm{a})} ; \mathrm{em} \\
\text { todas as } \\
\text { combinações de } \\
\text { ações }\end{array}$ & $\begin{array}{c}\xi=0,002 \text { apenas nas } \\
\text { combinações de } \\
\text { ações em que só } \\
\text { atuem forças } \\
\text { gravitacionais }\end{array}$ \\
\hline Redução de rigidez & - & - & - & - \\
\hline
\end{tabular}

A utilização do conceito de comprimento efetivo de flambagem ainda persiste como alternativa de avaliação da estabilidade apresentada pelas normas e é objeto de trabalhos publicados recentemente, os quais propõem outros métodos para avaliação do fator K como alternativa ao diagrama de alinhamento (GIRGIN et al., 2006; TONG; WANG, 2006).

A necessidade de considerar as imperfeições geométricas iniciais na análise estrutural levou à difusão do método das forças horizontais fictícias, que incorporou os efeitos inelásticos e tensões residuais. Esse conceito foi alterado pelo método da análise direta, o qual propõe a utilização de forças horizontais apenas para representação das imperfeições geométricas, enquanto que os efeitos inelásticos são representados pela redução da rigidez. 
Estes últimos métodos apresentam a vantagem de substituir o conceito de comprimento efetivo por procedimentos bastante práticos que podem ser inseridos na análise estrutural. A avaliação e análise comparativa desses métodos no contexto do Projeto de Revisão da NBR 8800 (set. 2006) frente a uma análise numérica avançada é o cerne do presente estudo. 


\section{Capítulo 3: ANÁLISE ESTRUTURAL}

Os exemplos analisados correspondem a pórticos planos de aço cuja estabilidade é garantida pela rigidez das ligações viga-pilar (pórticos não-contraventados). Essas ligações serão consideradas rígidas. Serão utilizados perfis I com seção transversal compacta para vigas e pilares. Esta hipótese foi admitida porque a análise numérica avançada proposta para o presente estudo não permite avaliar instabilidade local (alma e mesa).

Os perfis I foram adotados porque são amplamente utilizados em vigas e pilares pertencentes a edifícios de múltiplos andares, os quais constituem o foco do presente trabalho. A extensão dessa metodologia para outros perfis é imediata, desde que o panorama de tensões residuais seja conhecido.

A estabilidade fora do plano do pórtico também será admitida garantida por alguma contenção apropriada. Nesse caso, uma análise numérica avançada aplicada a pórticos espaciais também pode considerar o efeito da flexão e imperfeições geométricas iniciais fora do plano. A introdução desse efeito na análise complicaria bastante a validação dos métodos em foco, uma vez que envolveria procedimentos aproximados apresentados pelas normas para verificação da estabilidade lateral e a interpretação dos resultados e desvios apresentados seria prejudicada.

Com base nas simplificações admitidas são analisados exemplos propostos em outros trabalhos e sugeridos no presente estudo. Neste caso, a estrutura foi concebida verificando-se os estados limites último e de serviço. Os estados limites de serviço aplicados foram o 
deslocamento de topo do edifício e o deslocamento relativo entre pavimentos. Essas verificações aproximam os exemplos de situações práticas.

\subsection{MÉTODOS SIMPLIFICADOS}

As análises estruturais que envolvem procedimentos simplificados foram realizadas empregando-se o programa SAP 2000 (COMPUTER AND STRUCTURES INC., 2004), o qual permite avaliar os efeitos $\mathrm{P}-\delta$ e P- $\Delta$ diretamente e contém recursos que facilitam a avaliação de diferentes combinações de ações. A análise estrutural empregada para os procedimentos simplificados foi elástica linear.

Cada barra (vigas e pilares) da estrutura é discretizada em 4 elementos finitos, conforme Figura 3.1. Para avaliar a precisão da discretização proposta foram analisadas barras isoladas submetidas à flexo-compressão variando-se as condições de vínculo das extremidades.

Os deslocamentos transversais e momentos fletores foram comparados com uma discretização bem mais refinada, composta por 20 elementos por barra. Os resultados apresentaram um desvio inferior a $0,5 \%$ nos deslocamentos e $2 \%$ nos esforços internos. Quando se utilizou apenas um elemento por barra, obtiveram-se desvios da ordem de $0,7 \%$ e 8\%. Portanto, a discretização proposta foi considerada suficiente.

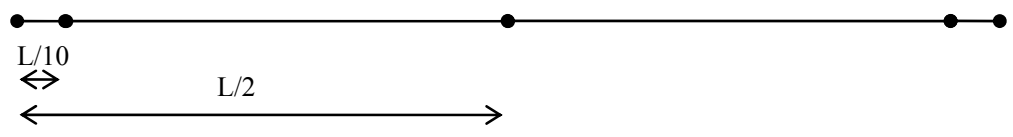

Figura 3.1 - Discretização de uma barra em quatro elementos finitos.

As tensões residuais e as imperfeições geométricas iniciais locais serão consideradas por meio das curvas de resistência à compressão apresentadas pelo Projeto de Revisão da 
NBR 8800 (set. 2006). As imperfeições geométricas iniciais globais, quando consideradas na análise, serão modeladas pelas forças horizontais fictícias.

$\mathrm{O}$ coeficiente de flambagem $\mathrm{K}$ será determinado empregando-se o diagrama de alinhamento para estruturas deslocáveis apresentado pela NBR 8800:1986.

\subsection{ANÁLISE NUMÉRICA AVANÇADA}

A análise numérica avançada considerando a não-linearidade física e geométrica é empregada para validar os métodos simplificados. Nessa análise, os efeitos desestabilizantes são considerados diretamente. Foi empregado o programa ABAQUS 6.5 (HIBBITT, KARLSSON AND SORENSON INC., 2005), o qual também foi utilizado na análise avançada de pórticos planos de aço realizada por Essa e Kennedy (2000) e Kim e Lee (2002).

A não-linearidade é avaliada por meio do procedimento incremental e iterativo com controle de força empregando-se o algoritmo de Newton-Rapson. Apenas na validação da análise avançada com a expressão de interação (Figura 3.6) é que será empregado controle de deslocamentos.

\subsubsection{NÃO-LINEARIDADE FÍSICA}

A não-linearidade física será considerada empregando-se um modelo constitutivo do tipo elastoplástico perfeito associado ao critério de escoamento de von Mises. Foi adotado o valor de cálculo resistência ao escoamento do aço $\left(\mathrm{f}_{\mathrm{yd}}\right)$, dada pela razão entra a resistência característica $\left(f_{\mathrm{yk}}\right)$ e o respectivo coeficiente de ponderação $\left(\gamma_{\mathrm{m}}\right)$ igual a 1,10 . Esse valor é apresentado pelo Projeto de Revisão da NBR 8800 (set. 2006) para verificações do estado limite último relacionadas ao escoamento do aço estrutural. 
O procedimento de minoração da resistência foi adotado porque os valores dos esforços internos resistentes também utilizam a resistência de cálculo. Um procedimento alternativo seria simplesmente adotar o valor característico da resistência ao escoamento na análise numérica em foco e também no cálculo dos esforços internos resistentes.

\subsubsection{ELEMENTO FINITO}

A estrutura foi discretizada empregando-se elementos finitos de pórticos tridimensionais (B32) capazes de representar um desenvolvimento geométrico parabólico e com 6 graus de liberdade por nó - três rotações e três deslocamentos. A descrição geométrica parabólica foi adotada para representar melhor as imperfeições geométricas locais (Figura $3.2)$.

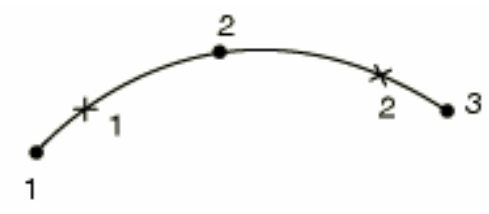

Figura 3.2 - Elemento finito B32.

Esse elemento possui alguns graus de liberdade que não são relevantes na análise plana, porém a distribuição dos pontos de integração da seção transversal é que justifica o emprego desse elemento frente ao elemento de pórtico plano. Os pontos de integração permitem reproduzir o diagrama de tensões residuais proposto, enquanto que o elemento finito para análise plana não possui pontos de integração ao longo das mesas (Figura 3.3). 


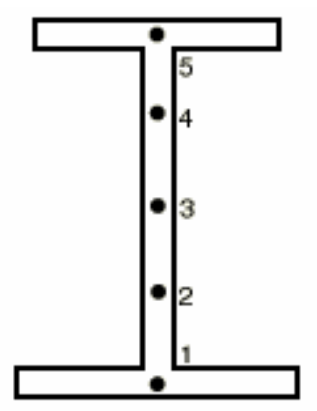

(a)

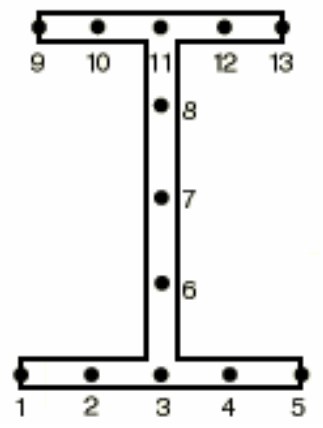

(b)

Figura 3.3 - Pontos de integração da seção transversal: (a) elemento plano e (b) tridimensional.

As rótulas, quando existirem, serão modeladas com elementos finitos de contato (Join+Flexion-Torsion) conectando as extremidades dos elementos de pórtico. Esses elementos de contato permitem acoplar os graus de liberdade referentes às translações (Join) e definir um parâmetro de rigidez para cada grau de liberdade referente à rotação (FlexionTorsion). Desse modo, é possível representar uma rótula definindo valores baixos de rigidez à rotação no plano do pórtico $\left(10^{-5}\right)$ e acoplando os demais graus de liberdade de rotação. A consistência do valor adotado para a rigidez à rotação do grau de liberdade referente à rótula é verificada observando-se os momentos fletores nas extremidades dos elementos adjacentes ao elemento de contato. Esses momentos fletores devem apresentar valores desprezíveis. Caso contrário, a rigidez à rotação é reduzida.

\subsubsection{TENSÕES RESIDUAIS}

A distribuição de tensões residuais adotada para os perfis foi proposta por Galambos e Ketter (1959) (Figura 3.4). De acordo com Essa e Kennedy (2000), essa distribuição é muito severa porque toda a alma do perfil está tracionada, entretanto foi adotada porque é bastante simples de ser inserida ao modelo. Além disso, os valores da tensão residual nas extremidades das mesas estão de acordo com outras distribuições e segundo Bild e Trahair (1989), essa é a propriedade mais significativa para a resistência dos pilares. 
As tensões residuais são inseridas no modelo como um estado de tensões inicias autoequilibrado (resultantes nulas) definido para os pontos de integração da seção transversal dos elementos. A atribuição dessas tensões residuais é realizada com o emprego de uma rotina computacional desenvolvida em linguagem FORTRAN e incorporada ao processamento do modelo. Essa rotina contém o valor das tensões residuais em cada ponto de integração da seção transversal.

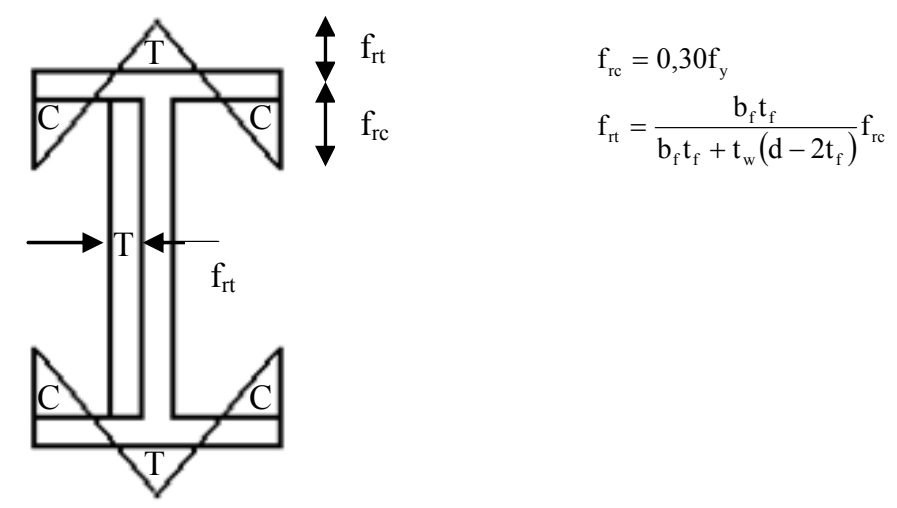

Figura 3.4 - Distribuição de tensões residuais adotada (GALAMBOS e KETTER, 1959).

A identificação do perfil e do diagrama a ser atribuído é realizada com uma verificação da coordenada nodal y (altura) dos pontos de integração do elemento. Quando essa coordenada coincide com a altura do pavimento, é atribuído o diagrama referente às vigas que compõem o respectivo pavimento. Caso contrário é atribuído o diagrama referente ao pilar localizado entre os pavimentos imediatamente superior e inferior.

\subsubsection{IMPERFEIÇÕES GEOMÉTRICAS}

As imperfeições geométricas iniciais foram inseridas diretamente no modelo. Adotaram-se os valores de L/1000 e L/500, respectivamente, para as imperfeições local e global. Esses valores foram sugeridos pela ASCE e pelo Projeto de Revisão da NBR 8800 
(set. 2006). A configuração das imperfeições geométricas será adotada conforme o procedimento da ASCE (1997), apresentado na Figura 3.5.

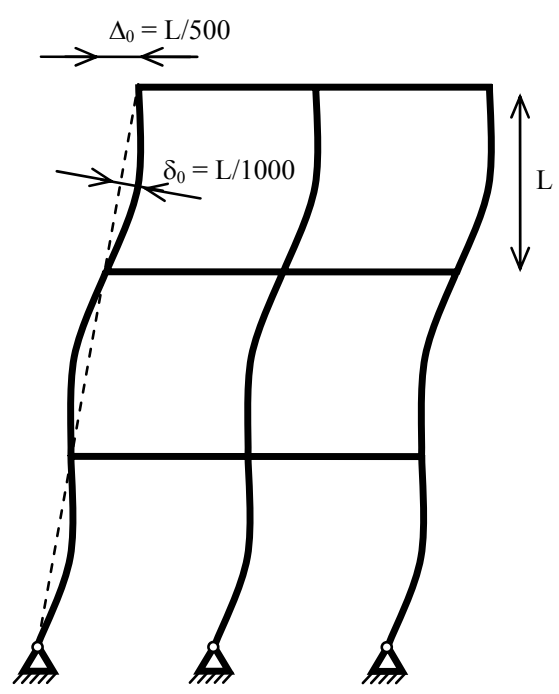

Figura 3.5 - Configuração das imperfeições geométricas iniciais (ASCE, 1997).

\subsubsection{VALIDAÇÃO}

De acordo com Alvarenga e Silveira (2006) uma análise numérica pode ser considerada avançada quando cumpre as seguintes exigências:

a) emprego de uma teoria matemática rigorosa fundada em teorias bem conhecidas da mecânica dos sólidos e dos materiais;

b) os esforços solicitantes nas seções não podem violar a resistência máxima definida pela condição de plasticidade completa da seção;

c) a plasticidade distribuída deve ser avaliada, tanto na deformação axial, como na deformação por flexão, ou combinadas; e, quando a seção solicitada está num ponto da superfície de plastificação, acréscimos de força normal devem provocar a redução do momento fletor correspondente; 
d) as resistências, as deformações, as distribuições internas dos esforços, as tensões, etc. devem ser confrontadas, previamente, com resultados de ensaios em escala real ou pórticos de calibragem. A carga limite encontrada pela análise avançada, não poderá ser superior em 5\% à carga limite obtida experimentalmente.

A condição a) foi verificada no manual do programa empregado nesta análise numérica avançada (HIBBITT, KARLSSON AND SORENSON INC., 2005). As condições b) e c) serão verificadas por meio da análise de um pilar submetido à flexo-compressão. A condição d) será verificada por meio da análise comparativa com um exemplo bem difundido na literatura e bastante empregado neste tipo de verificação.

Para verificar a concordância entre as superfícies de escoamento, utilizou-se uma barra comprimida rotulada nas extremidades. Analisaram-se duas situações, variando-se a intensidade da imperfeição inicial da barra $\left(\delta_{0}\right)$ : L/1000 e L/500. Aplicou-se um deslocamento vertical (u) na extremidade livre. Obtiveram-se os valores de momento fletor e força normal no meio do vão. Esses esforços foram normalizados pelos respectivos esforços de plastificação e são apresentados graficamente na Figura 3.6.

A avaliação do histórico de esforços internos na barra apresenta boa concordância com a superfície de escoamento definida pelo AISC (2005) e também pelo Projeto de Revisão da NBR 8800 (set. 2006), por isso o procedimento numérico avançado foi considerado adequado para representação das expressões de interação. Portanto, os desvios na expressão de interação entre os procedimentos simplificados e a análise numérica avançada serão atribuídos ao modo de representar os fenômenos desestabilizantes. 

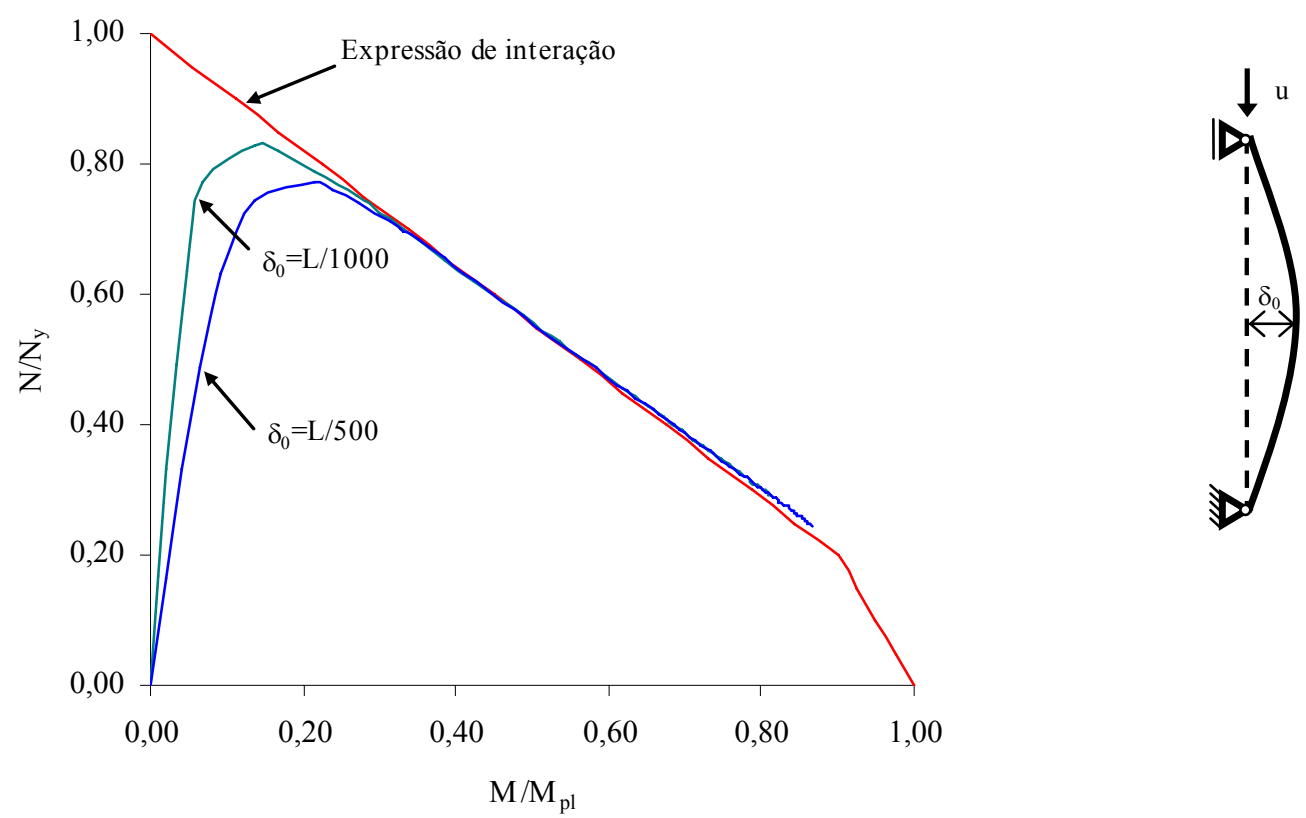

Figura 3.6 - Comparação entre trajetórias de equilíbrio e as expressões (2.2) e (2.3).

A comparação entre as trajetórias de equilíbrio e a superfície de interação permite verificar que as condições b) e c) são atendidas, ou seja, a resistência da seção, definida pela superfície de plastificação não foi violada e, para pontos da trajetória de equilíbrio sobre a superfície de plastificação, incrementos de força normal são associados à redução do momento fletor.

Para avaliar a condição d), empregou-se a análise numérica avançada do "Portal de Vogel”, o qual é apresentado na Figura 3.7. De acordo com Kim e Lee (2002), Gomes (2005), Alvarenga e Silveira (2006) esse pórtico já foi amplamente estudado e empregado na calibração de análises avançadas.

Os pilares e a viga têm seção I padrão europeu, as quais foram convertidas para perfis I equivalentes (ALVARENGA e SILVEIRA, 2006). 


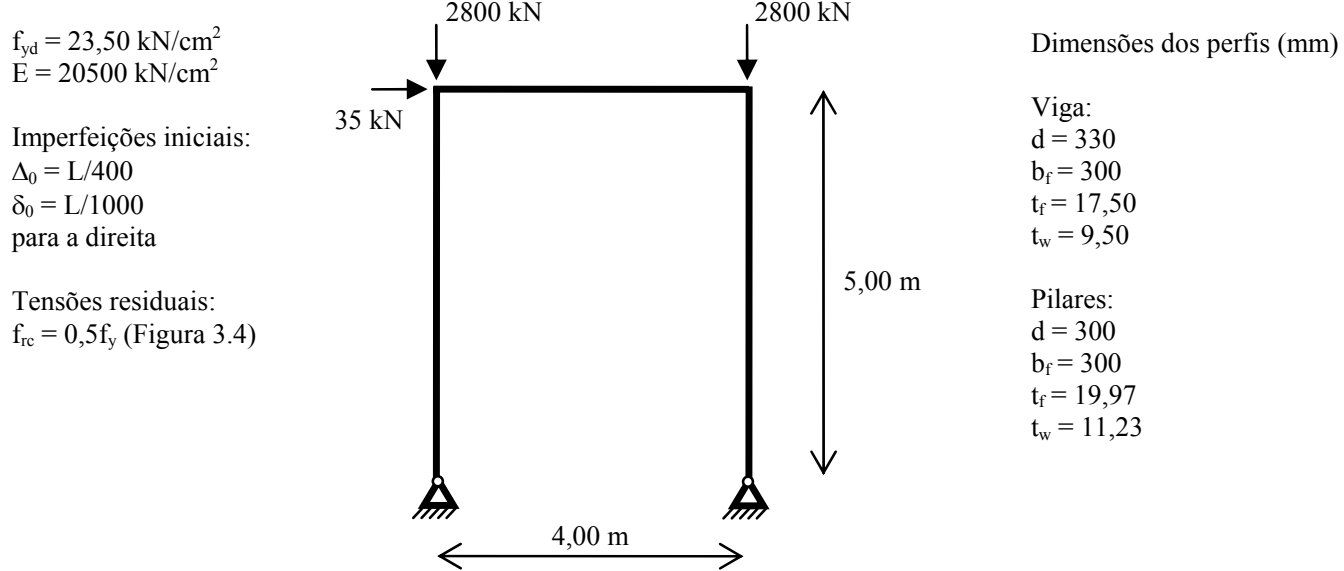

Figura 3.7 - Portal de Vogel (adaptação de Alvarenga e Silveira, 2006).

Foi empregada uma análise incremental iterativa para aplicação simultânea das forças verticais e horizontal. A Figura 3.8 ilustra a comparação entre os resultados experimentais apresentados por Kim e Lee (2002) e pela análise numérica descrita nesta seção.

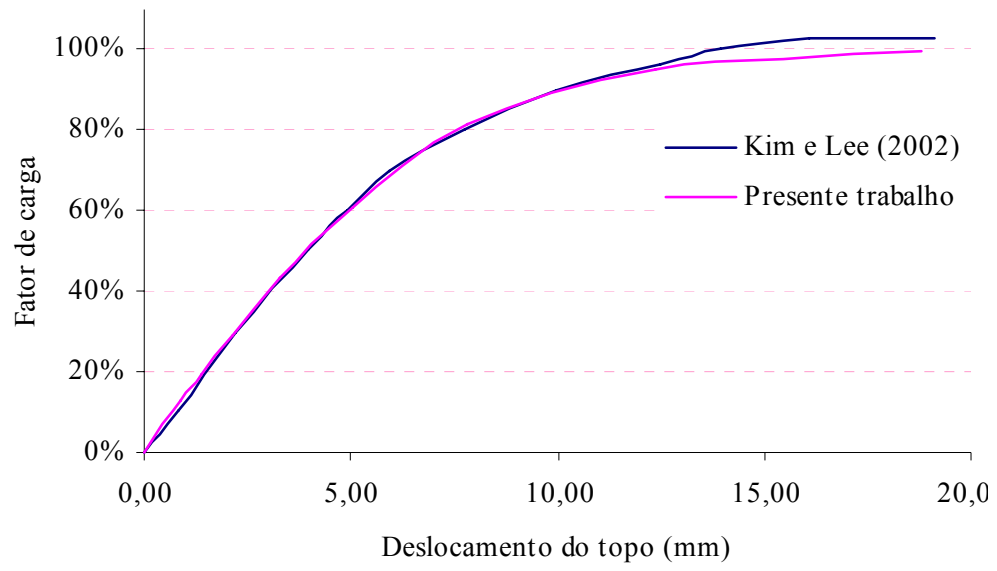

Figura 3.8 - Trajetórias de equilíbrio para portal de Vogel.

Obteve-se carregamento igual a 99,68\% daquele ilustrado na Figura 3.7 e uma boa concordância com outra resposta apresentada na literatura, verificando-se a exigência d). Portanto, atendidas as exigências apresentadas, segue-se com uma análise comparativa entre os métodos simplificados, tomando-se como referência os resultados obtidos por meio desta análise numérica avançada. 


\subsection{ANÁLISES COMPARATIVAS}

Para cada exemplo proposto, foi investigada a resposta dos métodos do comprimento efetivo de flambagem (NBR 8800:1986), da força horizontal fictícia (ASCE, 1997) e da análise direta (Projeto de Revisão da NBR 8800, set. 2006). Foram empregadas 6 análises envolvendo procedimentos simplificados de avaliação dos efeitos desestabilizantes.

As análises 0 e 1 compreendem os procedimentos de análise estrutural apresentados pela NBR 8800:1986, ou seja, sem força horizontal fictícia e avaliando-se o coeficiente de flambagem por meio do diagrama de alinhamento. A diferença é que a análise 0 é de primeira ordem e a análise 1 de segunda ordem.

A análise 2 traz os conceitos do método simplificado das forças horizontais fictícias, que foi sugerido para a norma canadense (ESSA e KENNEDY, 2000). Aplicam-se as forças horizontais fictícias e o coeficiente de flambagem é sempre igual a 1,0.

Na análise 3 é empregado o método da análise direta, apresentado pela última versão da especificação do AISC (2005) e pelo Projeto de Revisão da NBR 8800 (set. 2006), no qual são aplicadas forças horizontais fictícias e redução de rigidez.

A análise 4 é uma alternativa apresentada pelo AISC (2005), que consiste na aplicação de forças horizontais fictícias e avaliação do coeficiente de flambagem por meio do diagrama de alinhamento.

Na análise 5, será realizada uma análise de primeira ordem e serão introduzidas forças horizontais fictícias adicionais para simular os efeitos de segunda ordem.

A análise 6 é semelhante à 3 , mas os efeitos de segunda ordem são avaliados por meio dos coeficientes de amplificação dos esforços $\left(\mathrm{B}_{1}\right.$ e $\left.\mathrm{B}_{2}\right)$.

As combinações de ações referentes às análises 1 e 4 serão utilizadas para avaliação dos métodos aproximados de análise dos efeitos de segunda ordem, de acordo com a 
necessidade de adicionar ou não as forças horizontais que representam as imperfeições geométricas às forças horizontais de vento.

A Tabela 3.1 apresenta um resumo dos procedimentos simplificados que foram avaliados, destacando a metodologia de modelagem dos efeitos desestabilizantes.

Após a análise estrutural, a verificação dos pilares foi feita com base nas expressões de interação (2.2) e (2.3) (Projeto de Revisão da NBR 8800, set. 2006), o qual foi empregado como parâmetro de comparação entre as análises. O valor de referência admitido é aquele obtido na análise numérica avançada (análise 7).

Tabela 3.1 - Procedimentos empregados para as análises estruturais e dimensionamento dos pilares.

\begin{tabular}{|c|c|c|c|c|}
\hline análise & $\begin{array}{l}\text { Efeitos de segunda } \\
\text { ordem }\end{array}$ & Comprimento da barra & $\begin{array}{l}\text { Coeficiente de força } \\
\text { horizontal fictícia }(\xi)\end{array}$ & $\begin{array}{l}\text { Redução de rigidez } \\
\qquad\left(\mathrm{E}_{\mathrm{red}} / \mathrm{E}\right)\end{array}$ \\
\hline 0 & não & KL & 0,000 & 1,0 \\
\hline 1 & análise de $2^{\mathrm{a}}$ ordem & KL & 0,000 & 1,0 \\
\hline 2 & análise de $2^{\mathrm{a}}$ ordem & $\mathrm{L}$ & 0,005 & 1,0 \\
\hline 3 & análise de $2^{\mathrm{a}}$ ordem & $\mathrm{L}$ & 0,003 & 0,8 \\
\hline 4 & análise de $2^{\mathrm{a}}$ ordem & KL & 0,002 & 1,0 \\
\hline 5 & $\begin{array}{l}\text { força horizontal fictícia } \\
\text { adicional }^{(\mathrm{a})}\end{array}$ & $\mathrm{L}$ & $2,1(\Delta / \mathrm{h})>0,0042$ & 1,0 \\
\hline 6 & $\begin{array}{c}\text { amplificação dos } \\
\text { momentos } \mathrm{B}_{1}-\mathrm{B}_{2}{ }^{(b)}\end{array}$ & $\mathrm{L}$ & 0,003 & 0,8 \\
\hline 7 & \multicolumn{4}{|c|}{ Análise numérica avançada (item 3.2) } \\
\hline \multicolumn{5}{|c|}{$\begin{array}{l}\text { (a) é empregada uma análise de } 1^{\mathrm{a}} \text { ordem. Os efeitos de } 2^{\mathrm{a}} \text { ordem são considerados pela força horizontal fictícia } \\
\text { adicional. } \\
\text { (b) é empregada uma análise de } 1^{\mathrm{a}} \text { ordem. Os efeitos de } 2^{\mathrm{a}} \text { ordem são considerados os coeficientes de } \\
\text { amplificação } \mathrm{B}_{1} \text { e } \mathrm{B}_{2} \text {. }\end{array}$} \\
\hline
\end{tabular}




\section{Capítulo 4: ANÁLISE COMPARATIVA - EXEMPLOS}

Os exemplos serão analisados inicialmente com ênfase na comparação entre os procedimentos que utilizam o comprimento efetivo de flambagem e aqueles que propõem o emprego de forças horizontais fictícias, tomando-se como referência a análise numérica avançada (item 3.2).

Também será investigada a resposta do coeficiente $\gamma_{\mathrm{z}}$ como parâmetro global de classificação das estruturas quanto à deslocabilidade, comparando-se com o coeficiente $\mathrm{B}_{2}$, para um edifício de múltiplos andares.

\subsection{EXEMPLO 1 - PILAR EM BALANÇO}

O exemplo 1 consiste em um pilar em balanço sob compressão centrada. Admitindose uma contenção adequada para o eixo de menor inércia, a análise fica restrita ao eixo de maior inércia.

Inicialmente, avalia-se o pilar com base no comprimento efetivo de flambagem, sem imperfeição geométrica global. Será adotado K=2,10, de acordo com a NBR 8800:1986, resultando em $\lambda=126,50$. Desta forma, obtém-se um esforço normal resistente igual $326 \mathrm{kN}$, que será admitido igual à força normal solicitante de cálculo. Portanto, não há folga no dimensionamento. 


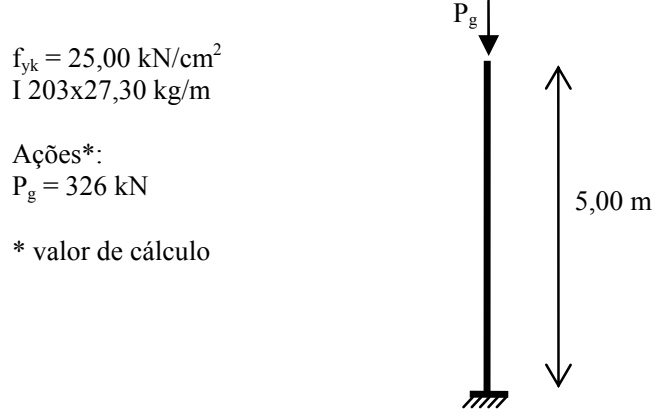

Figura 4.1 - Pilar em balanço sob compressão centrada.

O método da análise direta propõe a aplicação de uma força horizontal igual a $0,002 \mathrm{P}_{\mathrm{g}}$ para simular a imperfeição geométrica global. Avaliando-se o coeficiente $\mathrm{B}_{2}$ para essa estrutura, obtém-se $B_{2}=2,85$. Nesse caso, o parâmetro é uma estimativa razoável para a razão entre os deslocamentos de segunda e primeira ordem $\left(\mathrm{u}_{2} / \mathrm{u}_{1}=3,02\right)$. Portanto, a estrutura é classificada como de alta deslocabilidade e deve-se considerar a redução de rigidez, $\mathrm{E}_{\mathrm{red}}=0,8 \mathrm{E}$ $\left(\tau_{b}=1,00\right)$.

Analisando-se a estrutura com a rigidez reduzida obtém-se $\mathrm{B}_{2}$ igual a 5,38, que é empregado como fator de amplificação do momento fletor de primeira ordem, obtendo-se o momento fletor solicitante de cálculo de segunda ordem igual a $1.750 \mathrm{kN} . \mathrm{cm}$.

Para avaliar o resultado da expressão de interação, considera-se $K=1,00$ no cálculo do esforço normal resistente. Deste modo, a expressão de interação resulta igual a 0,74 . Os resultados obtidos por meio dos dois procedimentos são apresentados na Tabela 4.1

Tabela 4.1 - Esforços internos no pilar, em kN.cm e kN.

\begin{tabular}{lccccc}
\hline \multicolumn{1}{c}{ Procedimento } & $\mathrm{N}_{\mathrm{Sd}}$ & $\mathrm{N}_{\mathrm{Rd}}$ & $\mathrm{M}_{\mathrm{Sd}}$ & $\mathrm{M}_{\mathrm{Rd}}$ & $\begin{array}{c}\text { Expr. } \\
\text { interação }\end{array}$ \\
\hline Comprimento efetivo de flambagem & 326,00 & 326,00 & 0,00 & 6007,00 & 1,00 \\
Análise direta & 326,00 & 681,00 & 1750,00 & 6007,00 & 0,74 \\
Análise numérica avançada & 326,00 & 790,91 & 1198,28 & 6007,00 & 0,59 \\
\hline
\end{tabular}

Nota-se que o esforço normal resistente avaliado por meio do método da análise direta é maior que o obtido considerando o comprimento efetivo de flambagem $(K>1)$, o que é 
compensado pela introdução do momento fletor solicitante na análise. Entretanto, percebe-se que essa compensação retornou em um dimensionamento mais folgado. Quando a estrutura é estudada por meio da análise numérica avançada, a folga no dimensionamento é reduzida, apontando o método da análise direta como mais adequado.

A diferença acentuada verificada entre o método do comprimento efetivo de flambagem e o método da análise direta acontece por causa de dois motivos: a esbeltez da barra e a ausência de forças horizontais significativas que solicitem a barra à flexão.

O pilar apresentado possui esbeltez igual a 126,5, que é um valor elevado. Por isso, a redução da força normal resistente é bastante significativa quando o comprimento efetivo de flambagem é considerado.

O exemplo apresentado foi estudado alterando-se a seção transversal a fim de obter uma esbeltez igual a 80 . Deste modo, obteve-se uma força normal resistente igual a 830,3 kN, considerando o coeficiente de flambagem igual a 2,1. Portanto, admitindo-se uma força vertical solicitante igual a $830,3 \mathrm{kN}$, o dimensionamento da barra por meio do procedimento do comprimento efetivo de flambagem não apresenta folga.

Aplicando-se uma força vertical igual a $830,3 \mathrm{kN}$ e avaliando-se o dimensionamento do pilar empregando o método da análise direta $(\mathrm{K}=1,0)$, obtém-se um resultado igual a 0,91 para a expressão de interação. Ou seja, o desvio entre a análise direta e o comprimento efetivo de flambagem é inferior a $10 \%$ e menor do que o desvio apresentado na Tabela 4.1.

Além disso, o resultado da expressão de interação para o exemplo em tela depende essencialmente da parcela referente à força normal, uma vez que o momento fletor solicitante só é induzido pela força horizontal fictícia. Em geral, os pilares de edifícios pertencentes a estruturas de contraventamento são solicitados por momento fletor significativo. Nesse caso, a diferença na avaliação da parcela referente à força normal tem uma influência menor no resultado da expressão de interação. 


\subsection{EXEMPLO 2 - PÓRTICO REGULAR COM UM PAVIMENTO}

O pórtico de um pavimento, constituído por uma viga contínua apoiada em três pilares igualmente espaçados, submetido a um carregamento distribuído devido ao peso próprio e sobrecarga e uma força horizontal de vento (Figura 4.2) foi apresentado e resolvido pela ASCE (1997). A estabilidade do pórtico depende exclusivamente da ligação viga-pilar e da rigidez à flexão do pilar central.
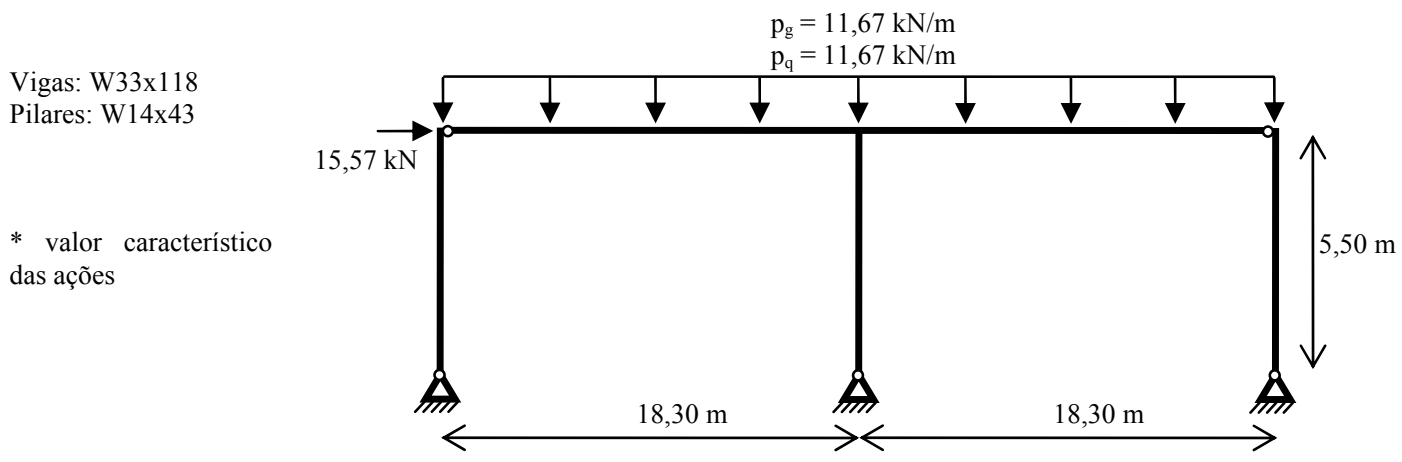

Figura 4.2 - Pórtico de um pavimento (ASCE, 1997).

Nesse exemplo, empregaram-se os coeficientes de ponderação das ações extraídos da norma brasileira de ações e segurança NBR 8681:2003 (Tabela 4.2). Os métodos estudados nesse exemplo serão avaliados apenas para a combinação de ações com força do vento. Entretanto, a combinação de ações gravitacionais será empregada para obter a razão entre os deslocamentos de segunda e primeira ordem e classificar a estrutura quanto à deslocabilidade.

Tabela 4.2 - Coeficientes de ponderação das ações.

\begin{tabular}{llccc}
\hline & & $\gamma_{\mathrm{f} 1} \gamma_{\mathrm{f} 3}$ & $\gamma_{\mathrm{f} 2}$ & $\gamma_{\mathrm{f}}$ \\
\hline \multirow{2}{*}{$\begin{array}{llc}\text { com força de } \\
\text { vento }\end{array}$} & $\mathrm{pp}$ & 1,40 & 1,00 & 1,40 \\
& sobrecarga & 1,40 & $0,50^{(\mathrm{a})}$ & 0,70 \\
& vento & 1,40 & 1,00 & 1,40 \\
\hline \multirow{2}{*}{$\begin{array}{l}\text { gpenas forças } \\
\text { gravitacionais }\end{array}$} & pp & 1,40 & 1,00 & 1,40 \\
\hline (a) $\gamma_{\mathrm{f} 2}=\psi_{0}=0,5$. Edificações residenciais de acesso restrito. & 1,40 \\
\hline
\end{tabular}


A combinação de ações empregada para a estrutura em estudo contém ação de vento e a razão $\mathrm{u}_{2} / \mathrm{u}_{1}$ é igual a 1,39 . Quando a combinação de ações em que só atuam forças gravitacionais é estudada, obtém-se $\mathrm{u}_{2} / \mathrm{u}_{1}=1,53$. Portanto, uma vez que em uma das combinações de ações a razão $\mathrm{u}_{2} / \mathrm{u}_{1}$ excedeu o limite de 1,50 , as imperfeições geométricas globais equivalentes a h/500 devem ser consideradas em todas as combinações de ações.

A intensidade das forças horizontais fictícias depende do somatório das forças verticais de cálculo atuantes no pavimento. A Tabela 4.3 apresenta os valores da força horizontal para cada análise realizada. Já que a estrutura é simétrica, basta aplicar essa força em um sentido (o mesmo da ação do vento).

Tabela 4.3 - Intensidade da força horizontal fictícia $(\mathrm{kN})$.

\begin{tabular}{lcccccccc}
\hline Análise & 0 & 1 & 2 & 3 & 4 & 5 & 6 & 7 \\
\hline$\xi$ & 0,000 & 0,000 & 0,005 & 0,003 & 0,002 & 0,014 & 0,003 & 0,000 \\
$\xi(\Sigma \mathrm{P})$ & 0,00 & 0,00 & 4,48 & 2,69 & 1,79 & 2,96 & 2,69 & 0,00 \\
\hline
\end{tabular}

$\mathrm{O}$ coeficiente de flambagem $\mathrm{K}$ foi determinado por meio da expressão (2.4), admitindo-se $\mathrm{G}$ tendendo a infinito (10.000) para a extremidade inferior do pilar central. Assim, obteve-se $\mathrm{K}=2,09$ e $\lambda=77,62$.

O resultado das expressões de interação para o pilar central são apresentados na Tabela 4.4. Observa-se que a análise numérica avançada não foi capaz de atingir a força de vento total, sendo interrompida em $87 \%$ do valor característico. Ainda, os procedimentos simplificados também indicaram que a estrutura não suporta as forças apresentadas. Portanto, para avaliar a resposta dos métodos simplificados, tomou-se como parâmetro de comparação o valor característico da força de vento $\left(\mathrm{F}_{\mathrm{u}}\right)$ correspondente ao estado limite último da estrutura, apresentado na $7^{\mathrm{a}}$ coluna da Tabela 4.4 . 
Tabela 4.4 - Esforços internos no pilar central e força horizontal máxima $\left(\mathrm{F}_{\mathrm{u}}\right)$, em kN.m e kN.

\begin{tabular}{ccccccc}
\hline Análise & $\mathrm{N}_{\mathrm{Sd}}$ & $\mathrm{N}_{\mathrm{Rd}}$ & $\mathrm{M}_{\mathrm{Sd}}$ & $\mathrm{M}_{\mathrm{Rd}}$ & $\begin{array}{c}\text { Expr. } \\
\text { interação }\end{array}$ & $\mathrm{F}_{\mathrm{u}}{ }^{(\mathrm{a})}$ \\
\hline 0 & 559,23 & 1246,86 & 119,45 & 282,93 & 0,862 & 20,77 \\
1 & 559,23 & 1246,86 & 166,60 & 282,93 & 1,024 & 14,90 \\
2 & 559,23 & 1687,03 & 201,59 & 282,93 & 1,028 & 14,81 \\
3 & 559,23 & 1687,03 & 208,40 & 282,93 & 1,052 & 14,32 \\
4 & 559,23 & 1246,86 & 180,20 & 282,93 & 1,071 & 13,61 \\
5 & 559,23 & 1687,03 & 191,95 & 282,93 & 0,995 & 15,57 \\
7 & 559,23 & 1687,03 & 232,04 & 282,93 & 1,133 & 13,83 \\
\hline
\end{tabular}

(a) Valor característico da ação de vento que corresponde à expressão de interação igual a 1,0.

(b) A análise numérica avançada atingiu $87 \%$ da força de vento.

As análises 1 e 2 apresentaram resultados próximos. Isso acontece porque o modelo de calibração do método das forças horizontais fictícias (Figura 2.13) representa bem a situação da estrutura, cuja estabilidade depende essencialmente do pilar central e para esse modelo os métodos fornecem resultados próximos.

A comparação entre as análises 1 e 4 ilustra a influência das imperfeições geométricas iniciais da estrutura na capacidade resistente e nos momentos fletores solicitantes de cálculo. Os dois métodos apresentaram um desvio relativo de $10 \%$ entre si na avaliação do valor característico da força horizontal máxima e dos momentos fletores de cálculo. Quando as imperfeições geométricas não foram consideradas (análise 1) obtiveram-se resultados contra a segurança, mas com desvios inferiores a 5\% em relação ao modelo numérico avançado.

\subsection{EXEMPLO 3 - EDIFÍCIO INDUSTRIAL SEM PONTE ROLANTE}

Nesse caso, só será estudada a combinação em que atuam apenas ações gravitacionais. A combinação de ações com vento comanda o dimensionamento, mas não será estudada porque produz tração nos pilares. 


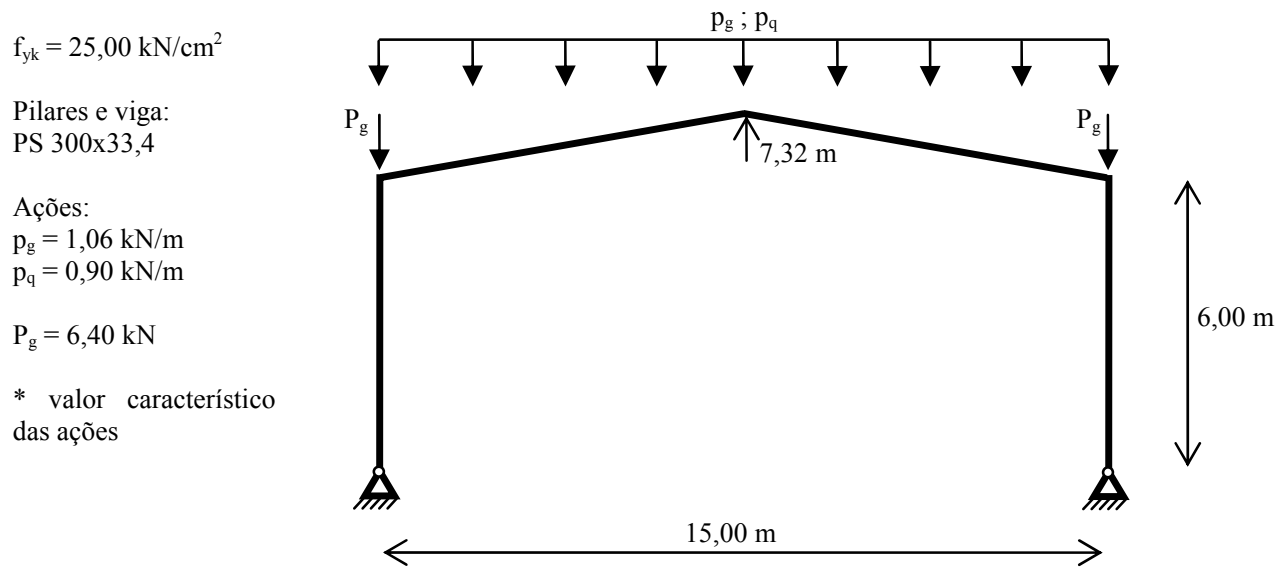

Figura 4.3 - Edifício industrial sem ponte rolante (SIDERBRÁS, 2001).

A razão entre os deslocamentos de segunda e primeira ordem é igual a 1,01. Portanto, segundo o critério de classificação do Projeto de Revisão da NBR 8800 (set. 2006), a estrutura é de pequena deslocabilidade.

Admitindo-se que as vigas restringem totalmente a rotação do topo dos pilares, obtémse $\mathrm{K}=2,10$, segundo a NBR 8800:1986, o que resulta em $\lambda=98,60$. O valor da força horizontal fictícia empregado em cada análise e o resultado da expressão de interação são apresentados nas Tabela 4.5 e Tabela 4.6, respectivamente.

Tabela 4.5 - Intensidade da força horizontal fictícia $(\mathrm{kN})$.

\begin{tabular}{lcccccccc}
\hline Análise & 0 & 1 & 2 & 3 & 4 & 5 & 6 & 7 \\
\hline$\xi$ & 0,000 & 0,000 & 0,005 & 0,003 & 0,002 & 0,0042 & 0,003 & 0,000 \\
$\xi(\Sigma \mathrm{P})$ & 0,00 & 0,00 & 0,28 & 0,17 & 0,11 & 0,23 & 0,17 & 0,00 \\
\hline
\end{tabular}


Tabela 4.6 - Esforços internos no pilar mais solicitado, em kN.cm e kN, e resultado da expressão de interação.

\begin{tabular}{cccccc}
\hline Análise & $\mathrm{N}_{\mathrm{Sd}}$ & $\mathrm{N}_{\mathrm{Rd}}$ & $\mathrm{M}_{\mathrm{Sd}}$ & $\mathrm{M}_{\mathrm{Rd}}$ & $\begin{array}{c}\text { Expr. } \\
\text { interação }\end{array}$ \\
\hline 0 & 28,10 & 541,96 & 3747,80 & 11659,09 & 0,35 \\
1 & 28,10 & 541,96 & 3761,60 & 11659,09 & 0,35 \\
2 & 28,20 & 841,58 & 3843,74 & 11659,09 & 0,35 \\
3 & 28,16 & 841,58 & 3815,20 & 11659,09 & 0,34 \\
4 & 28,14 & 541,96 & 3794,40 & 11659,09 & 0,35 \\
5 & 28,20 & 841,58 & 3819,40 & 11659,09 & 0,34 \\
6 & 28,22 & 841,58 & 3832,14 & 11659,09 & 0,35 \\
7 & 28,15 & 965,91 & 3795,72 & 11659,09 & 0,34 \\
\hline
\end{tabular}

Observa-se que, apesar da diferença significativa entre a força normal resistente, o resultado da expressão de interação é praticamente o mesmo, pois a força normal solicitante é relativamente baixo. Nesse caso, o dimensionamento em geral é governado pela análise de estabilidade fora do plano do pórtico, de modo que o procedimento de análise da estabilidade no plano pouco influencia o dimensionamento.

\subsection{EXEMPLO 4 - EDIFÍCIO INDUSTRIAL COM PONTE ROLANTE}

Será estudada a combinação de ações contendo ações permanentes, sobrecarga e ação da ponte rolante, conforme apresentado na Figura 4.4.

Foram considerados coeficientes de ponderação iguais a 1,3 para os carregamentos permanentes e 1,5 para a sobrecarga na cobertura e ação da ponte rolante. Nesse caso, optouse por aplicar a força horizontal fictícia em cada nível de força vertical aplicada, ou seja, foram aplicadas uma força no nível das cargas $\mathrm{P}_{\mathrm{g} 2}$ e outra força no topo do pilar, a qual representa a contribuição das forças no telhado e do fechamento lateral $\left(\mathrm{P}_{\mathrm{g} 1}\right)$. 


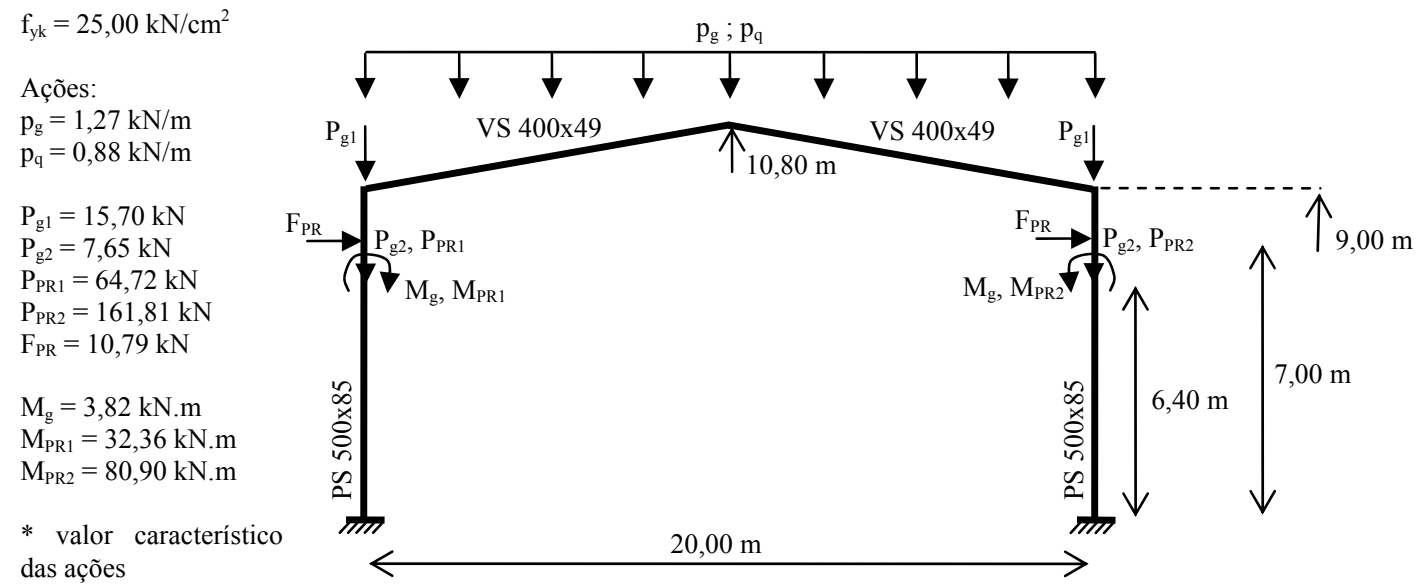

Figura 4.4 - Edifício industrial com ponte rolante (BELLEI, 1994).

Foi adotado $\mathrm{K}=1,75$ para os pilares (BELLEI, 1994), que resulta em $\lambda=76,50$. A Tabela 4.7 apresenta os esforços internos resistentes e solicitantes e o resultado das expressões de interação para o pilar mais solicitado.

Tabela 4.7 - Esforços internos no pilar mais solicitado, em kN.cm e kN, e resultado da expressão de interação.

\begin{tabular}{cccccc}
\hline Análise & $\mathrm{N}_{\mathrm{Sd}}$ & $\mathrm{N}_{\mathrm{Rd}}$ & $\mathrm{M}_{\mathrm{Sd}}$ & $\mathrm{M}_{\mathrm{Rd}}$ & $\begin{array}{c}\text { Expr. } \\
\text { interação }\end{array}$ \\
\hline 0 & 303,77 & 1677,64 & 15259,22 & 46802,05 & 0,42 \\
1 & 303,88 & 1677,64 & 15535,50 & 46802,05 & 0,42 \\
2 & 303,90 & 2170,81 & 16248,00 & 46802,05 & 0,42 \\
3 & 303,90 & 2170,81 & 16035,00 & 46802,05 & 0,41 \\
4 & 303,86 & 1677,64 & 15820,00 & 46802,05 & 0,43 \\
5 & 303,93 & 2170,81 & 16045,35 & 46802,05 & 0,41 \\
6 & 303,90 & 2170,81 & 15841,00 & 46802,05 & 0,41 \\
7 & 303,35 & 2445,45 & 15853,40 & 46802,05 & 0,40 \\
\hline
\end{tabular}

Nota-se que a força normal solicitante continua baixa em relação à força resistente. Por isso, a contribuição do primeiro termo da expressão de interação é pequena e a diferença observada na avaliação da força normal resistente não é percebida no valor final da expressão de interação. 


\subsection{EXEMPLO 5 - PÓRTICO ASSIMÉTRICO COM DOIS PAVIMENTOS}

O quinto exemplo consiste num pórtico assimétrico constituído por dois pavimentos apoiados em três pilares rotulados na base e submetido apenas a forças verticais distribuídas nas vigas, apresentado na Figura 4.5.

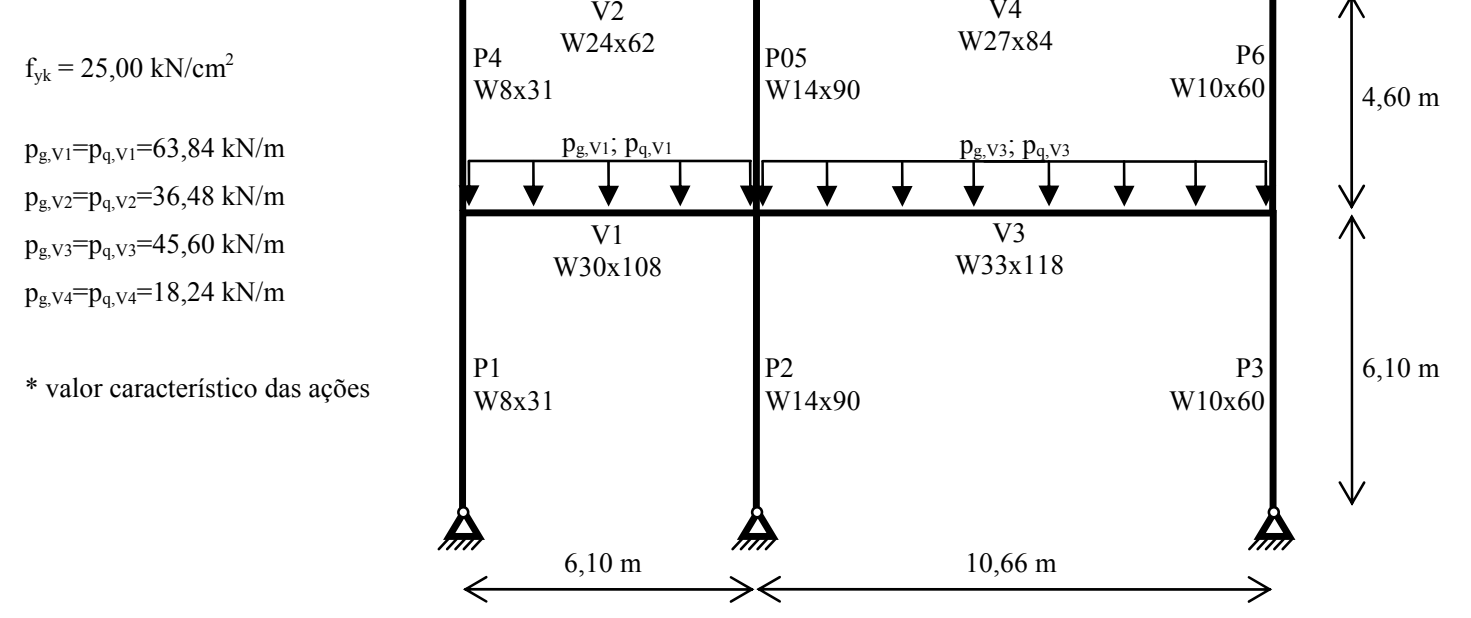

Figura 4.5 - Pórtico assimétrico com dois pavimentos (ASCE, 1997).

O exemplo será estudado para a combinação de ações em que só atuam forças gravitacionais, cujos coeficientes de ponderação são os mesmos aplicados no exemplo 2 (Tabela 4.2).

Avaliando-se os deslocamentos do topo da estrutura para a referida combinação de ações e considerando-se as forças horizontais fictícias atuando da direita para a esquerda (é a situação mais desfavorável), obtém-se a razão $\mathbf{u}_{2} / \mathrm{u}_{1}$ igual a 1,55. Portanto, as imperfeições geométricas globais e materiais devem ser consideradas.

A Tabela 4.8 apresenta os valores do coeficiente de flambagem para os pilares do exemplo 5. O parâmetro G referente à base dos pilares do térreo foi considerado tendendo a infinito (10.000). 
Tabela 4.8 - Coeficiente de flambagem K e esbeltez $(\lambda)$ dos pilares.

\begin{tabular}{lcccccc}
\hline Pilar & P1 & P2 & P3 & P4 & P5 & P6 \\
\hline K & 2,04 & 2,18 & 2,14 & 1,04 & 1,20 & 1,14 \\
$\lambda^{(\text {a) }}$ & 140,65 & 85,16 & 116,84 & 54,13 & 35,06 & 46,81 \\
\hline \multicolumn{7}{l}{ (a) } \\
A esbeltez foi avaliada com base no comprimento efetivo (KL) do pilar. \\
\hline
\end{tabular}

Devido à falta de simetria da estrutura, os procedimentos de avaliação dos efeitos das imperfeições geométricas globais devem ser aplicados duas vezes, considerando-se um desaprumo para a esquerda e outro para a direita. Assim, as forças horizontais fictícias devem ser aplicadas nos dois sentidos, bem como a análise avançada deve contemplar um modelo para cada configuração imperfeita. Os valores da força horizontal fictícia em cada pavimento são apresentados na Tabela 4.9.

Tabela 4.9 - Intensidade da força horizontal fictícia $(\mathrm{kN})$.

\begin{tabular}{lccccccccc}
\hline Análise & & 0 & 1 & 2 & 3 & 4 & 5 & 6 & 7 \\
\hline$\xi$ & 0,000 & 0,000 & 0,005 & 0,003 & 0,002 & 0,0042 & 0,003 & 0,000 \\
$\xi(\Sigma \mathrm{P})$ & $1^{\mathrm{o}}$ pav. & 0,00 & 0,00 & 12,27 & 7,34 & 4,89 & 10,28 & 7,34 & 0,00 \\
& $2^{\circ}$ pav. & 0,00 & 0,00 & 5,83 & 3,51 & 2,38 & 4,89 & 3,51 & 0,00 \\
\hline
\end{tabular}

Deste modo, obtêm-se os resultados apresentados na Tabela 4.10 e Figura 4.6 correspondentes à situação mais desfavorável para cada pilar.

Tabela 4.10 - Resultado da expressão de interação dos pilares.

\begin{tabular}{ccccccccc}
\hline Pilar & Análise 0 & Análise 1 & Análise 2 & Análise 3 & Análise 4 & Análise 5 & Análise 6 & Análise 7 \\
\hline P1 & 1,499 & 1,489 & 0,795 & 0,757 & 1,544 & 0,707 & 0,630 & 0,566 \\
P2 & 1,014 & 1,009 & 0,941 & 0,891 & 1,082 & 0,827 & 0,704 & 0,795 \\
P3 & 1,015 & 0,997 & 0,802 & 0,757 & 1,052 & 0,720 & 0,771 & 0,660 \\
P4 & 0,495 & 0,494 & 0,515 & 0,508 & 0,503 & 0,398 & 0,427 & 0,422 \\
P5 & 0,388 & 0,390 & 0,390 & 0,389 & 0,391 & 0,350 & 0,402 & 0,395 \\
P6 & 0,735 & 0,736 & 0,752 & 0,746 & 0,742 & 0,781 & 0,742 & 0,747 \\
\hline
\end{tabular}

Os resultados das análises que foram realizadas de acordo com o método do comprimento efetivo de flambagem apresentam um desvio elevado para o pilar P1. Para descobrir uma possível causa desse desvio tão acentuado, basta investigar as simplificações 
admitidas para a obtenção do coeficiente de flambagem $\mathrm{K}$ segundo o diagrama de alinhamento.

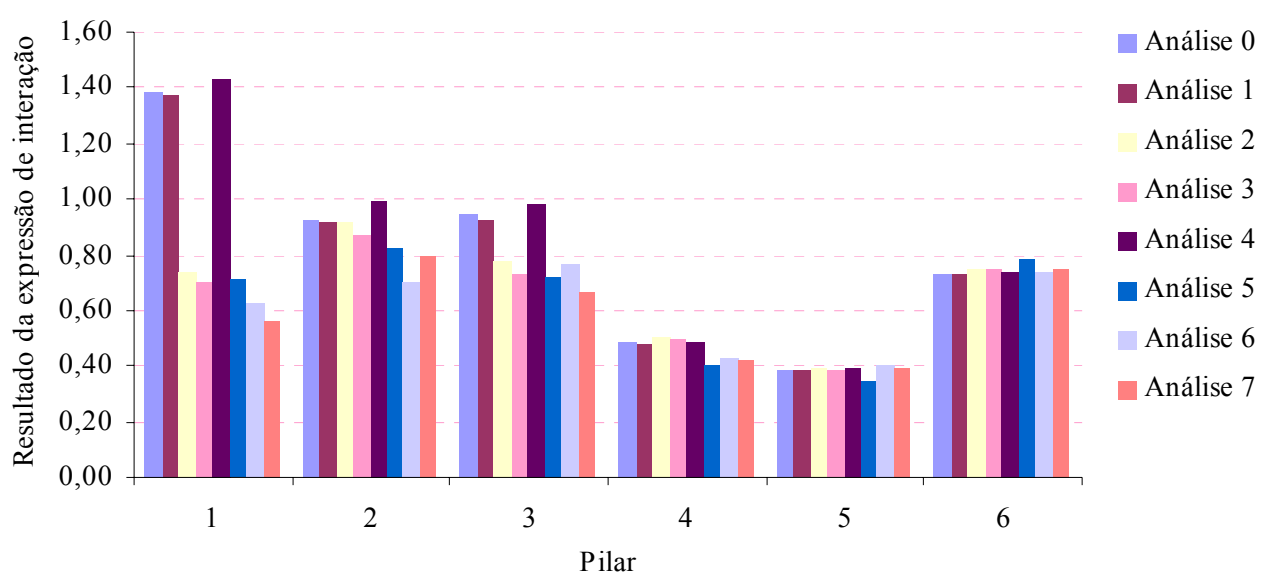

Figura 4.6 - Resultado da expressão de interação para os pilares do exemplo 2.

A principal violação das condições impostas à solução do problema está no parâmetro $\mathrm{L} \sqrt{\mathrm{N}_{\mathrm{Sd}} /(\mathrm{EI})}$. Esse parâmetro é admitido constante em todos os pilares do pavimento. Entretanto, para o caso em tela, obtêm-se valores iguais a 0,99 e 1,03 para os pilares P2 e P3 e 1,57 para o pilar P1. No segundo pavimento essa diferença também é verificada, obtendo-se valores próximos a 0,41, para os pilares $\mathrm{P} 5$ e P6, e igual a 0,74 para o pilar P4.

De fato, conforme discutido pela ASCE (1997), quando as hipóteses admitidas para a utilização do diagrama de alinhamento não são atendidas os erros podem ser elevados. Entretanto, tem-se observado o uso indiscriminado do diagrama de alinhamento como prática freqüente em projetos.

Verifica-se que os métodos da análise direta e das forças horizontais fictícias, apesar de fornecerem resultados mais próximos da análise numérica avançada, ainda apresentam desvios relativos elevados para os pilares P1, P3 e P4. Isso acontece principalmente porque a força normal resistente sofre reduções mais significativas nessas barras. 
Associados à alteração da força normal resistente estão os desvios provocados pela avaliação dos esforços internos, em destaque os momentos fletores. Isso é evidente para os pilares do primeiro pavimento (Figura 4.7). No segundo pavimento essa variação foi tolerável. Portanto, para o pilar P4 o desvio é atribuído à força normal resistente. Note-se que o método da análise direta fornece resultados bem próximos da análise numérica avançada.

A variação apresentada pelas análises 0,1 e 2 é bem mais pronunciada em relação àquela avaliada para a expressão de interação. Isso acontece porque o momento fletor e a força normal resistentes também mudam entre os métodos, reduzindo o desvio no dimensionamento do pilar. Quando normalizados em relação ao respectivo esforço de plastificação da seção, as discrepâncias são evidentes e serão refletidas no dimensionamento das ligações.
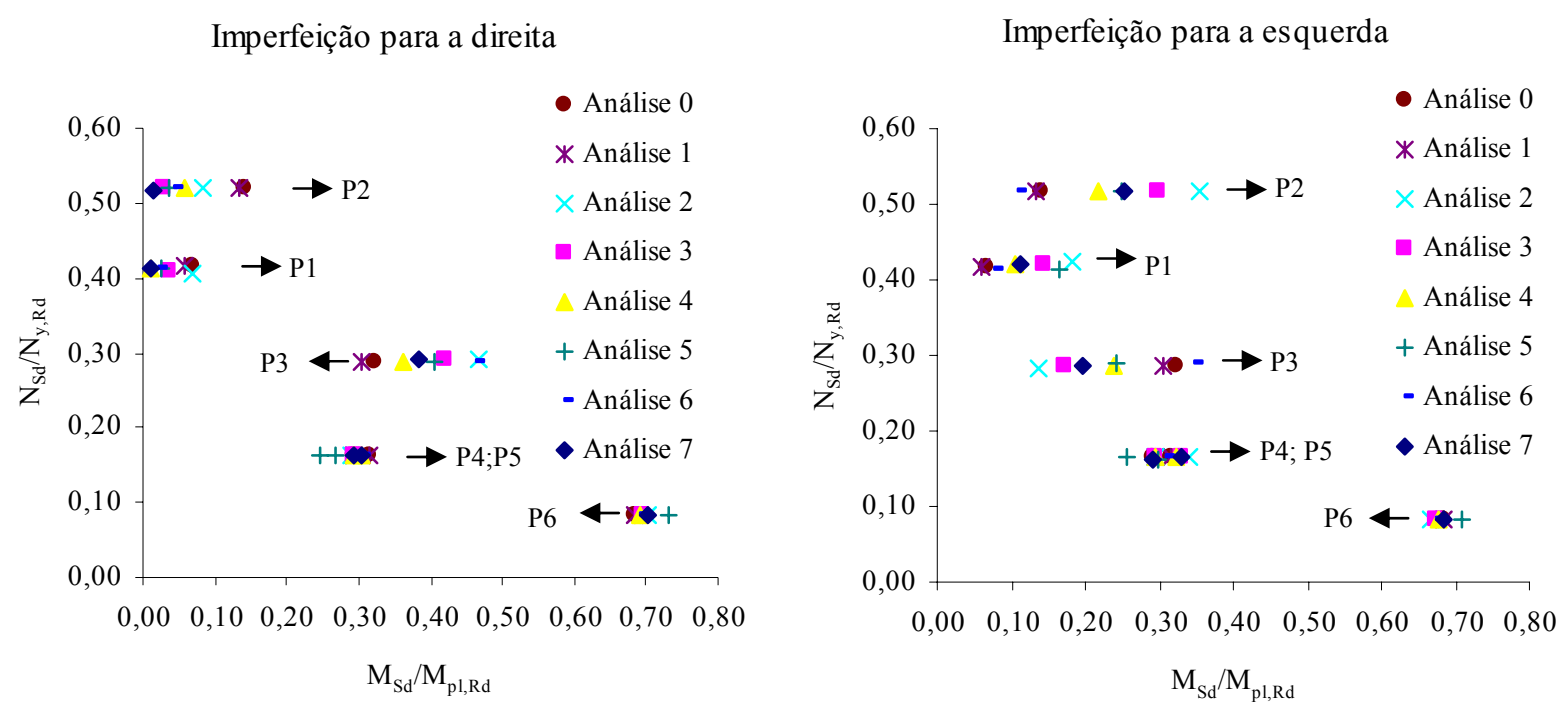

Figura 4.7 - Esforços internos máximos nos pilares.

Percebe-se que a força normal solicitante não sofre alteração significativa devido à aplicação das forças horizontais fictícias, o que fica ilustrado na Figura 4.7 pela dispersão praticamente horizontal dos resultados em cada pilar.

Os procedimentos apresentados pela ASCE (1997) para o método refinado das forças horizontais fictícias foram efetuados para esse exemplo, obtendo-se frações da força vertical 
de cálculo total $(\xi)$ iguais a $0,45 \%$ e $0,19 \%$ a serem aplicadas no primeiro pavimento com sentido para a direita e esquerda, respectivamente. Para o segundo pavimento, obtiveram-se intensidades nulas em ambos os sentidos de aplicação da força horizontal fictícia $\left(\mathrm{k}_{\mathrm{s}}=0,00\right)$.

O segundo pavimento da estrutura desloca-se pouco em relação ao primeiro. Por isso, o efeito das imperfeições geométricas iniciais é pequeno e a influência desse efeito é avaliada pelo método refinado. Esse método é mais trabalhoso, porém mais racional, pois a fração $\xi$ pode variar entre os pavimentos.

A Tabela 4.11 apresenta os desvios dos métodos simplificados em relação à análise numérica avançada. Observa-se uma redução significativa do desvio relativo quando o método refinado é empregado em comparação com os demais métodos simplificados. A redução dos coeficientes de força horizontal reduziu o desvio para menos da metade daqueles encontrados pelo método simplificado das forças horizontais fictícias (análise 2).

Tabela 4.11 - Desvios (\%) para os métodos simplificados, considerando todos os pilares.

\begin{tabular}{lcccccccc}
\hline Análise & 0 & 1 & 2 & 3 & 4 & 5 & 6 & refinado \\
\hline Desvio mínimo $^{(a)}$ & $-2,25$ & $-1,84$ & $-1,68$ & $-1,87$ & $-1,56$ & $-11,37$ & $-11,54$ & $-2,80$ \\
Desvio médio $^{(a)}$ & 37,25 & 36,46 & 13,73 & 9,98 & 41,52 & 4,26 & 3,17 & 5,81 \\
Desvio máximo $^{(a)}$ & 147,64 & 145,95 & 30,86 & 24,29 & 155,46 & 25,00 & 16,83 & 14,49 \\
\hline
\end{tabular}

(a) O sinal negativo indica que o resultado da expressão de interação é menor que o obtido pela análise avançada, portanto contra a segurança.

Foram analisados os momentos fletores e forças cortantes atuantes nas ligações vigapilar para discutir a influência das forças horizontais fictícias na avaliação desses esforços internos solicitantes. A análise 1 foi adotada como referência porque não utiliza forças horizontais. Os resultados obtidos são apresentados graficamente na Figura 4.8. 

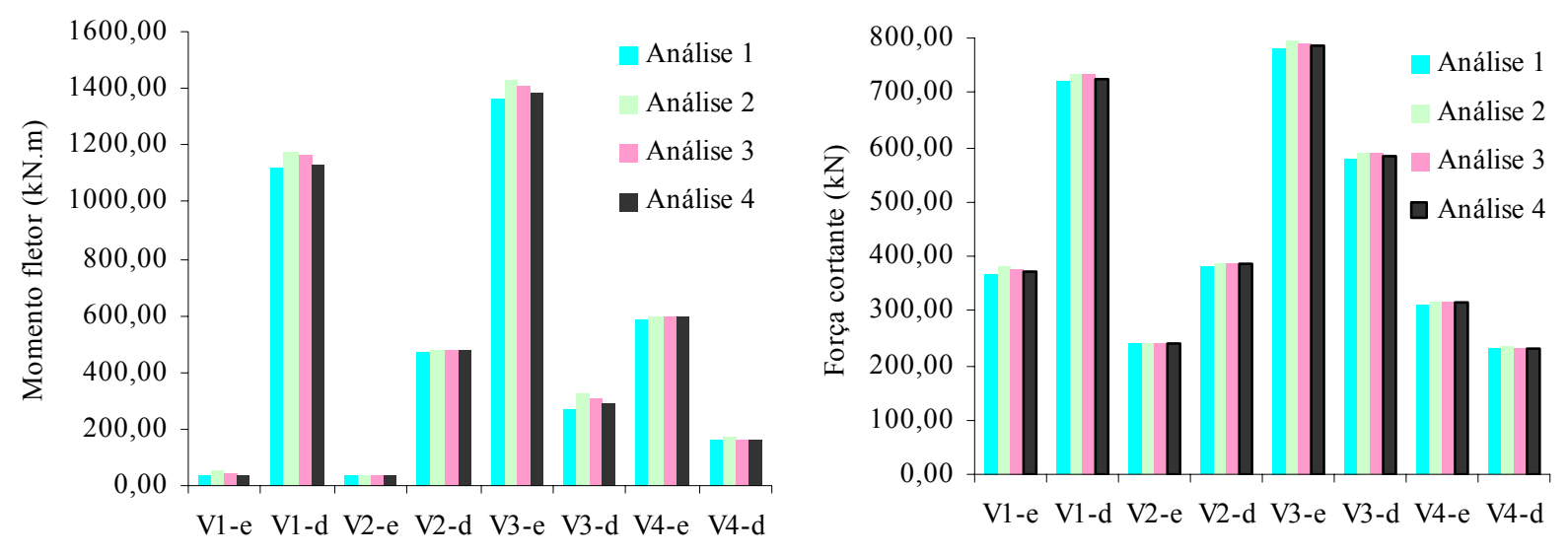

Figura 4.8 - Esforços internos nas extremidades das vigas.

Note-se que não há variação significativa entre os momentos fletores e forças cortantes. Os desvios encontrados em relação à análise 1 são pequenos (Tabela 4.12), à exceção do momento fletor na extremidade esquerda da viga V1, que é muito baixo, portanto a variação não é muito importante.

Tabela 4.12 - Desvio (\%) em relação à análise 1 na avaliação dos momentos fletores e forças cortantes.

\begin{tabular}{clcccccc}
\hline & & \multicolumn{2}{c}{ Análise 2} & \multicolumn{2}{c}{ Análise 3 } & \multicolumn{2}{c}{ Análise 4 } \\
\cline { 2 - 7 } Viga & Extremidade & $\mathrm{M}_{\mathrm{Sd}}$ & $\mathrm{V}_{\mathrm{Sd}}$ & $\mathrm{M}_{\mathrm{Sd}}$ & $\mathrm{V}_{\mathrm{Sd}}$ & $\mathrm{M}_{\mathrm{Sd}}$ & $\mathrm{V}_{\mathrm{Sd}}$ \\
\hline \multirow{2}{*}{$\mathrm{V} 1$} & Esquerda & 49,64 & 3,49 & 34,13 & 2,51 & 15,89 & 1,04 \\
& Direita & 5,47 & 1,78 & 4,07 & 1,32 & 1,07 & 0,36 \\
\multirow{2}{*}{ V2 } & Esquerda & 7,87 & 0,47 & 5,27 & 0,32 & 2,78 & 0,14 \\
& Direita & 0,84 & 0,29 & 0,51 & 0,19 & 0,39 & 0,11 \\
V3 & Esquerda & 4,91 & 1,41 & 3,64 & 1,07 & 1,16 & 0,28 \\
& Direita & 18,37 & 1,89 & 12,85 & 1,35 & 6,46 & 0,55 \\
\multirow{2}{*}{ V4 } & Esquerda & 1,08 & 0,37 & 0,71 & 0,24 & 0,31 & 0,12 \\
& Direita & 3,66 & 0,50 & 2,43 & 0,32 & 1,15 & 0,18 \\
\hline
\end{tabular}

Todos os desvios são a favor da segurança.

Os esforços internos analisados nas vigas têm como principal causa as forças distribuídas de peso próprio e sobrecarga. As forças horizontais fictícias exercem pouca influência nesses esforços. Apenas quando a intensidade dos momentos fletores é baixa é que se percebe alguma perturbação significativa devido às forças horizontais. 


\subsection{EXEMPLO 6 - PÓRTICO IRREGULAR E ASSIMÉTRICO}

Admita-se o pórtico irregular e assimétrico apresentado na Figura 4.9 submetido a forças gravitacionais e à ação do vento. Nesse exemplo adotou-se $\gamma_{\mathrm{f} 2}$ igual a 0,7 para a sobrecarga de utilização.

Devido à assimetria geométrica, a força de vento foi considerada nos dois sentidos. Os resultados são apresentados para a situação mais desfavorável em cada pilar.

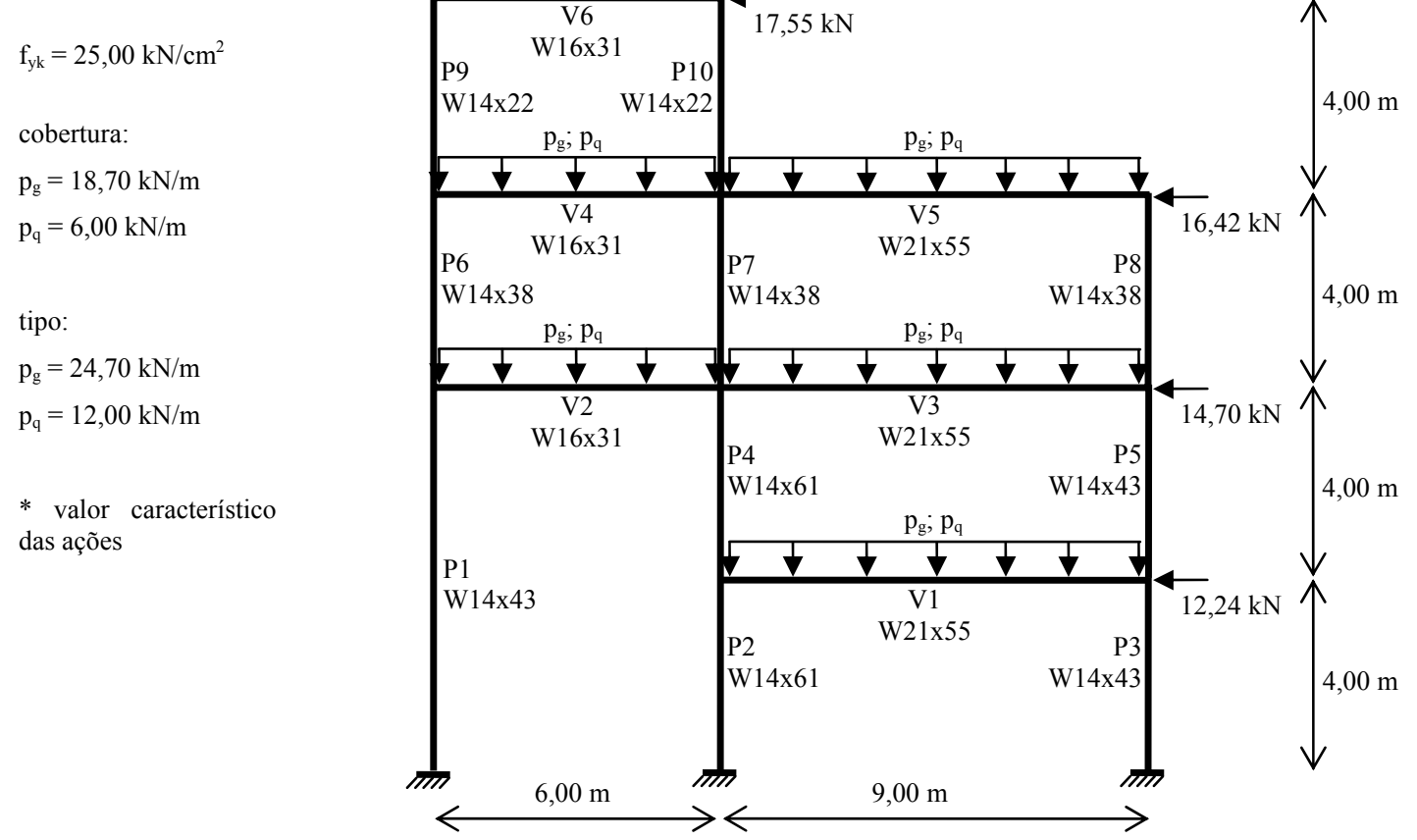

Figura 4.9 - Pórtico irregular e assimétrico com cinco pavimentos.

A Tabela 4.13 apresenta os valores de alguns parâmetros necessários para classificação da estrutura quanto à deslocabilidade. 
Tabela 4.13 - Parâmetros necessários para classificação quanto à deslocabilidade.

\begin{tabular}{|c|c|c|c|c|c|c|}
\hline Comb. & pav. & $\mathrm{B}_{2}$ & $\mathrm{u}_{1}(\mathrm{~cm})$ & $\mathrm{u}_{2}(\mathrm{~cm})$ & $\mathrm{u}_{2} / \mathrm{u}_{1}$ & $\mathrm{M}_{2} / \mathrm{M}_{\mathrm{i}}^{(\mathrm{a})}$ \\
\hline \multirow{5}{*}{$1,4 \mathrm{~g}+1,4 \mathrm{q}+\mathrm{FHF}(\xi=0,002)$} & 1 & 1,057 & 0,072 & 0,076 & 1,063 & \multirow{4}{*}{1,005} \\
\hline & 2 & $0,959^{(\mathrm{b})}$ & 0,042 & 0,046 & 1,098 & \\
\hline & 3 & 1,000 & 0,010 & 0,016 & 1,550 & \\
\hline & 4 & 1,047 & 0,380 & 0,400 & 1,053 & \\
\hline & 5 & 1,084 & 0,500 & 0,530 & 1,060 & 1,000 \\
\hline \multirow{5}{*}{$\begin{array}{c}1,4 \mathrm{~g}+1,4 \mathrm{v}+1,5(0,7 \mathrm{q})+\mathrm{FHF} \\
(\xi=0,002)\end{array}$} & 1 & 1,074 & 0,940 & 1,000 & 1,064 & \multirow[t]{5}{*}{1,044} \\
\hline & 2 & 1,087 & 2,200 & 2,330 & 1,059 & \\
\hline & 3 & 1,057 & 3,230 & 3,420 & 1,059 & \\
\hline & 4 & 1,063 & 4,130 & 4,350 & 1,053 & \\
\hline & 5 & 1,042 & 4,690 & 4,930 & 1,051 & \\
\hline
\end{tabular}

(a) Máxima razão entre o momento fletor de segunda ordem pelo de primeira ordem para os pilares do pavimento.

(b) $\mathrm{B}_{2}<1,0$ significa que os deslocamentos do pavimento apresentaram sentido oposto ao da força horizontal.

Observa-se que a máxima razão $\mathrm{u}_{2} / \mathrm{u}_{1}$ resultou maior que 1,50 para a combinação de ações gravitacionais. Portanto, de acordo com o Projeto de Revisão da NBR 8800 (set. 2006), a estrutura é de grande deslocabilidade. Entretanto, quando os esforços internos são avaliados por meio de uma análise de segunda ordem, obtêm-se resultados praticamente iguais àqueles obtidos por meio de uma análise de primeira ordem $\left(\right.$ ver $\mathrm{M}_{2} / \mathrm{M}_{1}$ ), ou seja, os efeitos de segunda ordem não são relevantes na análise estrutural.

O contraste entre a classificação quanto à delocabilidade e a influência dos efeitos de segunda ordem observado para a combinação de ações gravitacionais acontece porque os valores absolutos obtidos para os deslocamentos horizontais $\mathrm{u}_{2} \mathrm{e} \mathrm{u}_{1}$ são baixos, de modo que a pequena diferença entre esses deslocamentos resulta em um valor elevado para a razão $\mathrm{u}_{2} / \mathrm{u}_{1}$.

Quando a combinação em que atua força devido ao vento é avaliada, o contraste já não é observado, pois as forças horizontais são suficientes para induzir deslocamentos significativos na estrutura. Essa inconsistência não foi verificada para o parâmetro $\mathrm{B}_{2}$, o qual mostrou-se coerente em ambos os casos de combinação de ações. 
A Tabela 4.14 apresenta os valores do coeficiente de flambagem para os pilares do exemplo 6. O parâmetro $\mathrm{G}$ referente à base dos pilares do térreo foi considerado igual a 1,00, seguindo a recomendação da NBR 8800:1986.

Tabela 4.14 - Coeficiente de flambagem K e esbeltez $(\lambda)$ dos pilares.

\begin{tabular}{lcccccccccccc}
\hline Pilar & P1 & P2 & P3 & P4 & P5 & P6 & P7 & P8 & P9 & P10 & P11 & P12 \\
\hline K & 1,62 & 1,64 & 1,64 & 1,81 & 1,94 & 1,98 & 1,50 & 1,40 & 1,84 & 1,54 & 1,39 & 1,39 \\
$\lambda^{(\text {a) }}$ & 87,80 & 43,17 & 44,29 & 47,71 & 52,52 & 53,10 & 40,42 & 37,66 & 52,20 & 43,91 & 39,63 & 39,63 \\
\hline
\end{tabular}

(a) A esbeltez foi avaliada com base no comprimento efetivo (KL) do pilar.

Os valores da força horizontal fictícia aplicada em cada pavimento são apresentados na Tabela 4.15.

Tabela 4.15 - Intensidade da força horizontal fictícia $(\mathrm{kN})$.

\begin{tabular}{|c|c|c|c|c|c|c|c|c|c|c|}
\hline \multicolumn{2}{|c|}{ Análise } & \multirow{2}{*}{$\frac{0}{0,000}$} & \multirow{2}{*}{$\frac{1}{0,000}$} & \multirow{2}{*}{$\frac{2}{0,005}$} & \multirow{2}{*}{$\frac{3}{0,003}$} & \multirow{2}{*}{$\frac{4}{0,002}$} & \multicolumn{2}{|c|}{5} & \multirow{2}{*}{$\frac{6}{0,003}$} & \multirow{2}{*}{$\begin{array}{c}7 \\
0,000\end{array}$} \\
\hline$\xi$ & & & & & & & var. ${ }^{\text {(a) }}$ & var. ${ }^{(b)}$ & & \\
\hline & $1^{\circ}$ pav. & 0,00 & 0,00 & 2,09 & 1,25 & 0,83 & 2,39 & 1,97 & 1,25 & 0,00 \\
\hline & $2^{\circ}$ pav & 0,00 & 0,00 & 3,48 & 2,09 & 1,39 & 4,85 & 4,38 & 2,09 & 0,00 \\
\hline \multirow[t]{3}{*}{$\xi(\Sigma \mathrm{P})$} & $3^{\circ}$ pav & 0,00 & 0,00 & 2,83 & 1,70 & 1,13 & 2,92 & 2,97 & 1,70 & 0,00 \\
\hline & $4^{\circ}$ pav & 0,00 & 0,00 & 1,39 & 0,83 & 0,56 & 2,51 & 1,24 & 0,83 & 0,00 \\
\hline & $5^{\circ}$ pav & 0,00 & 0,00 & 1,35 & 0,81 & 0,54 & 1,14 & 1,14 & 0,81 & 0,00 \\
\hline
\end{tabular}

De acordo com os resultados ilustrados na Figura 4.10 a resposta dos métodos aproximados foi mais próxima daquela obtida pela análise numérica avançada, quando comparada aos exemplos 2 e 5. Os desvios mais acentuados foram detectados para os pilares P1 e P10. No primeiro caso, provocado principalmente pela diferença na avaliação da força normal resistente e no segundo caso, pela diferença no momento fletor solicitante. 


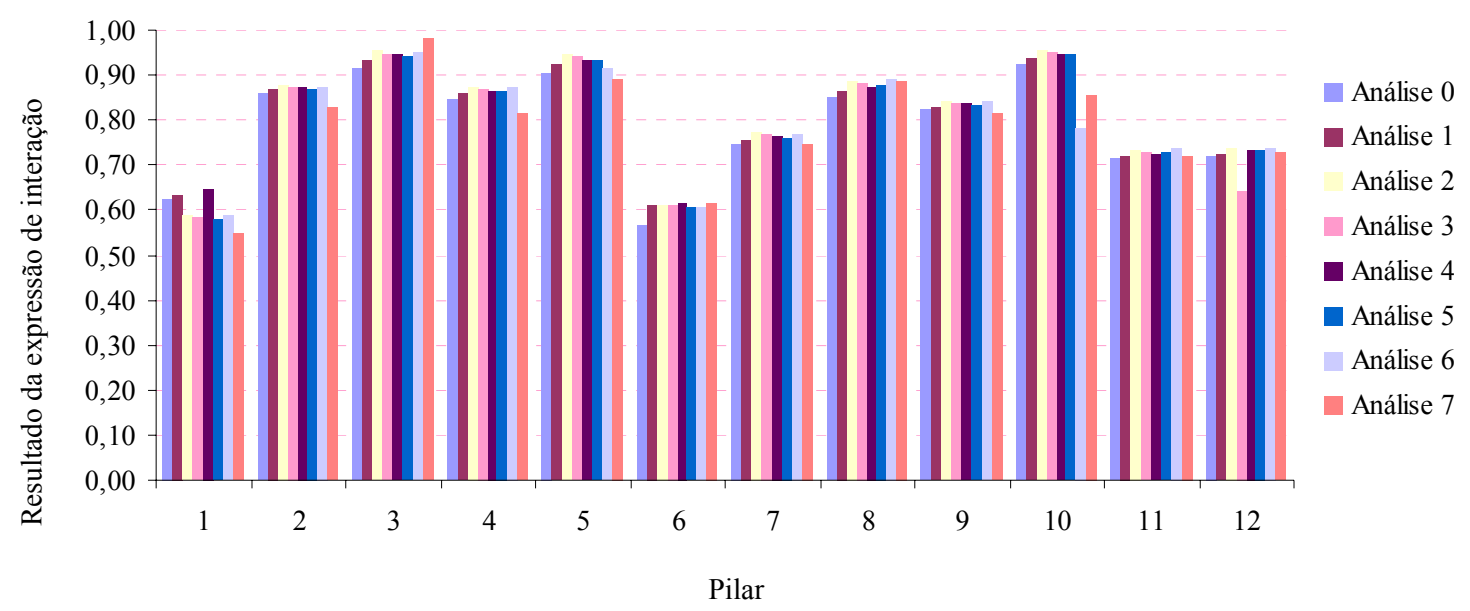

Figura 4.10 - Expressão de interação para os pilares do exemplo 6.

Comparando-se os resultados das análises 0 e 1 percebe-se que os efeitos de segunda ordem exercem pouca influência nessa estrutura $\left(\mathrm{B}_{2}<1,10\right)$ devido à baixa relação altura/largura.

A análise numérica avançada também foi aplicada para estudar a influência dos efeitos desestabilizantes no comportamento da estrutura. Foram estudadas três situações para esse mesmo exemplo, considerando apenas as imperfeições locais, apenas as globais e com a estrutura perfeita. Em cada caso, manteve-se a análise geométrica e fisicamente não-linear.

Observou-se que as imperfeições geométricas, locais e globais, exercem pouca influência nos resultados da análise. Os momentos fletores nos pilares obtidos quando consideradas apenas as imperfeições locais ou apenas as globais apresentaram desvios inferiores a 5\% em relação aos momentos obtidos com a estrutura perfeita.

Em outra simulação, foram compararados os momentos fletores nos pilares obtidos pela análise numérica avançada considerando-se imperfeições geométricas locais e globais com a análise admitindo-se a estrutura perfeita. A alteração nos momentos fletores dos pilares manteve-se inferior a $5 \%$.

A proximidade dos métodos se explica pela baixa relação altura/largura do pórtico e baixa esbeltez dos pilares, que reduzem a influência das imperfeições globais e locais na 
avaliação dos esforços solicitantes e resistentes, respectivamente, além dos efeitos de segunda ordem. Nesse exemplo, a análise estrutural poderia ser feita considerando-se $\mathrm{K}=1,00$ e desprezando-se a redução da rigidez, as forças horizontais fictícias e os efeitos de segunda ordem.

De forma geral os métodos simplificados apresentaram valores a favor da segurança. A Tabela 4.16 apresenta um resumo dos desvios médio, mínimo e máximo em relação à análise numérica avançada.

Tabela 4.16 - Desvios (\%) para os métodos simplificados considerando todos os pilares.

\begin{tabular}{|c|c|c|c|c|c|c|c|}
\hline Análise & 0 & 1 & 2 & 3 & 4 & 5 & 6 \\
\hline Desvio mínimo $^{(a)}$ & $-6,11$ & $-3,76$ & $-2,67$ & $-11,60$ & $-2,56$ & $-3,85$ & $-8,48$ \\
\hline Desvio médio $^{(a)}$ & 2,60 & 4,47 & 3,86 & 2,09 & 5,51 & 2,65 & 1,77 \\
\hline Desvio máximo $^{(a)}$ & 19,66 & 21,83 & 11,83 & 11,18 & 23,76 & 10,77 & 7,56 \\
\hline
\end{tabular}

Observa-se uma redução acentuada dos desvios máximos e médios obtidos pelos métodos que empregam forças horizontais fictícias (análises 2 3, por exemplo) em relação àqueles que empregam o comprimento efetivo de flambagem (análises 1 e 4).

Foram analisados os momentos fletores e forças cortantes nas ligações viga-pilar e nas emendas dos pilares. Os valores obtidos pela análise sem e com forças horizontais fictícias (análises 1, 2 e 3) foram comparados e apresentaram desvios máximos inferiores a 5\%. Apenas na base dos pilares do térreo foram encontrados desvios um pouco maiores, entre 5\% e 10\%. Esses resultados sugerem que a introdução das forças horizontais fictícias não modifica o dimensionamento das ligações de forma significativa. 


\subsection{EXEMPLO 7 - EDIFÍCIO COM 15 PAVIMENTOS}

Esse exemplo consiste em um edifício com 20 pavimentos cuja planta é apresentada na Figura 4.11. O sistema resistente às ações horizontais na direção "y" é constituído pelos dois pórticos extremos, cujas ligações viga-pilar são rígidas. As vigas dos pórticos internos possuem extremidades rotuladas e a inércia à flexão dos pilares contidos nesses pórticos foi desprezada.

Serão discutidas as considerações necessárias para avaliar os efeitos de segunda ordem nos pórticos que constituem o sistema de contraventamento na direção y empregandose uma análise plana. Além disso, por se tratar de uma estrutura regular e que possui um número razoável de pavimentos, será apresentada uma comparação entre os parâmetros $\gamma_{\mathrm{z}} \mathrm{e}$ $\mathrm{B}_{2}$, empregados na classificação quanto à deslocabilidade.

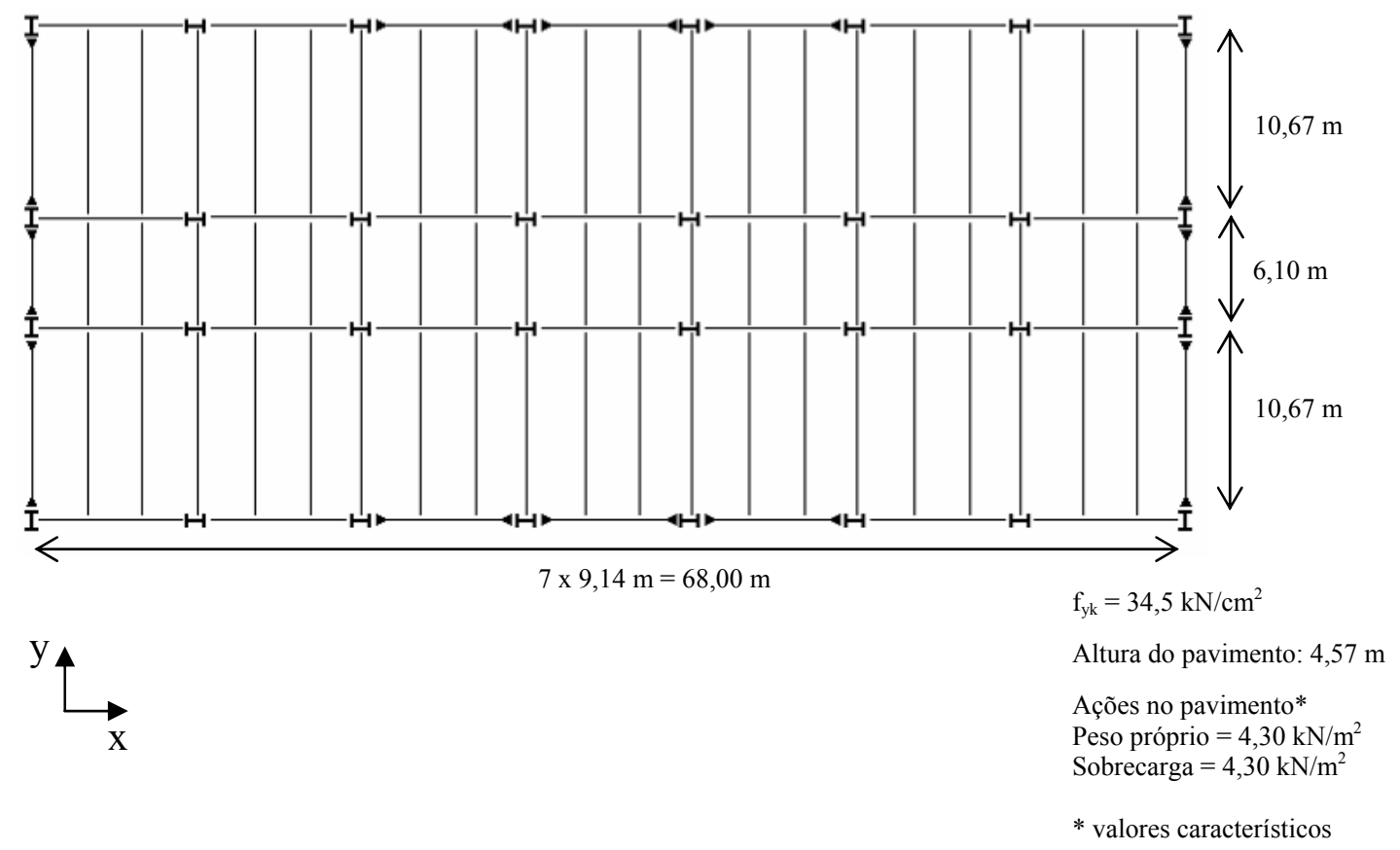

Figura 4.11 - Planta do pavimento (Adaptação de Englekirk, 1994).

Os valores característicos da força de vento na direção "y" que atua em cada pórtico e os perfis empregados na análise são apresentados na Figura 4.12. 


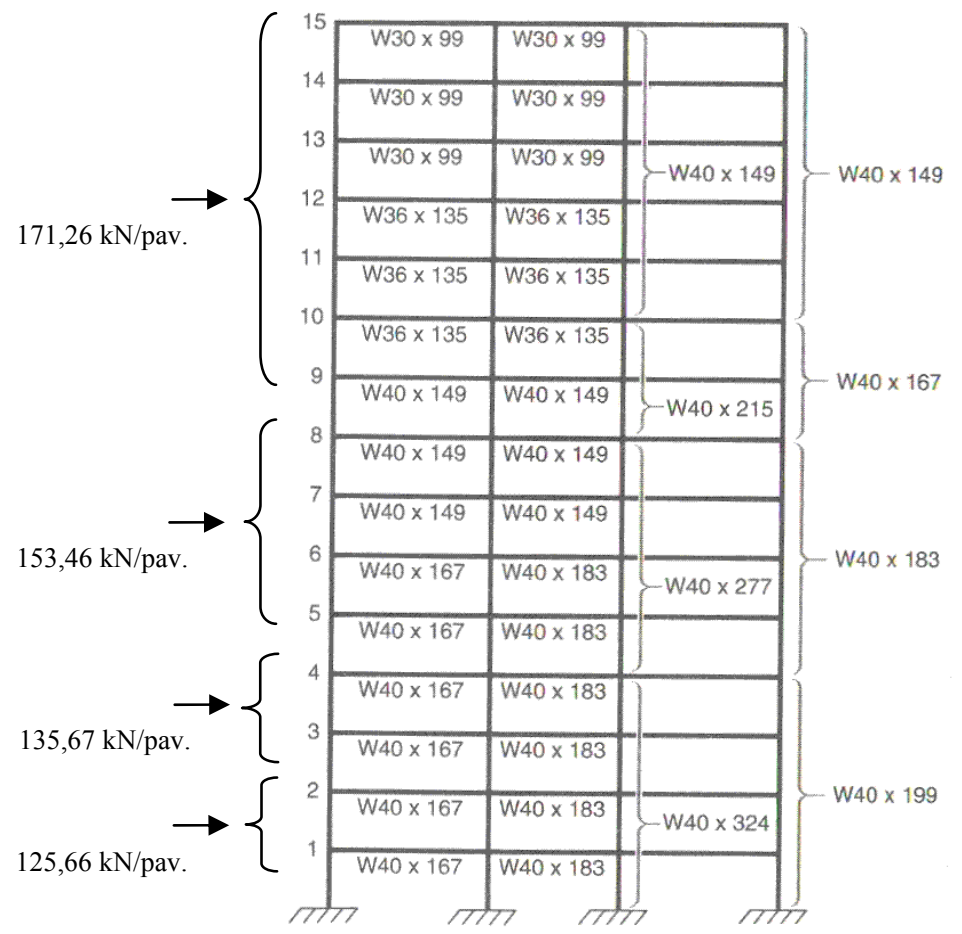

Figura 4.12 - Ação do vento e perfis dos pórticos de extremidade (ENGLEKIRK, 1994).

Para obter os deslocamentos de segunda ordem do sistema de contraventamento é preciso considerar todo o efeito de segunda ordem das ações verticais que atuam no pavimento. Os pilares contraventados resistem apenas às ações verticais e a parcela de ação horizontal proveniente do efeito P- $\Delta$ é resistida pelo sistema de contraventamento.

Uma alternativa para capturar esses efeitos de segunda ordem na análise plana, é criar uma prumada de pilares contraventados adjacentes ao sistema de contraventamento, com extremidades rotuladas e conectados por barras horizontais também rotuladas nas duas extremidades (Figura 4.13).

Essa prumada de pilares contraventados recebe a força vertical do pavimento $\left(\mathrm{P}_{\mathrm{i}}\right)$ que é resistida pelos pilares que não pertencem ao sistema de contraventamento. Assim, o efeito de segunda ordem (P- $\Delta$ ) é induzido na estrutura de contraventamento sem alterar a rigidez da mesma, uma vez que esses pilares adjacentes são rotulados. 


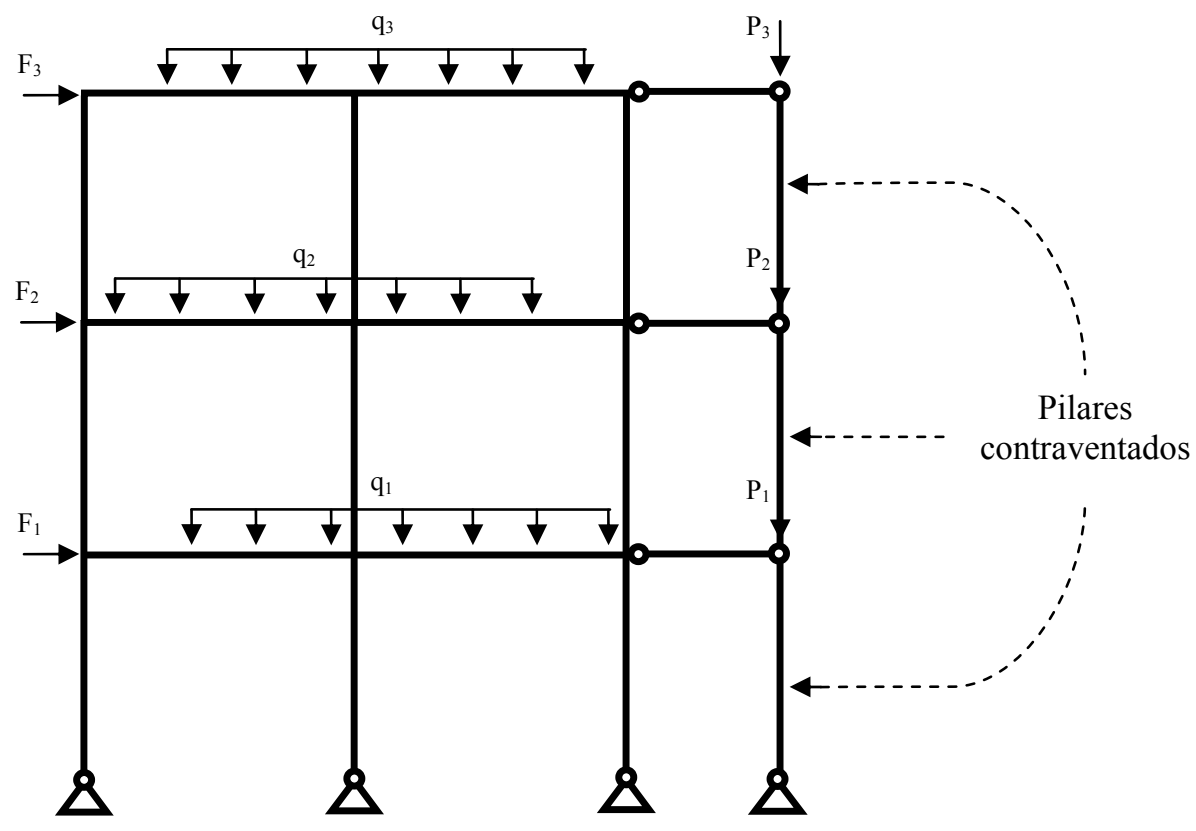

Figura 4.13 - Modelo de pórtico plano para análise do sistema de contraventamento sugerido por Corrêa, 2006 (informação pessoal).

Avaliando-se a disposição dos pilares do exemplo 7 (Figura 4.11), observa-se que metade dos pilares contraventados contribui para cada sistema de contraventamento. Portanto, a força $\mathrm{P}_{\mathrm{i}}$ aplicada em cada nível é dada pela metade da soma das forças verticais resistidas pelos pilares contraventados. Além disso, são aplicadas as forças horizontais de vento $\left(F_{i}\right)$ e as forças verticais provenientes das reações das lajes nas vigas $\left(\mathrm{q}_{\mathrm{i}}\right)$ do sistema de contraventamento.

Para representar bem o conjunto de pilares contraventados, ainda é preciso definir uma área equivalente para os pilares da prumada adjacente, neste caso, dada pela metade da soma das áreas dos pilares não-contidos no sistema de contraventamento. Esse procedimento é necessário, pois em análises com não-linearidade geométrica, a matriz de rigidez depende da

\footnotetext{
${ }^{6}$ Informação fornecida por Márcio Roberto Silva Corrêa em São Carlos, em 2006.
} 
força normal em cada elemento. Portanto, a rigidez axial deve ser compatível com a força normal aplicada.

Foram estudadas três situações de análise estrutural: (i) análise plana do sistema de contraventamento sem considerar o efeito das forças verticais resistida pelos pilares que não pertencem ao sistema de contraventamento; (ii) análise plana do sistema de contraventamento com os pilares adjacentes contraventados sob a ação do quinhão de força vertical do pavimento (Figura 4.13); e (iii) análise tridimensional. A comparação entre a configuração deformada obtida em cada situação é apresentada na Figura 4.14.
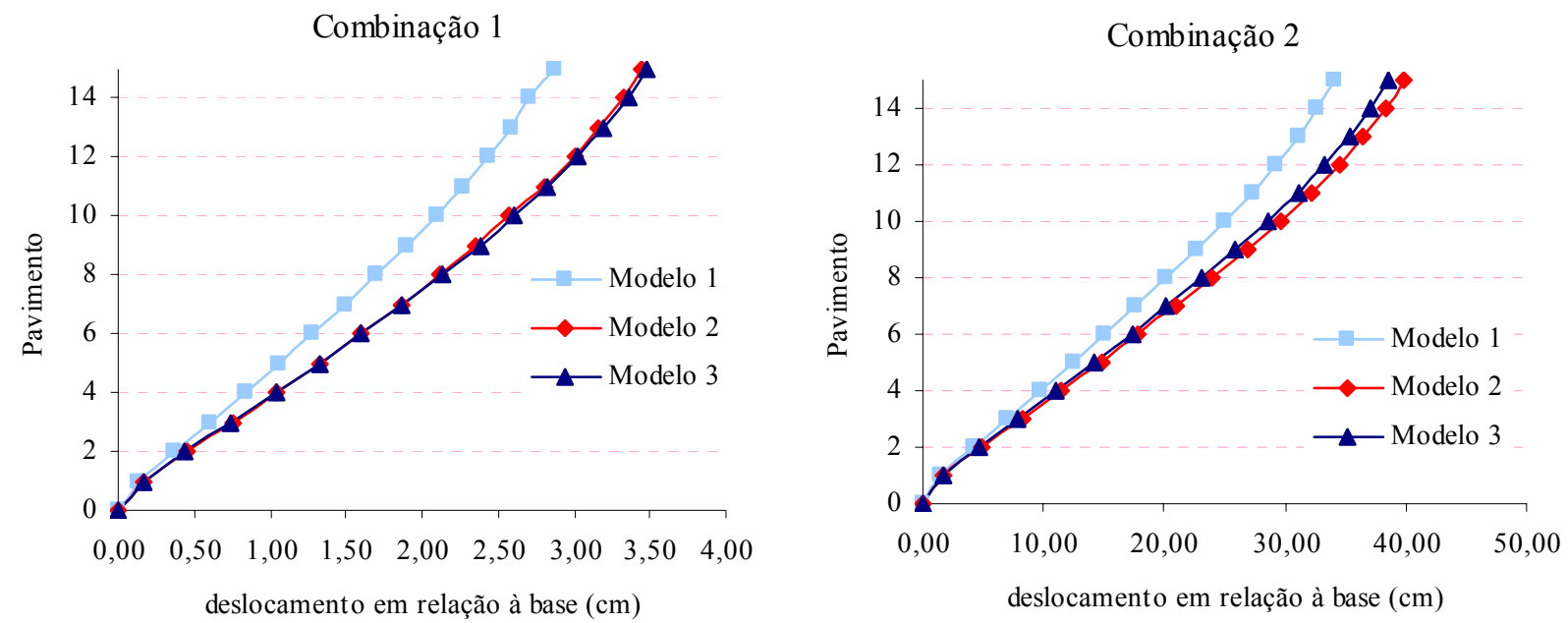

Combinação $1: 1,4 \mathrm{~g}+1,4 \mathrm{q}+\mathrm{FHF}(\xi=0,002)$

Combinação 2: $1,4 \mathrm{~g}+1,4 \mathrm{v}+1,5(0,5 \mathrm{q})+\mathrm{FHF}(\xi=0,002)$

Modelo 1: Pórtico plano sem pilares adjacentes sob ação vertical

Modelo 2: Pórtico plano com pilares adjacentes sob ação vertical

Modelo 3: Pórtico tridimensional

Figura 4.14 - Configuração deformada do edifício.

Tomando-se o modelo 3 como referência, nota-se que o modelo sem pilares adjacentes de fato é inadequado, pois não é capaz de capturar o efeito de segunda ordem induzido pela parcela de força vertical resistida pelos pilares contraventados. O modelo com pilares adjacentes representou bem a estrutura para a combinação de ações gravitacional e 
apresentou desvios inferiores a 1\% para a combinação com ação do vento. Para o modelo 1 , foram encontrados desvios da ordem de $12 \%$ em relação ao modelo 3.

Os parâmetros empregados para a classificação da estrutura avaliados para o Modelo 2 são apresentados na Tabela 4.17. Percebe-se que o parâmetro $\gamma_{z}$ se aproxima bastante do valor médio do parâmetro $\mathrm{B}_{2}$. Para a combinação com vento, os valores desses parâmetros ficam ainda mais próximos porque a variação de $\mathrm{B}_{2}$ é menor, confirmando o resultado apresentado na equação (2.24) que os parâmetros coincidem quando a variação de $\mathrm{B}_{2}$ tende a zero.

Tabela 4.17 - Parâmetros para classificação da estrutura (Modelo 2).

\begin{tabular}{|c|c|c|c|c|c|c|}
\hline \multirow[b]{2}{*}{ Pav. } & \multicolumn{3}{|c|}{ Comb. 1: 1,4g+1,4q+FHF } & \multicolumn{3}{|c|}{ Comb. $2: 1,4 \mathrm{~g}+1,4 \mathrm{v}+1,5(0,5 \mathrm{q})+\mathrm{FHF}$} \\
\hline & $\mathrm{u}_{2} / \mathrm{u}_{1}$ & $\mathrm{~B}_{2}$ & $\gamma_{\mathrm{z}}$ & $\mathrm{u}_{2} / \mathrm{u}_{1}$ & $\mathrm{~B}_{2}$ & $\gamma_{\mathrm{z}}$ \\
\hline 1 & 1,218 & 1,210 & & 1,331 & 1,151 & \\
\hline 2 & 1,264 & 1,390 & & 1,396 & 1,273 & \\
\hline 3 & 1,285 & 1,415 & & 1,426 & 1,289 & \\
\hline 4 & 1,293 & 1,407 & & 1,440 & 1,282 & \\
\hline 5 & 1,304 & 1,397 & & 1,445 & 1,277 & \\
\hline 6 & 1,301 & 1,375 & & 1,445 & 1,261 & \\
\hline 7 & 1,299 & 1,363 & & 1,443 & 1,253 & \\
\hline 8 & 1,299 & 1,349 & 1,27 & 1,439 & 1,244 & 1,19 \\
\hline 9 & 1,293 & 1,335 & & 1,434 & 1,234 & \\
\hline 10 & 1,287 & 1,310 & & 1,429 & 1,218 & \\
\hline 11 & 1,286 & 1,299 & & 1,424 & 1,211 & \\
\hline 12 & 1,284 & 1,257 & & 1,418 & 1,183 & \\
\hline 13 & 1,275 & 1,233 & & 1,412 & 1,166 & \\
\hline 14 & 1,278 & 1,199 & & 1,407 & 1,142 & \\
\hline 15 & 1,275 & 1,146 & & 1,403 & 1,121 & \\
\hline Média & & 1,312 & 1,27 & & 1,220 & 1,19 \\
\hline Desvio padrão & & 0,085 & & & 0,056 & \\
\hline Máximo & 1,304 & 1,415 & & 1,445 & 1,289 & \\
\hline
\end{tabular}

O modelo 2 será empregado para avaliar a resposta dos métodos simplificados e da análise numérica avançada, pois representa bem o modelo tridimensional e mantém o escopo da análise plana deste trabalho. Os resultados do dimensionamento dos pilares mais solicitados são apresentados graficamente na Figura 4.15. 


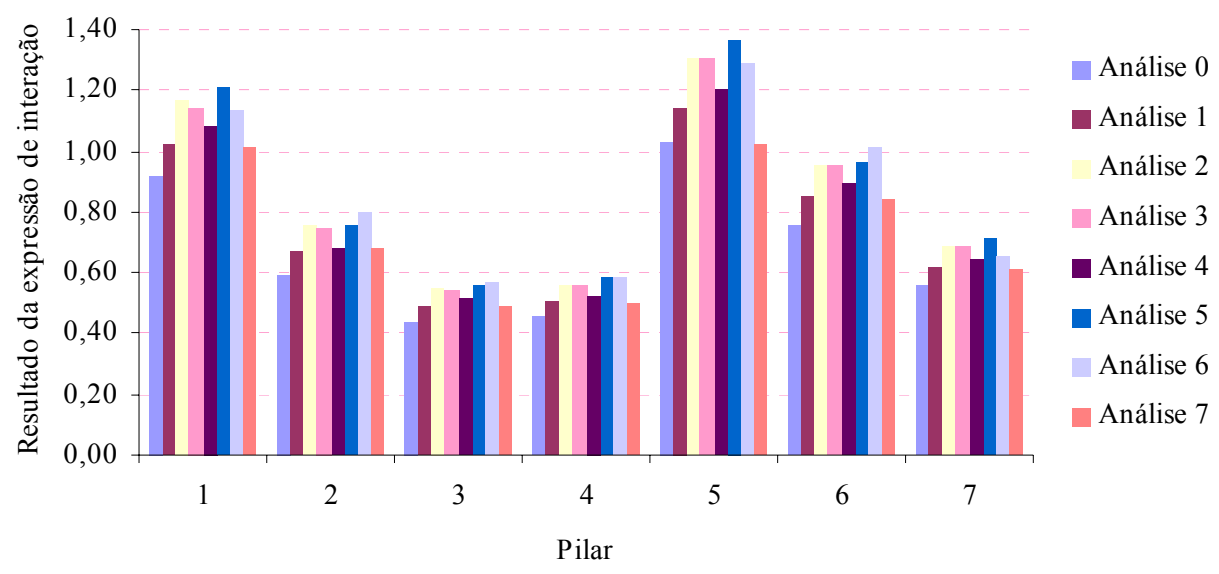

Figura 4.15 - Expressão de interação para os pilares do exemplo 7.

Nesse caso, observou-se que não existe variação da força normal resistente entre as análises simplificadas. Isso acontece porque a esbeltez dos pilares é muito baixa, mesmo quando o comprimento efetivo de flambagem (KL) é considerado. Portanto, a diferença entre os métodos simplificados é proveniente da avaliação da força normal e momento fletor solicitantes de cálculo.

Os métodos simplificados indicam que os pilares 1 e 5 devem ser substituídos, pois a expressão de interação resultou maior que 1,00. Entretanto, quando a análise numérica avançada é empregada (análise 7), verifica-se que a expressão de interação é satisfeita sem folga (igual a 1,00). Isso acontece porque a não-linearidade física limita a capacidade resistente da seção, de modo que o esforço adicional nas barras mais solicitadas seja redistribuído entre as barras menos solicitadas da estrutura.

Os desvios em relação à análise numérica avançada são apresentados na Tabela 4.18. Percebe-se que os métodos que empregam forças horizontais fictícias apresentaram desvios mais conservadores em relação àqueles que empregam o comprimento efetivo de flambagem. Isso acontece porque o edifício em tela é mais esbelto em relação aos exemplos 5 e 6 . Assim, a influência das forças horizontais fictícias no momento de tombamento é maior, refletindo no aumento significativo dos momentos fletores e força normal solicitantes de cálculo. 
Tabela 4.18 - Desvios (\%) para os métodos simplificados.

\begin{tabular}{lccccccc}
\hline Análise & 0 & 1 & 2 & 3 & 4 & 5 & 6 \\
\hline Desvio mínimo $^{(a)}$ & $-8,59$ & 2,04 & 14,74 & 13,99 & 6,61 & 18,03 & 16,32 \\
Desvio médio $^{(a)}$ & $-8,59$ & 2,04 & 14,74 & 13,99 & 6,61 & 18,03 & 16,32 \\
Desvio máximo $^{(a)}$ & 0,67 & 11,54 & 27,28 & 27,28 & 17,84 & 33,41 & 25,64 \\
\hline
\end{tabular}

(a) $\mathrm{O}$ sinal negativo indica que o resultado da expressão de interação é menor que o obtido pela análise avançada, portanto contra a segurança.

Avaliando-se a Figura 4.16, percebe-se uma dispersão significativa entre a força normal e o momento fletor solicitantes obtidos pelas 7 análises, quando normalizados em relação ao respectivo esforço de plastificação. Essa dispersão se reflete no resultado da expressão de interação, uma vez que os esforços resistentes são iguais para todas as análises.

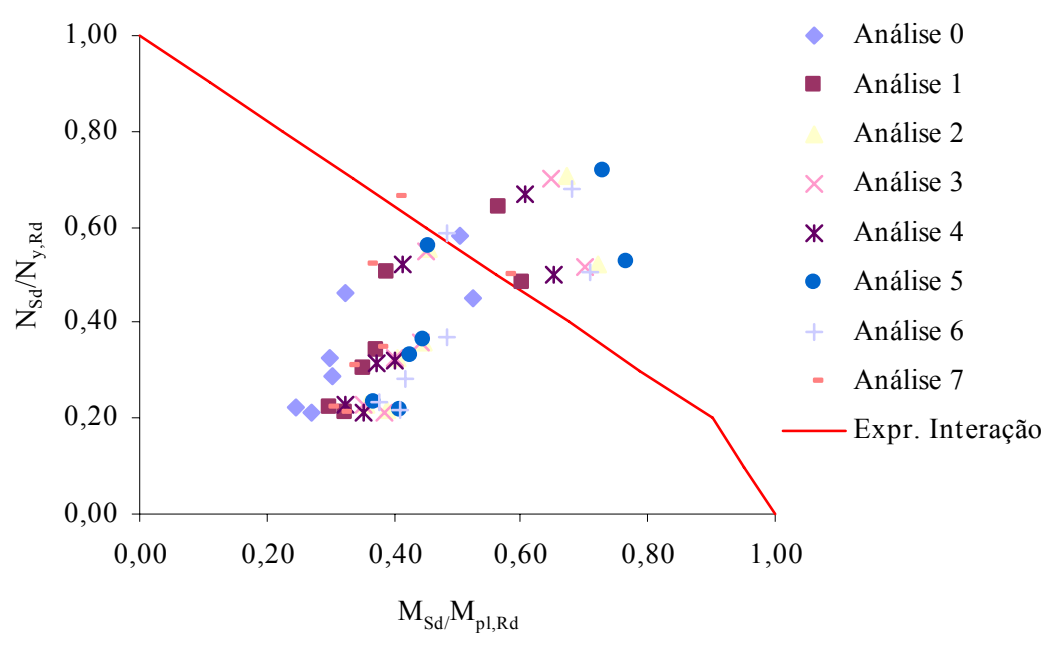

Figura 4.16 - Esforços internos máximos nos pilares.

Nota-se ainda, uma suave influência das forças horizontais fictícias na força normal solicitante de cálculo. Isso é caracterizado pela falta de alinhamento horizontal entre os resultados das análises. O desvio apresentado em relação à análise numérica avançada na avaliação do esforço normal solicitante foi inferior a 8,0\%.

Esse efeito não foi verificado na análise do exemplo 5 (Figura 4.7) porque a estrutura é pouco esbelta, ou seja, a relação altura/largura do edifício estudado no exemplo 5 é baixa. 
No exemplo 7, essa razão é maior, portanto a influência das forças fictícias na força normal é mais pronunciada. 


\section{Capítulo 5: CONCLUSÃO}

Apresentou-se uma comparação entre os parâmetros $\gamma_{z}$ e B , à luz da classificação das estruturas quanto à deslocabilidade. Foi possível demonstrar que o parâmetro $\gamma_{z}$ coincide com o valor médio do parâmetro $\mathrm{B}_{2}$. Portanto, em estruturas com geometria e distribuição de carregamentos regulares, o parâmetro $\gamma_{\mathrm{z}}$ pode ser empregado satisfatoriamente para classificação.

Constatou-se que a classificação quanto à deslocabilidade por meio da razão entre os deslocamentos de segunda $\left(\mathrm{u}_{2}\right)$ e primeira ordem $\left(\mathrm{u}_{1}\right)$ pode induzir a resultados equivocados para combinações gravitacionais, quando esses deslocamentos podem apresentar valores absolutos baixos. Assim, valores elevados da razão $\mathrm{u}_{2} / \mathrm{u}_{1}$ não implicam necessariamente em influência significativa dos efeitos de segunda ordem.

Os procedimentos que utilizam o conceito do comprimento efetivo de flambagem apresentaram desvios elevados, na maioria dos casos a favor da segurança, quando comparados com a análise numérica avançada. Além disso, o cálculo do coeficiente de flambagem por meio do diagrama de alinhamento foi considerado pouco prático, embora amplamente empregado em projeto.

Para os exemplos de edifícios pouco esbeltos, os procedimentos baseados no conceito das forças horizontais fictícias apresentaram resultados menos conservadores em relação aos obtidos pelos procedimentos baseados no comprimento efetivo de flambagem. A avaliação do 
coeficiente de força horizontal $(\xi)$ foi considerada simples frente ao cálculo do coeficiente de flambagem (K).

A avaliação de um edifício mais esbelto mostrou que a introdução das forças horizontais fictícias pode induzir a resultados conservadores, devido principalmente ao aumento significativo dos momentos fletores provocado pelo efeito de tombamento. Foram encontrados desvios mais acentuados, porém não muito distantes dos desvios apresentados pelo procedimento do comprimento efetivo de flambagem.

A verificação dos pilares por meio do método da análise direta, proposto pelo Projeto de Revisão da NBR 8800 (set. 2006), apresentou resultados ainda melhores. Além disso, a separação da estratégia de representação das imperfeições geométricas e regime inelástico por meio de forças horizontais fictícias e redução de rigidez, respectivamente, mostrou-se bastante interessante, pois facilita a compreensão e a avaliação da influência desses efeitos pelo projetista.

O método refinado das forças horizontais fictícias também apresentou resultados bons, mas os procedimentos necessários para contabilizar a intensidade das forças horizontais foram considerados pouco práticos.

Em estruturas de pequena deslocabilidade, a influência dos efeitos de segunda ordem, das imperfeições geométricas globais e do regime inelástico não foi relevante, ou seja, não houve variação significativa dos esforços internos solicitantes. Portanto, esses efeitos poderiam ser desprezados na análise, mesmo adotando $\mathrm{K}=1$.

De forma geral, a diferença entre os resultados obtidos por meio do comprimento efetivo de flambagem e daqueles obtidos pelos métodos que empregam forças horizontais fictícias foi mais acentuada em pilares com esbeltez elevada e submetidos a força normal significativa. Nesse caso, a diferença na avaliação da força normal resistente é significativa e 
a parcela associada à força normal exerce mais influência no resultado da expressão de interação.

Nos casos de edifícios industriais, onde a força normal solicitante nos pilares é relativamente baixa, os resultados da expressão de interação foram bastante próximos, apesar da diferença observada na avaliação da força normal resistente, isto porque a parcela da força normal é muito baixa em relação à parcela do momento fletor.

O procedimento simplificado de amplificação dos esforços internos de primeira ordem por meio dos coeficientes $\mathrm{B}_{1}$ e $\mathrm{B}_{2}$ para obtenção dos esforços de segunda ordem apresentado pelo Projeto de Revisão da NBR 8800 (set. 2006) apresentou desvios toleráveis em relação aos esforços avaliados por meio de uma análise de segunda ordem. Entretanto, a divisão da análise estrutural em duas situações, contida e não-contida horizontalmente, foi considerada pouco prática, uma vez que duplica o número de análises necessárias e que em geral os pacotes comerciais permitem avaliar os efeitos de segunda ordem diretamente. 


\section{REFERÊNCIAS}

AMERICAN IRON AND STEEL INSTITUTE - AISI. Cold-formed Steel Design Manual. Draft. Jun, 2006.

AL-MASHARY, F.; CHEN, W.F. Elastic Second Order Analysis for Frame Design. Journal of Constructional Steel Research, v. 15, no. 4, p. 302-322, 1990.

ALVARENGA, A.R.; SILVEIRA, R.A.M. A Configuração Geométrica Inicial na Análise Avançada de Portais Planos de Aço. Revista Escola de Minas. v. 59, no. 2, p. 185-197, 2006.

ANTUNES, M.C. Comprimento Efetivo de Colunas de Aço em Pórticos Planos Deslocáveis. 2001. 102 f. Dissertação (Mestrado) - Escola de Engenharia de São Carlos, Universidade de São Paulo, São Carlos.

ASSOCIAÇÃO BRASILEIRA DE NORMAS TÉCNICAS - ABNT. NBR 8800: Projeto e Execução de Estruturas de Aço de Edifícios: método dos estados limites. Rio de Janeiro, 1986.

. NBR 6118: Projeto de Estruturas de Concreto - Procedimento. Rio de Janeiro, $2003 \mathrm{a}$.

. NBR 8681: Ações e Segurança nas Estruturas. Rio de Janeiro, 2003b.

Projeto de Revisão da NBR 8800: Projeto e Execução de Estruturas de Aço e de Estruturas Mistas Aço-concreto de Edifícios - Procedimento, set. 2006. Disponível em: $<$ http://www.dees.ufmg.br/edu/app> Acesso em 03 out. 2006.

AMERICAN INSTITUTE OF STEEL CONSTRUCTION - AISC. Load and Resistence Factor Design Specification for Structural Steel Buildings. Chicago, 1999.

. Specification for Structural Steel Buildings. Chicago, 2005a.

. Commentary on the Specification for Structural Steel Buildings. Chicago, 2005b. 
AMERICAN SOCIETY OF CIVIL ENGINEERS - ASCE. Effective Length and Notional Load Approaches for Assessing Frame Stability: implications for American steel design. By the Task Committee on Effective Length. New York, 1997.

BALliO, G.; MAZZOLANI, F.M.; Theory and Design of Steel Structures. London: Chapman and Hall, 1983.

BAYO, E.; LOUREIRO, A.; An efficient and Direct Method for Buckling Analysis of Steel Frame Structures. Journal of Constructional Steel Research, v. 57, p. 1321-1336, 2001.

BELLEI, I.H. Edifícios Industriais em Aço. PINI. 1994.

BILD, S.; TRAHAIR, N.S. In-plane Strengths of Steel Columns and Beam-Columns. Journal of Constructional Steel Research, v. 13, p. 1-22, 1989.

BRITISH STANDARD. BS 5950-1:2000: Structural Use of Steelwork in Building. 2000.

CALDAS, R.B. Análise Numérica de Pilares Mistos Aço-Concreto. 2004. 200f. Dissertação (Mestrado) - Escola de Minas, Universidade Federal de Ouro Preto, Ouro Preto.

CANADIAN STANDARDS ASSOCIATION - CSA. CSA-S16.1-94: Limit States Design of Steel Structures. Ontario, 1994.

CHAN, S.L.; ZHOU, Z.H. Second-Order Elastic Analysis of Frames Using Single Imperfect Element per Member. Journal of Structural Engineering, ASCE, v. 121. no. 6, p. 939-945, 1995.

COMPUTER AND STRUCTURES INC. SAP 2000 Static and Dynamic Finite Element Analysis of Structures. University Ave, Berkley, USA, 2004.

DUAN, L.; CHEN, W.F. Effective Length Factors of Compression Members. In: Structural Engineering Handbook. CRC Press LLC, 1999.

ENGLEKIRK, R. Steel Structures: Controlling Behavior through Design. John Wiley \& Sons, 1994.

ESSA, H.S.; KENNEDY, D.J.L. Proposed Provisions for the Design of Steel Beam-Columns in S16-2001. Canadian Journal of Civil Engineering, no. 27, p. 610-619, 2000.

EUROPEAN COMMITTEE FOR STANDARDIZATION. prEN 1993-3: Eurocode 3: Design of Steel Structures. Part 1.1: General Rules and Rules for Buildings. Final Draft. Brussels, 2003.

EUROPEAN STEEL DESIGN EDUCATION PROGRAMME - EDESP. Stability of Slender Steel Columns, 2006. Disponível em: <www.kuleuven.be/bwk/materials/Teaching/>. Acesso em 23 Jan. 2006. 
GALAMBOS, T.V. Guide to Stability Design Criteria for Metal Structures. John Wiley \& Sons, 1998.

GALAMBOS, T.V.; KETTER, R.L. Columns under Combined Bending and Thrust. Journal of the Engineering Mechanics Division, ASCE, v. 85, no. EM2, p. 1-30, 1959.

GIRGIN, K.; ORAKDOGEN, E.; OZMEN, G. Buckling Lengths of Irregular Frame Columns. Journal of Constructional Steel Research, v. 62, no. 6, p. 605-613, 2006.

GOMES, C.H. Verificação de Pilares de Aço à Flexão Composta Considerando Comprimentos de Flambagem, Forças Horizontais Fictícias e Análise Avançada. 2005. 150 f. Dissertação (Mestrado). Escola Politécnica da Universidade de São Paulo, Universidade de São Paulo, São Paulo.

HAJJAR, J.H.; WHITE, D.W. Stability of Steel Frames: The Case for Simple Elastic and Rigorous Inelastic Analysis/Design Procedures. Engineering Structures, v. 22, no. 200, p. 155-167, 2000.

HIBBITT, KARLSSON AND SORENSON INC. ABAQUS Analysis User's Manual, 2005.

JIANG, J-M; CHEN, H; LIEW, J.Y.R. Sread-of-Plasticity Analysis of Three-Dimensional Steel Frames. Journal of Constructional Steel Research, v. 59, p. 193-212, 2002.

KANCHANALAI, T.; LE-WU, L. Analysis and Design of Framed Columns Under Minor Axis Bending. Engineering Journal, AISC, v. 16, no. 2, p. 29-41, 1979.

KAVANAGH, T.C. Effective Length of Framed Columns, Transactions, ASCE, v. 127, p. 81-101, 1962.

KENNEDY, D.J.L.; PICARD, A.; BEAULIEU, D. Limit States Design of Beam-Columns: the Canadian Approach and Some Comparisons. Journal of Constructional Steel Research, v. 25, no. 1-2, p. 141-164, 1993.

KIM, S.E.; LEE, D.H. Second-order Distributed Plasticity Analysis of Space Steel Frames. Engineering Strucutres. v. 24, no 6, p. 735-744, 2002.

LANDESMANN, A.; BATISTA, E.M. Advanced Analysis of Steel Framed Buildings to Brazilian Standard and Eurocode-3. Journal of Constructional Steel Research, Essex, Inglaterra, v. 61, nO. 8, p. 1051-1074, 2005.

LEE, J.H. Local Buckling Behaviour and Design of Cold-Formed Steel Compression Members at Elevated Temperatures. 2004. 248 f. Tese (Doutorado) - School of Civil Engineering, Queensland University of Technology, Brisbane.

LIEW, J.Y.R; CHEN, W.F. Multistory Frame Structures. Structural Engineering Handbook. CRC Press LLC, 1999. 
LIEW, J.Y.R.; WHITE, D.W.; CHEN, W.F. Beam-Column Design in Steel Frameworks Insights on Current Methods and Trends. Journal of Constructional Steel Research, v. 18, No. 4, p. 269-308, 1991.

LIEW, J.Y.R.; WHITE, D.W.; CHEN, W.F. Notional-Load Plastic-hinge Method for Frame Design. Journal of Structural Engineering, ASCE, v. 120, no. 5, p. 1434-1454, 1994.

MACHADO, F.C.S. Análise Inelástica de Segunda Ordem de Sistemas Estruturais Metálicos. 2005. 161f. Dissertação (Mestrado) - Escola de Minas, Universidade Federal de Ouro Preto, Ouro Preto.

MALECK-S., A.E.; WHITE, D.W. Alternative Approaches for Elastic Analysis and Design of Steel Frames. I: Overview. Journal of Structural Engineering, ASCE, v. 130, no. 8, p. 1186-1196, 2004a.

MALECK-S., A.E.; WHITE, D.W. Alternative Approaches for Elastic Analysis and Design of Steel Frames. II: Verification Studies. Journal of Structural Engineering, ASCE, v. 130, no. 8 , p. 1197-1205, 2004b.

MALECK-S., A.E.; WHITE, D.W.; LEON, R.T. Direct Analysis for Design of Partially Restrained Steel Framing Systems. Journal of Structural Engineering, ASCE, v. 131, no. 9, p. 1376-1389, 2005.

MUNIZ, C.F.D.G. Modelos Numéricos para Análise de Elementos Estruturais Mistos. 2005. 151f. Dissertação (Mestrado) - Escola de Minas, Universidade Federal de Ouro Preto, Ouro Preto.

PINTO, R.S. Não-linearidade Física e Geométrica no Projeto de Edifícios Usuais de Concreto Armado. 1997. 108f. Dissertação (Mestrado) - Escola de Engenharia de São Carlos, Universidade de São Paulo, São Carlos.

REIS, A.; CAMOTIM, D. Estabilidade Estrutural. Mcgraw-Hill, 2000.

SALMON, C.G.; JOHNSON, J.E. Steel Structures: Design and Behavior. HarperCollins, 1996.

SCHMITH, J.A. Design of Steel Columns in Unbraced Frames Using Notional Loads. Practice Periodical on Structural Design and Construction, v. 4, no. 1, p. 24-28, 1999.

SIDERBRÁS. Manual da Construção em Aço - Galpões para Usos Gerais. 2001.

TONG, G.S.; WANG, J.P. Column Effective Lengths Considering Inter-Story and InterColumn. Journal of Constructional Steel Research, v. 62, no. 5, p. 413-423, 2006.

WHITE, D.W.; HAJJAR, J.F. Design of Steel Frames without Consideration of Effective Length. Engineering Structures, v. 19, no. 10, p. 797-810, 1997. 